\title{
Workshop on Temperature Measurement of Semiconductor Wafers Using Thermocouples
}

\section{K. G. Kreider \\ D. P. DeWitt \\ B. K. Tsai}

U. S. DEPARTMENT OF COMMERCE Technology Administration

National Institute of Standards and Technology

Gaithersburg, MD 20899

\section{B. Lojek}

ATMEL Corporation

Colorado Springs, $\mathrm{CO}$

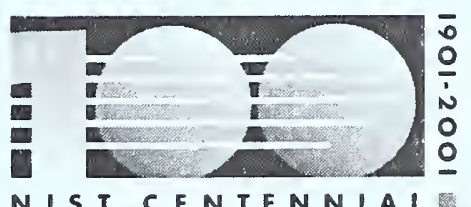

NIST CENTENNIAL

\section{NLT}

National Institute of Standards and Technology

Technology Administration

U.S. Department of Commerce 



\section{Workshop on Temperature Measurement of Semiconductor Wafers Using Thermocouples}

\section{K. G. Kreider \\ D. P. DeWitt \\ B. K. Tsai}

U. S. DEPARTMENT OF COMMERCE Technology Admınistratıon

Natıonal Institute of Standards and Technology

Gatthersburg, MD 20899

\section{B. Lojek}

ATMEL Corporation

Colorado Sprıngs, CO

January 5, 2001

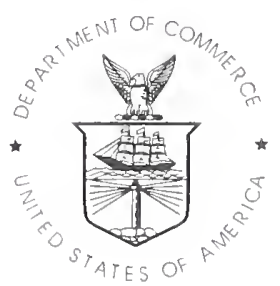

U.S. DEPARTMENT OF COMMERCE Norman Y. Mineta, Secretary TECHNOLOGY ADMINISTRATION

Dr. Cheryl L. Shavers, Under Secretary of Commerce for Technology

NATIONAL INSTITUTE OF STANDARDS AND TECHNOLOGY

Dr. Karen H. Brown, Actıng Director 



\title{
Workshop on
}

\section{Temperature Measurement of Semiconductor Wafers Using Thermocouples}

\author{
K.G. Kreider, D.P. DeWitt, B.K. Tsai
}

National Institute of Standards and Technology

Gaithersburg, MD

and

B. Lojek

ATMEL Corporation

Colorado Springs, $\mathrm{CO}$

September 19, 2000

NIST, Gaithersburg, MD

A satellite workshop held at NIST conducted in collaboration with the $8^{\text {th }}$ International Conference on Advanced Thermal Processing of Semiconductors - RTP'2000. 


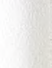




\section{Summary of the Workshop}

RTP'2000 is a conference for engineers, scientists, managers, and marketing specialists working in the thermal processing of semiconductors, manufacturing, simulation, and equipment development. The goal is to provide a comprehensive overview of current and future directions of thermal processing technology and processing systems. The primary emphasis is on the state-of-the-art tools, and on rapid thermal processing (RTP) and furnace concepts and methods as they apply to commercial Ultra Large Scale Integration (ULSI) processing.

Temperature measurement is an important parameter in most semiconductor processes. These measurements are necessary in temperature ranges as low as below $0^{\circ} \mathrm{C}$ in some plasma etch processes, to near room temperature for soft bakes of resists, to $500{ }^{\circ} \mathrm{C}$ for low temperature chemical vapor deposition (CVD) and sputter deposition, and all the way up to $1150{ }^{\circ} \mathrm{C}$ for oxidation. Accurate temperature measurements are needed to control the quality of the wafer processing. Although non-contact temperature measurements have advantages on the processing tools, these techniques must be calibrated by running expensive test wafers or by comparison with contact sensors. The thermocouple can be a very useful sensor when calibrated on an international temperature scale such as the International Temperature Scale of I990 (ITS-90). In this workshop, we will describe how to use thermocouples for measurements of temperature in semiconductor processing and how to achieve the highest accuracy.

Our workshop will begin with a presentation by Dr. Dean Ripple, Group Leader for the Thermometry Group at the National Institute of Standards and Technology (NIST). He will first describe the temperature scale, uncertainty, and traceability. Then he will discuss the use of thermocouples and thermocouple wires. Dr. Ken Kreider will follow with a talk on surface temperature measurement, and Dr. David DeWitt will present an explanation of the relationships between thermocouples and radiation temperature measurements.

Bruce Adams of Applied Materials will describe his experience in the use of thermocouples and radiation thermometers in measuring temperature in rapid thermal processing. Karl Williams of Silicon Valley Group, Thermal Systems Division, will discuss the thermal characterization of batch furnaces using thermocouple instrumented wafers. The final talks will be presented by Bakul Damle of National Instruments and Tom Hayden of Keithley Instruments on instrumentation issues. A panel, moderated by Dr. David DeWitt, will feature brief presentations by Tony Fiory, Lucent Technologies, Inc., and Jeff Gelpey, Steag RTP Systems, and will address issues of concern to the workshop.

B.K. Tsai, Editor

K.G. Kreider

D.P. DeWitt

B. Lojek 


\section{Table of Contents}

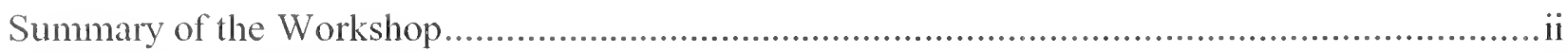

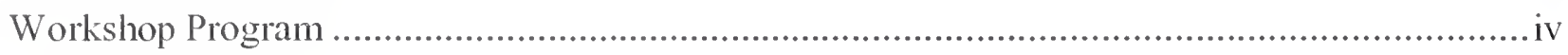

Affiliations of the Presenters and Panelists ..............................................................

Temperature Scales, Uncertainty, and Traceability, Dean Ripple, NIST .............................A-1

Thermocouples and Thermoconple Wires, Dean Ripple, NIST .......................................A-7

Surface Temperature Measurements, Ken Kreider, NIST ..............................................B-1

Relationship between Thermocouple and Radiation Thermometer Measurements, .................C-1 D.P. DeWitt, NIST

RTA T/C and RT Measurements, B.E. Adams, Applied Materials ...................................D-1

Measurement of Wafer Surface Temperature using Thermocouples and............................... E-1

Temperature Calibrotion of RTP Equipment, B. Lojek, ATMEL Corporation

Thermal Characterization of Batch Furnaces using Thermocouple Instrumented ................... F-1

Wafers, Cole Porter and Karl Williams, Silicon Valley Group

Computer-Based Temperature Measurements Systems, ............................................G-1

Bakul Damle, National Instruments

Instrumentation Issues for Thernocouple Measurements,

Tom Hayden, Keithley Instruments

Temperature Profiling of Ripple Pyrometers with Thermoconple Wafers,

A.T. Fiory, Lucent Technologies, Inc.

Issues with Using TC's to Calibrate RTP Tools, Jeff Gelpey, Steag RTP Systems 


\title{
Workshop Program
}

\section{Morning Session - Fundantentals of Tenperature Measurements}

\author{
$9: 00-9: 15$ \\ Helcome, Introductions and Overview - Ken Kreider, NIST \\ $9: 15-10: 00$ \\ Temperature Scales, Lncertainty, and Traceability - Dean Ripple, NIST \\ Break \\ $10: 15-11: 00$ \\ Thermocouples and Thermocouple Wires - Dean Ripple, NIST \\ $11: 00-11: 30$ \\ Surface Temperature Measurements - Ken Kreider, NIST \\ $11: 30-12: 00$ \\ Relationship between TCS and RT Measurements - Dave DeWitt, NIST \\ $12: 00-12: 30$ \\ RTA T/C and RT Measurements - B.E. Adams, Applied Materials \\ Luncls
}

Afternoon Session - Applications of Tenperatnre Measurenents

1:30-2:15 Measurement of Wafer Surface Temperature using Thermocouples and Temperature Calibration of RTP Equipment

B. Lojek, ATMEL Corporation

$2: 15-3: 00$

Thermal Characterization of Batch Furnaces using Thermocouple

Instrumented Wafers, Cole Porter and Karl Williams, Silicon Valley Group,

Thermal Systems Division

$3: 00-3: 25$

Computer-Based Temperature Measurement Sy'stems

Bakul Damle, National Instruments

$3: 25-3: 45$

Instrumentation Issues for Themocouple Measurements

Tom Hayden, Keithley Instruments

Break

$4: 00-5: 00$

Participants' Questions - Panelists* and Speakers - Dave DeWitt, Moderator (* Provided 5-7 minutes for presentations)

A.T. Fiory, Lucent Technologies, Inc.

Jeff Gelpey, Steag RTP Systems

Bruce Adams, Applied Materials

Ken Kreider, NIST 


\section{Affiliations of the Presenters and Panelists}

Bruce Adams

Member of the Technical Staff

Applied Materials

Santa Clara, CA

bruce adams@ (amat.com

Bakul Damle

Group Manager

National Instruments

Austin, TX

bakul.damleani.com

D.P. DeWitt

Faculty Staff

Optical Technology Division, NIST

Gaithersburg, MD

dpd@nist.gov

A.T. Fiory

Silicon Processing Research

Bell Laboratories, Lucent Technologies, Inc.

Murray Hill, NJ

atf@lucent.com

Jeff Gelpey

Vice President of Technology

STEAG RTP Systems

San Jose, CA

j.gelpey@steat-ast.com

Tom Hayden

Manager of Sales Training and Support

Keithley Instruments

Cleveland, $\mathrm{OH}$

hayden tom@keithley.com

Ken Kreider

Metallurgist

Process Measurements Division, NIST

Gaithersburg, MD

kkreider@nist.gov
B. Lojek

Senior Integration Engineer

ATMEL Corporation

Colorado Springs, $\mathrm{CO}$

blojek@atmel.com

Cole Porter

Applications Lab Manager

SVG, Thermal Systems Division

San Jose, CA

cporter@svg.com

Dean Ripple

Group Leader

Process Measurements Division, NIST

Gaithersburg, MD

dean.ripple@nist.gov

Karl Williams

Sr. Staff Engineer

SVG, Thermal Systems Division

San Jose, CA

williaka@svg.com 
Process Measurements DIvision

I. Temperature Scales, Uncertainty, and Traceability

II. Thermocouples and Thermocouple Wires

\author{
Dean Ripple \\ Thermometry Group \\ Process Measurements Division \\ NIST - Gaithersburg, MD
}

Workshop on

Temperature Measurement

of Semiconductor Waters

Using Thermocouples

RTP 2000 Conference

September 19, 2000

NLI

Notional inssituse of Standards and Technolagy

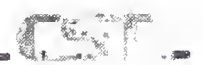

\title{
Outline
}

Temperature Scales

Overview of thermocouples (TCs) and reference functions

Traceability

Thermocouple construction types

Laws of thermocouple circuits

Electrical characteristics, differential thermocouples, extension wires, and feedthroughs

Limitations on thermocouple performance

Calibration uncertainties and methods

Calibration of used thermocouples

Resources 


\section{What is Thermodynamic Temperature?}

Thermodynamic temperature ( $T$ ) satisfies all of the laws of thermodynamics

Primary Thermometer is an apparatus whose temperature can be calculated from other measured properties (pressure, radiance, speed of sound, etc.).

Examples of Physical Systems: Black body radiation Speed of sound in ideal gas

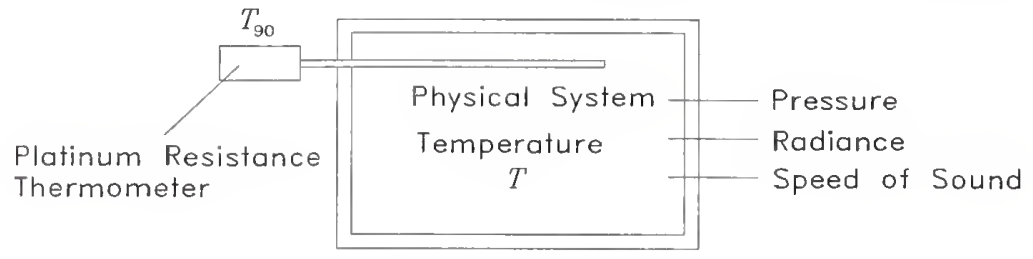

Typically, $T-T_{90}$ is measured, where $T_{90}=$ temperature on the International Temperature Scale of 1990 (ITS-90)

\section{What is the international Temperature Scale of 1990 (ITS-90)?}

The ITS-90 is an approximation of the thermodynamic temperature scale.

The ITS-90 is a specific recipe for "realizing" temperature, including:

Defined thermometer types

Reproducible fixed points (triple point of water, freezing point of silver, etc.)

The triple point of water is defined as $273.16 \mathrm{~K}\left(0^{\circ} \mathrm{C}=273.15 \mathrm{~K}\right)$

Defining instruments relevant to semiconductor thermometry:

Standard Platinum Resistance Thermometer (SPRT) from $13.6 \mathrm{~K}$ to $962{ }^{\circ} \mathrm{C}$

Spectral Radiation Thermometer from $962{ }^{\circ} \mathrm{C}$ to all higher temperatures

The ITS-90 replaces earier International Temperature Scales:

$\begin{array}{ll}1968 & \text { (IPTS-68) } \\ 1948 & \text { (ITS-48) } \\ 1927 & \text { (ITS-27) }\end{array}$

The IPTS-68 is still in use by some industries 


\section{Why use the International Temperature Scale of 1990 (ITS-90)?}

- The ITS-90 is much easier to realize than true thermodynamic temperature.

- The ITS-90 is internationally accepted.

- For all present commercial applications, the thermodynamic inconsistency of the ITS-90 is negligible.

- Establishment of temperature uncertainty more straightforward on the ITS-90 than with "Process measurement scales".

- Consistency of temperature readings worldwide and across applications.

What is a Thermocouple?

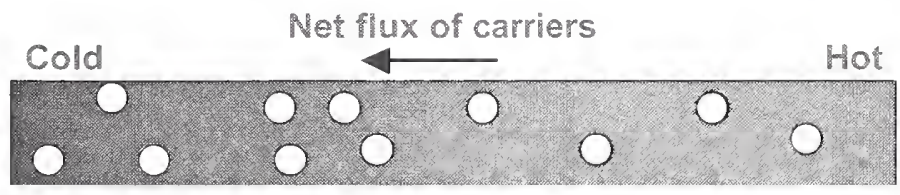

Hotter carriers travel farther before equilibrating with the crystal lattice than cold carriers.

Consequence: charge imbalance when crystal is in thermal gradient

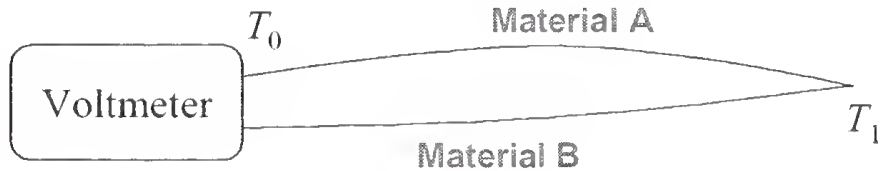

Net electromotive force $=\mathrm{emf}=E=E_{\mathrm{A}}\left(T_{1}, T_{0}\right) \cdot E_{\mathrm{B}}\left(T_{1}, T_{0}\right)$ 


\section{Advantages of Thermocouples}

- Cheap

- Wide temperature range $\left(-270^{\circ} \mathrm{C}\right.$ to $\left.2100^{\circ} \mathrm{C}\right)$

- Small (down to $0.25 \mathrm{~mm}$ diameter)

- Easy to integrate into automated data systems

\section{Disadvantages of Thermocouples}

- Small signals, limited temperature resolution ( $1 \mathrm{mK}$ to $1 \mathrm{~K}$ )

- Thermocouple wires must extend from the measurement point to the readout. Signal generated wherever wires pass through a thermal gradient.

- At higher temperatures, thermocouples may undergo chemical and physical changes, leading to loss of calibration.

- Recalibration of certain types of thermocouples or in certain applications is very difficult.

\section{Letter-designated Thermocouple Types}

\begin{tabular}{|c|c|c|c|}
\hline \multirow[t]{2}{*}{$\begin{array}{l}\text { TC } \\
\text { type }\end{array}$} & \multirow[t]{2}{*}{$\begin{array}{l}\text { Ref. func. } \\
\text { range, }{ }^{\circ} \mathrm{C}\end{array}$} & \multicolumn{2}{|c|}{$\begin{array}{l}\text { Nominal composition } \\
\text { majority component in italics, \% in mass }\end{array}$} \\
\hline & & Positive leg & Negative leg \\
\hline B & 0 to 1820 & platinum-30\% rhodium & platinum- $6 \%$ rhodium \\
\hline$E$ & -270 to 1000 & nickel-chromium alloy & copper-nickel alloy \\
\hline$J$ & -210 to 1200 & iron & copper-nickel alloy \\
\hline K & -270 to 1372 & nickel-chromium alloy & nickel-aluminum alloy \\
\hline N & -270 to 1300 & nickel-chromium-silicon & nickel-silicon-magnesium \\
\hline $\mathrm{R}$ & -50 to 1768 & platinum-13\% rhodium & platinum \\
\hline S & -50 to 1768 & platinum-10\% rhodium & platinum \\
\hline $\mathrm{T}$ & -270 to 400 & copper & copper-nickel alloy \\
\hline
\end{tabular}

The letter designations define emf versus temperature only - not composition 


\section{Emf-Temperature Relationships \\ for the 8 Letter-Designated Thermocouple Types}

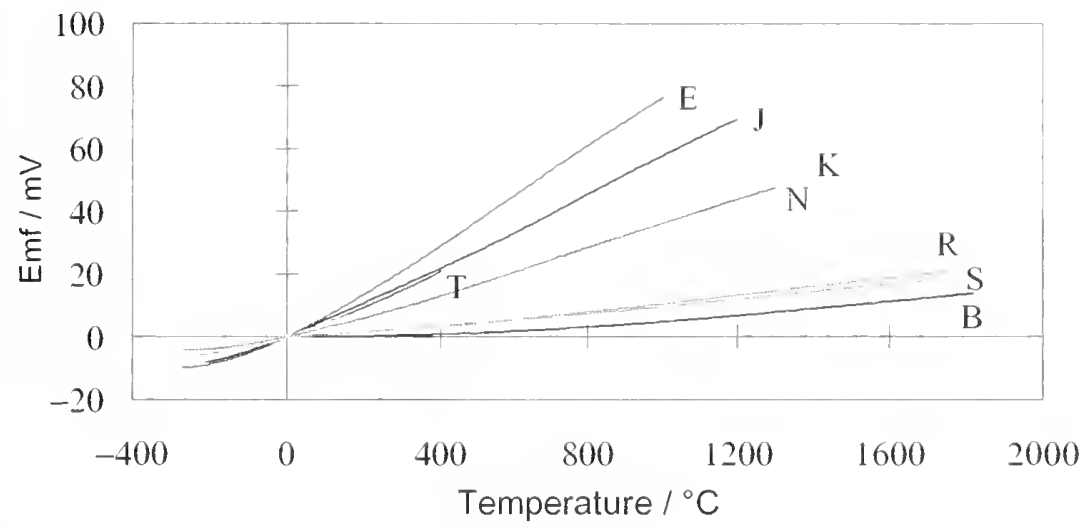

Notation: $E=E m f=$ Electromotive Force $=$ Thermoelectric Voltage $S=d E / d T=$ Seebeck Coefficient = Sensitivity

\section{Thermocouple Reference Functions}

Sources:

- Reference functions for letter-designated TC types in ASTM E230,

IEC 584, NIST Monograph 175

(ASTM = American Society for Testing and Materials,

$I E C=$ International Electrotechnical Commission)

- Reference functions for non-letter designated types in: ASTM E1751, E988

Cautions:

- Only a set of spools is guaranteed to match reference function

- Some reference functions are not smooth near $0{ }^{\circ} \mathrm{C}$

\section{Manufacturer develops alloy}

Emf versus temperature measured. Reference function fit to data.

Alloy manufactured to match reference function. 


\section{Choosing a Thermocouple Type}

type E: High Seebeck coefficient, homogeneous materials. Good for low temperatures.

type J: Cheap!

type K: Fairly cheap high temperature thermocouple.

type N: Best base metal thermocouple for high temperatures.

type T: Homogeneous materials. Direct connection of differential pairs to voltmeters.

Use type $\mathrm{K}, \mathrm{E}$, or $\mathrm{T}$ at room temp., type $\mathrm{K}$ up to $200{ }^{\circ} \mathrm{C}$, type $\mathrm{N}$ in the range $300{ }^{\circ} \mathrm{C}$ to $600^{\circ} \mathrm{C}$, type $\mathrm{N}$ or $\mathrm{K}$ above $600^{\circ} \mathrm{C}$

type R, S: Noble metal thermocouple for range $0{ }^{\circ} \mathrm{C}$ to $1400{ }^{\circ} \mathrm{C}$.

type B: Noble metal thermocouple used from $800^{\circ} \mathrm{C}$ to $1700^{\circ} \mathrm{C}$.

Use type $R$ or $S$ below $1300^{\circ} \mathrm{C}$, type $\mathrm{B}$ above $1300^{\circ} \mathrm{C}$.

Platinel: High Seebeck coefficient with some of the stability of types $B, R$, and $S$.

Au/Pt: The best accuracy from $0{ }^{\circ} \mathrm{C}$ to $1000^{\circ} \mathrm{C}$.

Pt/Pd: The best accuracy from $1000^{\circ} \mathrm{C}$ to $1500^{\circ} \mathrm{C}-$ not commercial

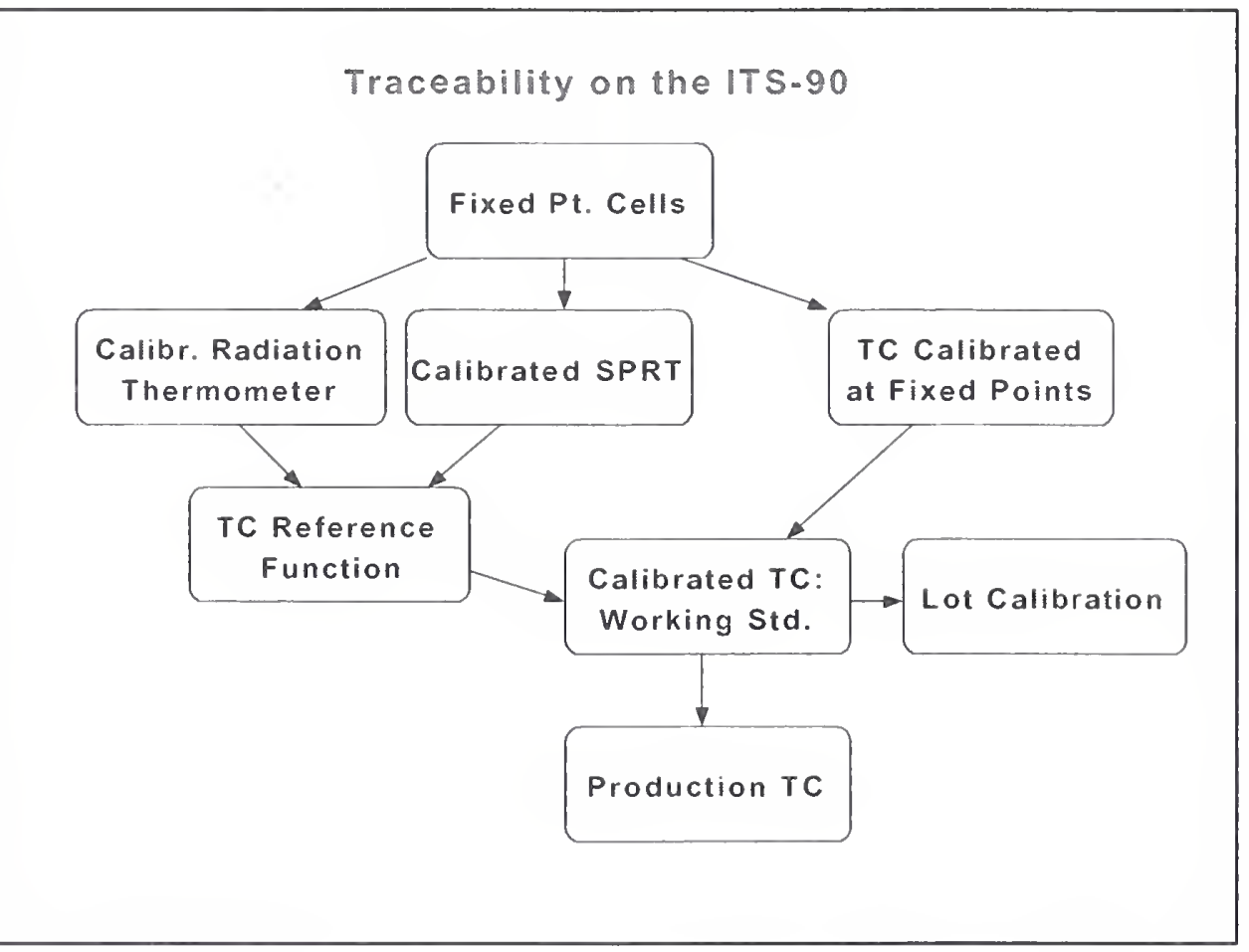


Traceability using Process Measurements

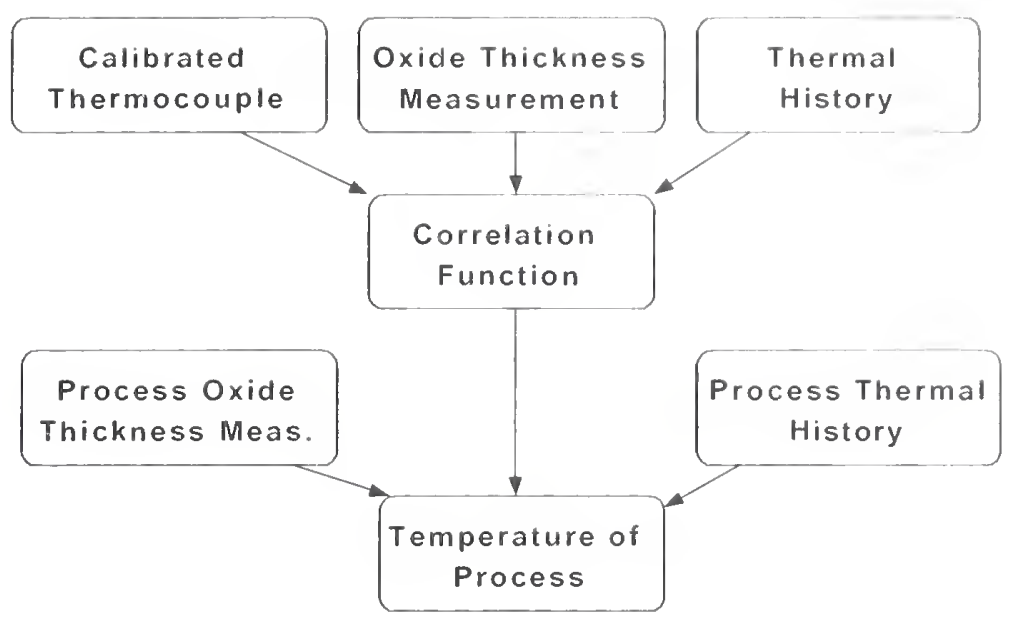

Traceability depends on the quality and ease of replication of original measurements

\section{Thermocouple Construction Types}

Bare wire with ceramic insulators

- the best performance for clean, high temp. environments

Soft-insulated wire

- polymer coatings excellent for use up to $200{ }^{\circ} \mathrm{C}$

- woven ceramic sleeving-not well characterized

Mineral-insulated, metal-sheathed construction (MIMS):

- excellent for base-metal thermocouples at high temperatures

- excellent for unclean environments

- can be bent to shape

Bare wire with ceramic insulators, and outer metal sheath

- not flexible

- better contamination resistance and less mechanical strain than MIMS construction for noble metal thermocouples

Thin-film thermocouples: discussed by K. Kreider in this Workshop 


\section{Bare Wire with Ceramic Insulators}

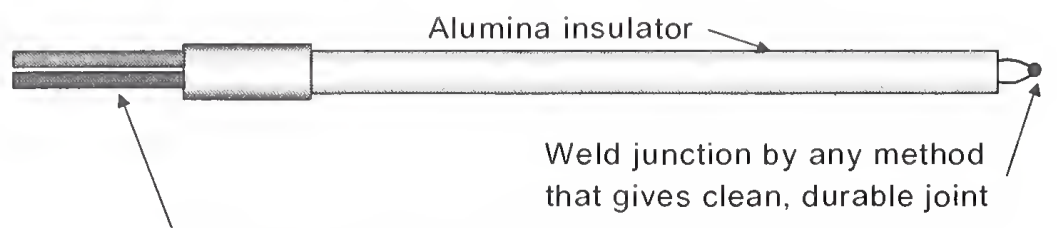

Flexible sleeving held with heat shrink tubing,

or thermocouple plug

- For noble-metal alloys, use high-purity alumina (99 mass \% for typical uses, 99.7 mass\% for highest accuracy and stability).

- If old insulators are used, avoid cross contamination. e.g.: Pt wire into a bore that held $\mathrm{Pt}-\mathrm{Rh}$, or other base metals into bore that held iron

- Above $1300{ }^{\circ} \mathrm{C}$, alumina insulator itself is a source of impurities.

- Use single, unbroken lengths of ceramic, to prevent contamination and loss of volatile alloy components

- Pt-Rh alloys annealed pre or post assembly for best performance

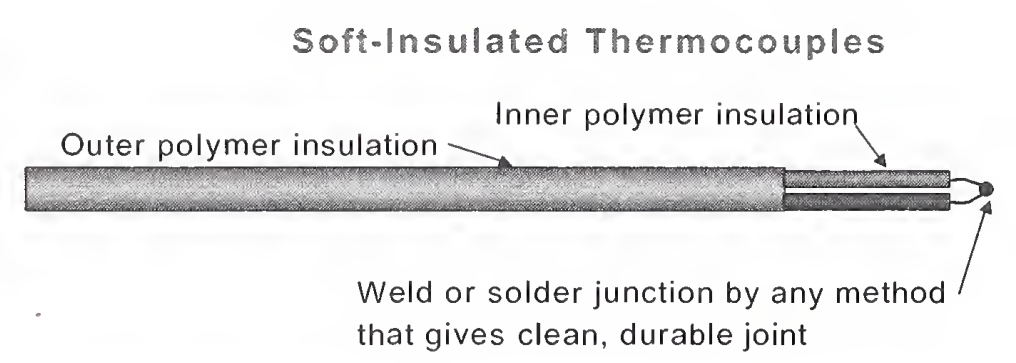

- Choose polymer insulation based on upper temperature limit

- Woven ceramics are popular in semiconductor applications

- Always bake out binders to avoid contamination

- Contamination of thermocouples by ceramic has not been studied well

- Use single lengths of alumina in high-gradient zone, if possible

- Contamination is more of an issue with diffusion furnaces than RTP applications (much less time at temperature) 


\section{Mineral-insulated, Metal-Sheathed (MuMS) Thermocouples}

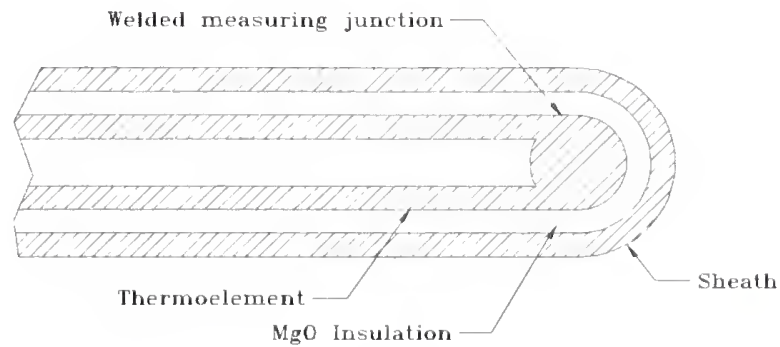

- At high temperatures, choice of sheath material is critical

- for types $\mathrm{K}$ and $\mathrm{N}$, sheath material dominates performance

- for noble metal, Pt-Rh sheaths preferred. Large problems with contamination/strain with non-Pt-Rh sheaths

- MIMS thermocouples are available in small diameters $(0.25 \mathrm{~mm})$

- Sheath protects thermoelements from contamination

\begin{tabular}{|c|c|c|c|}
\hline \multicolumn{4}{|c|}{ Thermocouple Color Codes } \\
\hline $\begin{array}{l}\text { TC } \\
\text { Type }\end{array}$ & $\begin{array}{l}\text { IEC } \\
\text { Positive Cond., } \\
\text { Extension Sheath }\end{array}$ & $\begin{array}{l}\text { ASTM } \\
\text { Extension } \\
\text { Sheath }\end{array}$ & $\begin{array}{l}\text { ASTM } \\
\text { Positive } \\
\text { Conductor }\end{array}$ \\
\hline $\begin{array}{l}\text { B } \\
\text { E } \\
J \\
K \\
N \\
R, S \\
T\end{array}$ & $\begin{array}{l}\text { - } \\
\text { Violet } \\
\text { Black } \\
\text { Green } \\
\text { Orange } \\
\text { Brown }\end{array}$ & $\begin{array}{l}\text { Gray } \\
\text { Purple } \\
\text { Black } \\
\text { Yellow } \\
\text { Orange } \\
\text { Green } \\
\text { Blue }\end{array}$ & $\begin{array}{l}\text { Gray } \\
\text { Purple } \\
\text { White } \\
\text { Yellow } \\
\text { Orange } \\
\text { Black } \\
\text { Blue }\end{array}$ \\
\hline \multicolumn{4}{|c|}{$\begin{array}{l}\text { IEC: Negative Conductor is White for all Types } \\
\text { ASTM: } \\
\text { - Negative Conductor is Red for all Types } \\
\text { - For base metal types, duplex insulated thermocouple wire has } \\
\text { identical color codes, but with brown overall insulation. }\end{array}$} \\
\hline
\end{tabular}




\section{A Key to Understanding Thermocouples...}

\section{FURNACE}
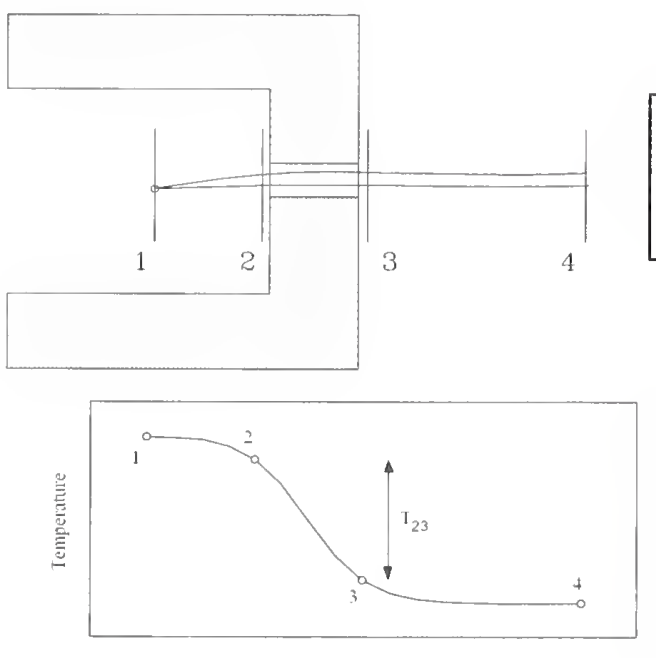

Distance
Thermocouples generate signal primarily in regions of strong thermal gradients. (Region 2-3)

$E_{12}=S_{12}\left(T_{1}-T_{2}\right) \quad$ Small $E_{23}=S_{23}\left(T_{2}-T_{3}\right) \quad$ Large $E_{34}=S_{34}\left(T_{3}-T_{4}\right) \quad$ Small $S_{12}=$ average Seebeck coefficient between points 1 and ?

\section{Fundamental Laws of Thermoelectric Circuits}

\section{EMF OF HOMOGENEOUS WIRE}

A homogeneous piece of wire (uniform chemical composition, uniform metallurgical state) will generate no emf if the two ends are at the same temperature, regardless of the temperature between the endpoints.

Example: hook up a copper wire to the inputs of a DVM and immerse the loop into liquid nitrogen. The measured emf will be very small.

A homogeneous piece of wire passing through a thermal gradient will develop an emf, $E\left(T_{0}, T_{1}\right)$, between its two ends. The emf depends only on the temperature of the end points; cross section is irrelevant.

A pair of wires:

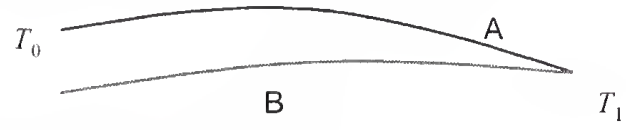

$E=$ emf generated by the loop of wire

$$
=E_{A}\left(T_{0}, T_{1}\right)+E_{B}\left(T_{1}, T_{0}\right)=E_{A}\left(T_{0}, T_{1}\right)-E_{B}\left(T_{0}, T_{1}\right)
$$




\section{EMF OF INHOMOGENEOUS WIRE}

An inhomogeneous piece of wire will generate no emf if the whole piece is at a uniform temperature.

Example: A thermocouple junction is made by brazing, with a silver alloy, a copper and a constantan wire. The junction is placed in an isothermal zone of a furnace. The emf generated by the thermocouple is independent of the composition at the junction because the junction is at a uniform temperature.

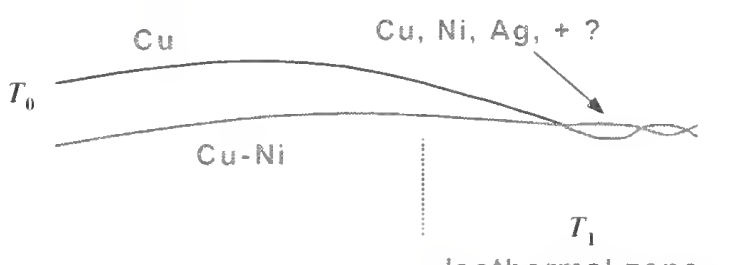

Isothermal zone

\section{EQUIVALENT THERMOCOUPLE CIRCUITS}

For thermocouple circuits with reference junctions at a temperature different from $0{ }^{\circ} \mathrm{C}$, an equivalent circuit can be drawn with $0{ }^{\circ} \mathrm{C}$ reference junctions. Example: a differential thermocouple pair made of copper/constantan.

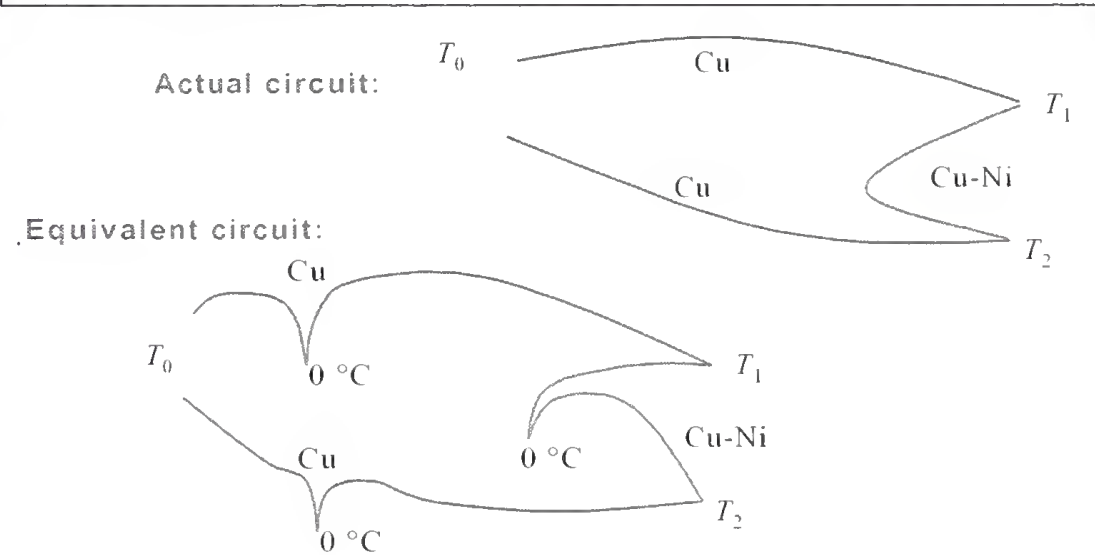




\section{Typical thermocouple circuit}

Reference junctions maintained at $0^{\circ} \mathrm{C}$ by

- immersion into ice bath, made from water/ice slurry

- immersion into thermoelectrically-cooled, sealed ice bath

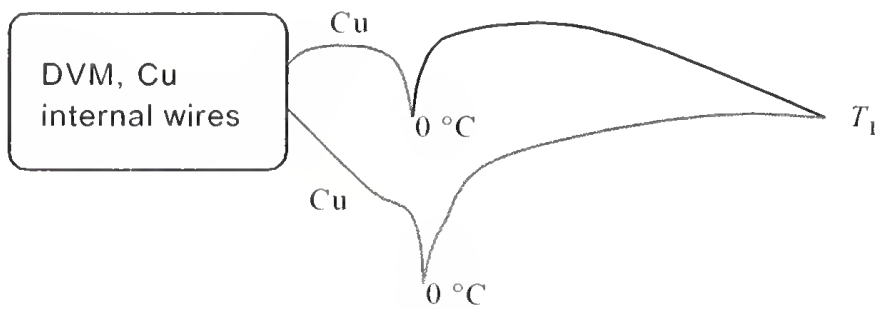

Reference

junctions at $0{ }^{\circ} \mathrm{C}$

If Reference junctions are not at $0{ }^{\circ} \mathrm{C}$, compensation of emf signal is necessary, by appropriate addition of voltage

\section{Thermocouple Electrical Characteristics}

Electrical characteristics

- low resistance $(<100 \Omega)$

- low DC voltage $(<40 \mathrm{mV})$

Sources of DC noise

- Extraneous thermal emf (voltmeters, scanner relays, wiring)

- Offset voltages (voltmeters, analog-to-digital converters)

- At high temperatures, electrical leakage through poor insulators

Sources of $\mathrm{AC}$ noise

- Magnetic pickup. Use twisted pair leadwire, keep thermoelements close. 


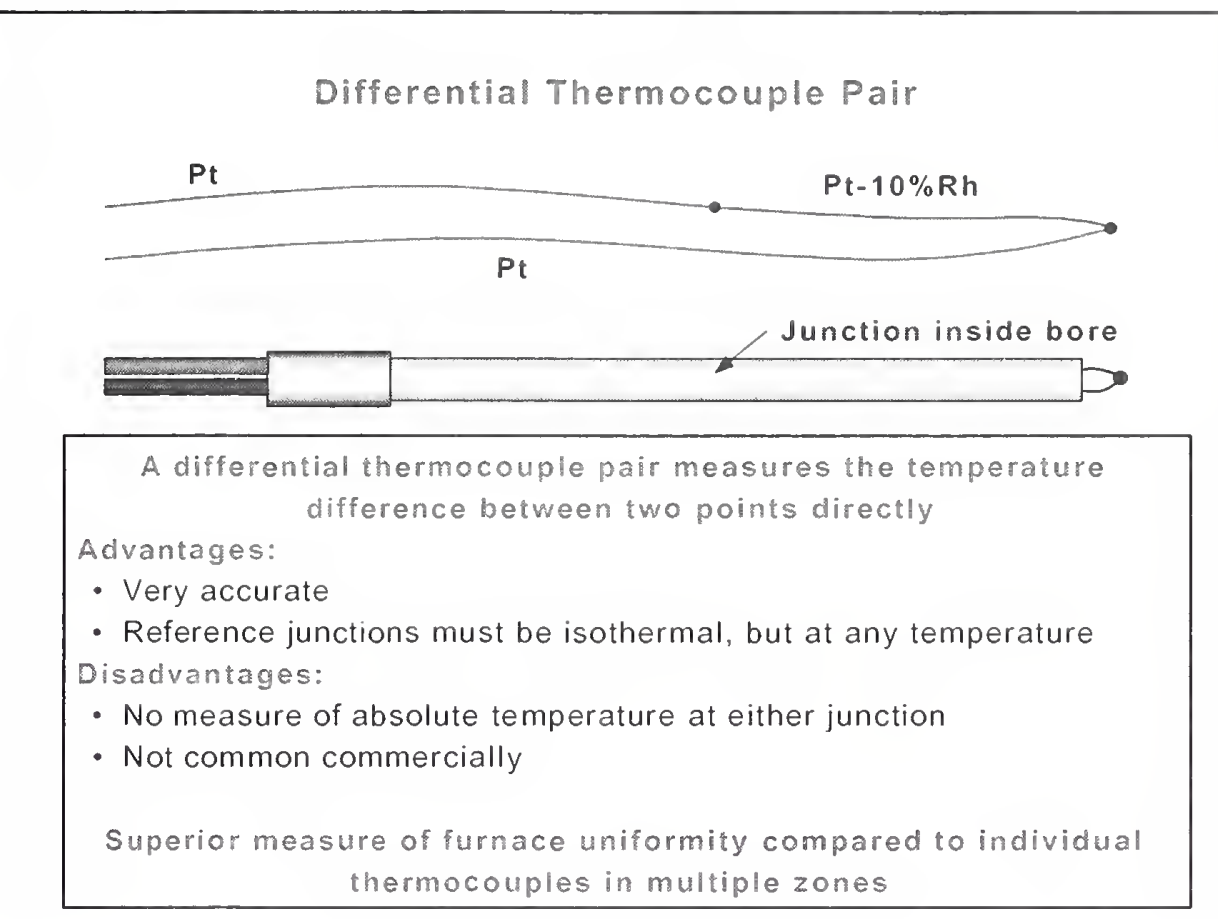

\section{Extension Wires and Cables for Thermocouples}

- Extension wires are fabricated from $\mathrm{Cu}-\mathrm{Ni}$ alloys that are designed to mimic emf response of the standard thermocouple types

- If both ends of the extension wire are within $1^{\circ} \mathrm{C}$, the error in using extension wire is generally negligible

- If there is a large temperature difference between the ends, the error can be dominant

- Emf readings can be corrected, if the temperature difference between the ends remains constant

Example: type $\mathrm{S}$ extension wire from $0^{\circ} \mathrm{C}$ to $23^{\circ} \mathrm{C}$ introduces an error of $\approx 15 \mu \mathrm{V}$, equivalent to $1.4{ }^{\circ} \mathrm{C}$ for measurement of $900^{\circ} \mathrm{C}$

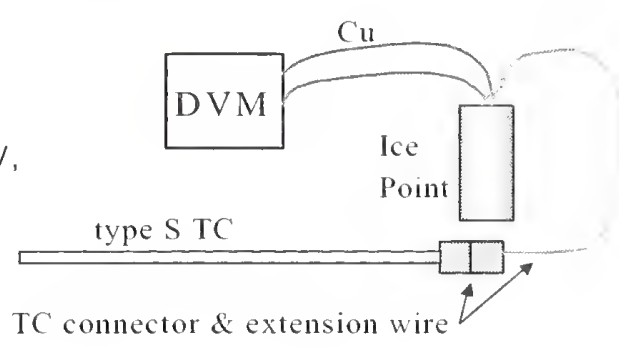


Hermetic Feedthroughs for Thermocouples

Compression fitting on outer sheath

- Simple

- Poor thermal contact

- Straight insertion only

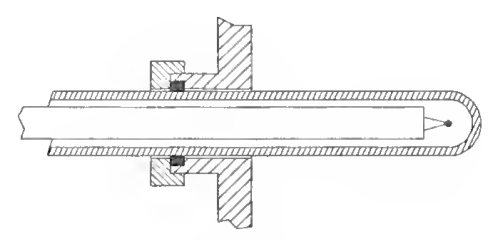

Thermoelements laminated between adhesive film

- Simple

- Not truly hermetic

- Wires may kink at door

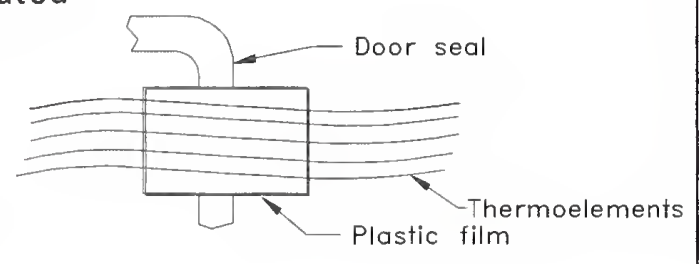

\section{Hermetic Feedthroughs for Thermocouples}

Thermoelements attached to hermetic feedthrough

- No leaks

- Possible extraneous emf

- Difficult to change TC

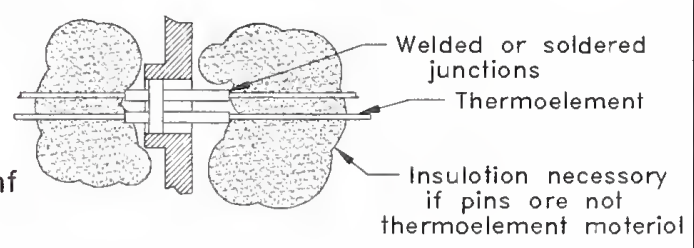

Thermoelements pass through feedthrough

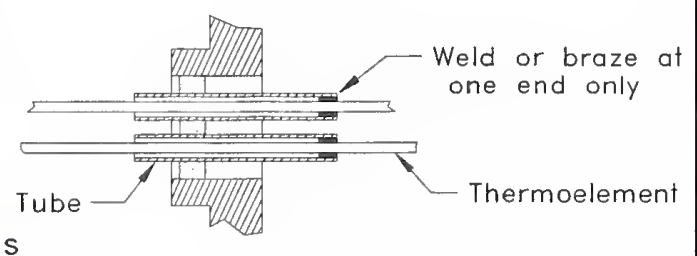

- No leaks

- Difficult to manufacture Tube

- Solution for unusual TCs 


\section{Limitations on Thermocouple Performance}

- Intrinsic variations in alloy composition (small, unavoidable)

- Chemical contamination (potentially very large)

- Physical strain (moderate: see Bentley in Resources)

- Preferential oxidation, volatilization (potentially large)

- Hysteresis in structural phase changes (small to moderate, worst for type $E$ and $K$ )

- Extension wires, thermocouple connectors, feedthroughs (potentially large, but avoidable)

\begin{tabular}{|c|c|c|}
\hline \multicolumn{3}{|c|}{$\begin{array}{l}\text { Typical variations in indicated } T \text {, } \\
\text { for each effect, } T \approx 900^{\circ} \mathrm{C}\end{array}$} \\
\hline & Base & Noble \\
\hline small & $1^{\circ} \mathrm{C}$ & $0.1^{\circ} \mathrm{C}$ \\
\hline moderate & $3^{\circ} \mathrm{C}$ & $1^{\circ} \mathrm{C}$ \\
\hline large & $\geq 10^{\circ} \mathrm{C}$ & $\geq 3{ }^{\circ} \mathrm{C}$ \\
\hline
\end{tabular}

Intrinsic Variations in Thermocouple Homogeneity

There are unavoidable variations in thermoelectric properties along the length of a wire caused by:

- compositional variations in the wire alloy

- variations in the annealing state

In the best circumstances, the fractional uncertainty $\triangle T / T$ of measuring a temperature interval $T_{1}-T_{2}$ is very approximately:

Base metal $10^{-3}$

Pt-Rh alloy $10^{-4}$

$\mathrm{Au} / \mathrm{Pt}$ or the best $\mathrm{Pt} / \mathrm{Pd} \quad 10^{-5}$

This level of performance requires careful manufacture and use 


\section{Chemical Contamination}

- Pure elements are more sensitive to impurities than alloys

- In semiconductor processing, absence of oxygen may lead to reduction of oxides and increased levels of free impurities such as $\mathrm{Si}$

Examples of the sensitivity of $P t$ to impurities
$\begin{array}{cc}\text { Element } & \Delta E / \mu \vee \text { at } 1200^{\circ} \mathrm{C} \\ \mathrm{Cu} & \text { per } 10^{-6} \text { mass fraction impurity } \\ \mathrm{Fe} & 0.12 \\ \mathrm{Cr} & 2.30 \\ \mathrm{Mn} & 4.04 \\ \mathrm{Si} & 0.32 \\ & 1.17\end{array}$

(at $1200{ }^{\circ} \mathrm{C}, 1 \mu \mathrm{V}$ equivalent to $0.08{ }^{\circ} \mathrm{C}$ for type $\mathrm{S}$ )

Cochrane, Temperature, Vol. 3, p. 1619 (ISA, 1973)

\section{Preferential Oxidation in Pt-Rh Alloy Thermocouples}

Example: emf of a type S TC at Ag freezing point $\left(961.78^{\circ} \mathrm{C}\right)$ is altered as $\mathrm{Rh}$ changes oxidation state during test.

- Effect is $3 X$ larger for some cases of rapid temperature change.

- Effect is reversible, unless oxide is volatile and sublimates

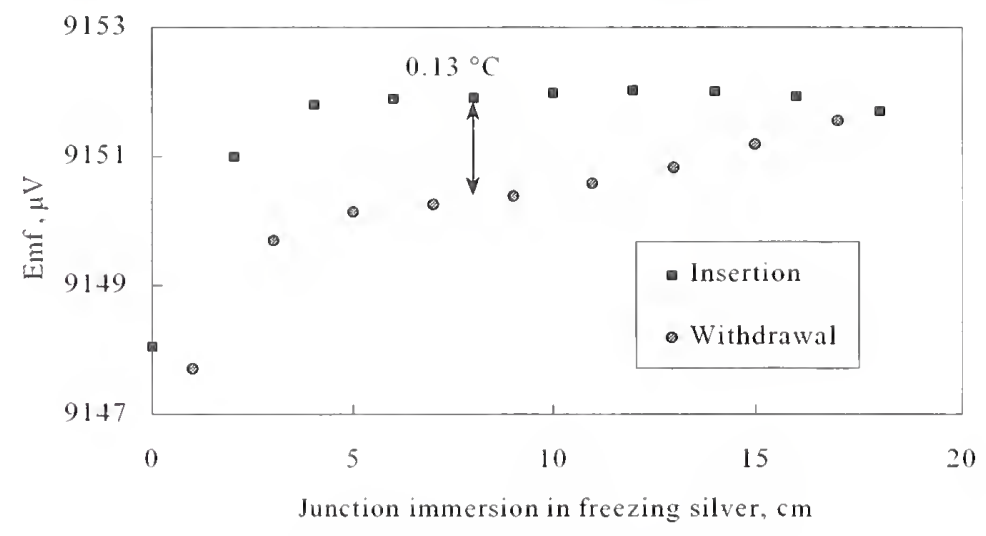



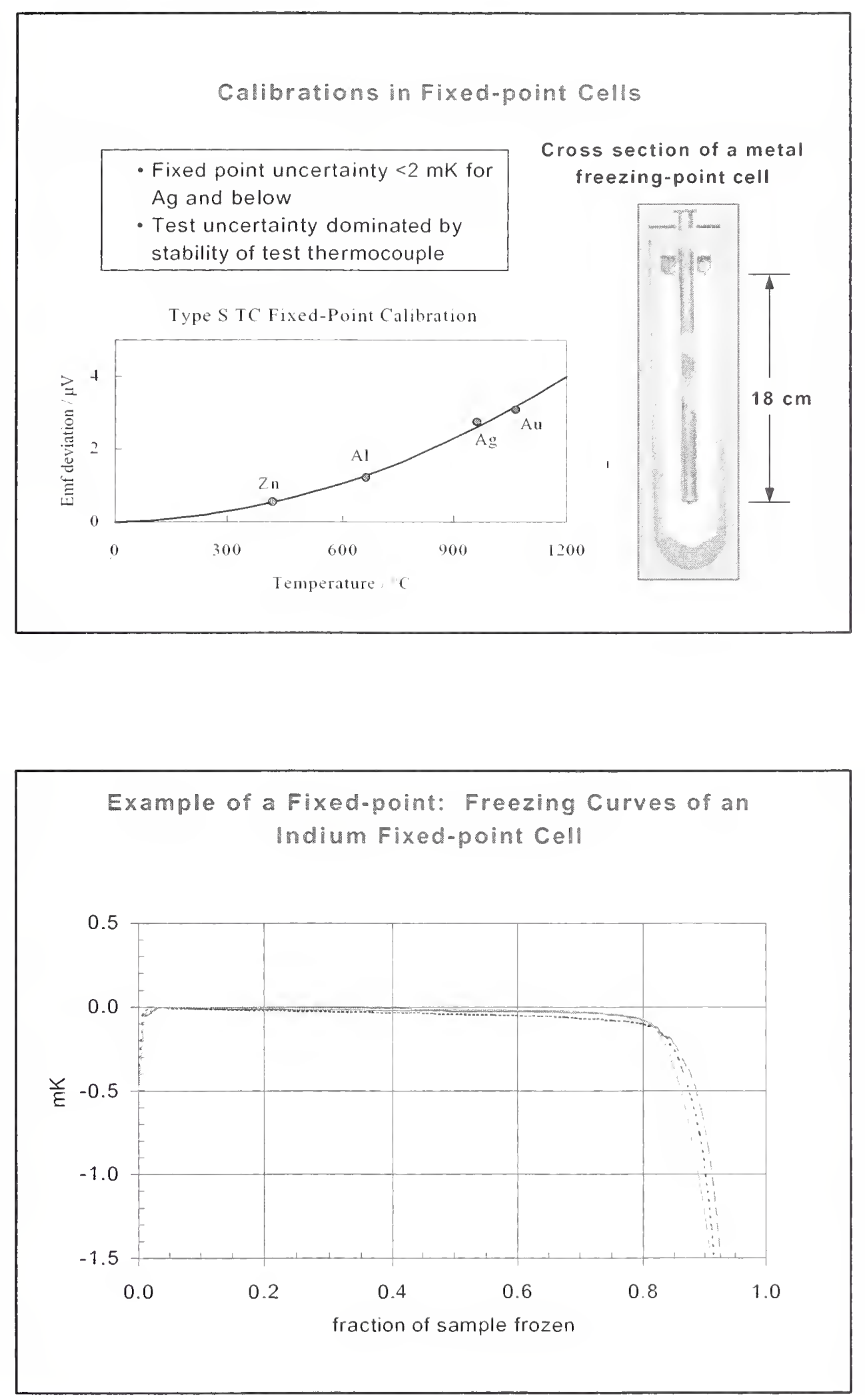


\section{Comparison Calibrations in Furnaces}

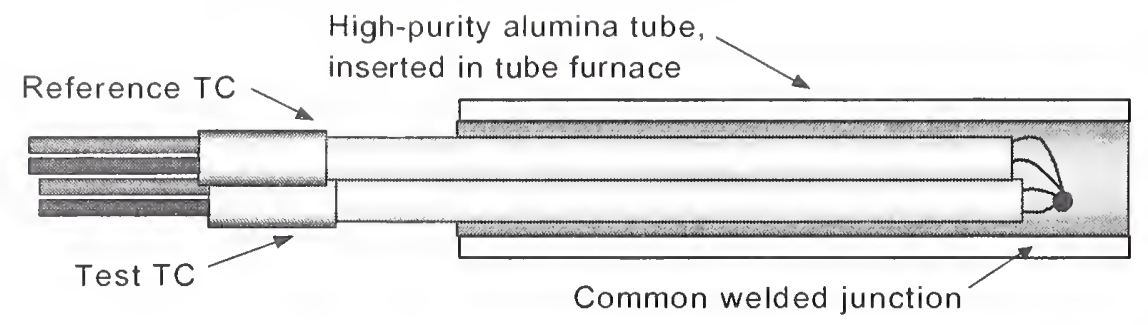

- TCs measured simultaneously, to cancel temperature drift

- Measuring junctions at center of furnace to minimize gradients

- Reference TC calibrated at fixed points

NIST Exp. Uncertainties in ${ }^{\circ} \mathrm{C}$

Base TCs Noble TCs

$\begin{array}{lll}0{ }^{\circ} \mathrm{C} & 0.1 & 0.1\end{array}$

$\begin{array}{lll}400{ }^{\circ} \mathrm{C} & 0.4 & 0.2\end{array}$

$\begin{array}{lll}900{ }^{\circ} \mathrm{C} & 1.0 & 0.3\end{array}$

\section{Comparison Calibrations in Stirred-liquid Baths}

- SPRT expanded uncertainty $<1 \mathrm{mK}$ (negligible)

- Bath stability, gradients $<20 \mathrm{mK}$ (generally negligible)

- Test uncertainty dominated by stability of test thermocouple

Operating range:

ethanol

water

oil

salt $-90^{\circ} \mathrm{C}$ to $5^{\circ} \mathrm{C}$

$0.5^{\circ} \mathrm{C}$ to $95^{\circ} \mathrm{C}$

$95^{\circ} \mathrm{C}$ to $275^{\circ} \mathrm{C}$ $275^{\circ} \mathrm{C}$ to $550^{\circ} \mathrm{C}$

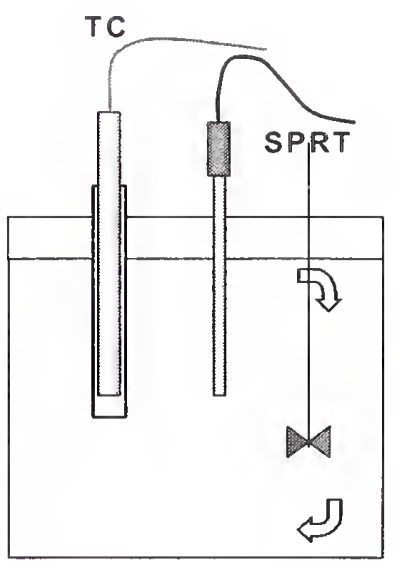


Calibration of Thermocouples above $961.78^{\circ} \mathrm{C}$ Furnace

Radiometer
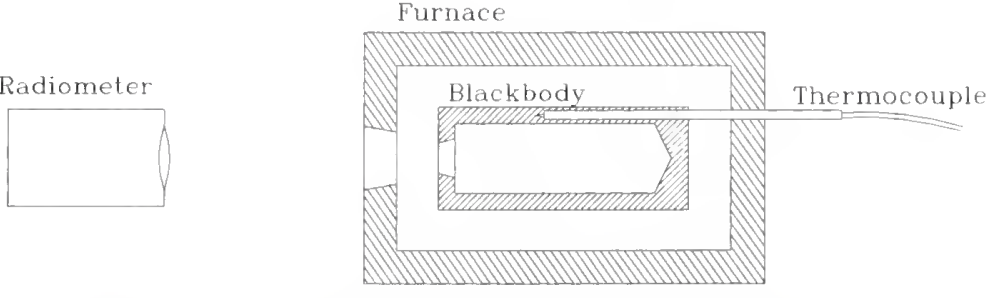

Temperatures on the ITS -90 above $961.78{ }^{\circ} \mathrm{C}$ defined by radiation thermometry

1. Calibrate radiometer on the ITS-90 at a single fixed-point temperature: silver, gold, or copper.

2. Place thermocouples in or near the blackbody.

3. Measure the emf of the thermocouple while simultaneously measuring the blackbody temperature radiometrically.

Difficult and expensive: Often only done in determination of reference function

\section{Calibration Uncertainty Components}

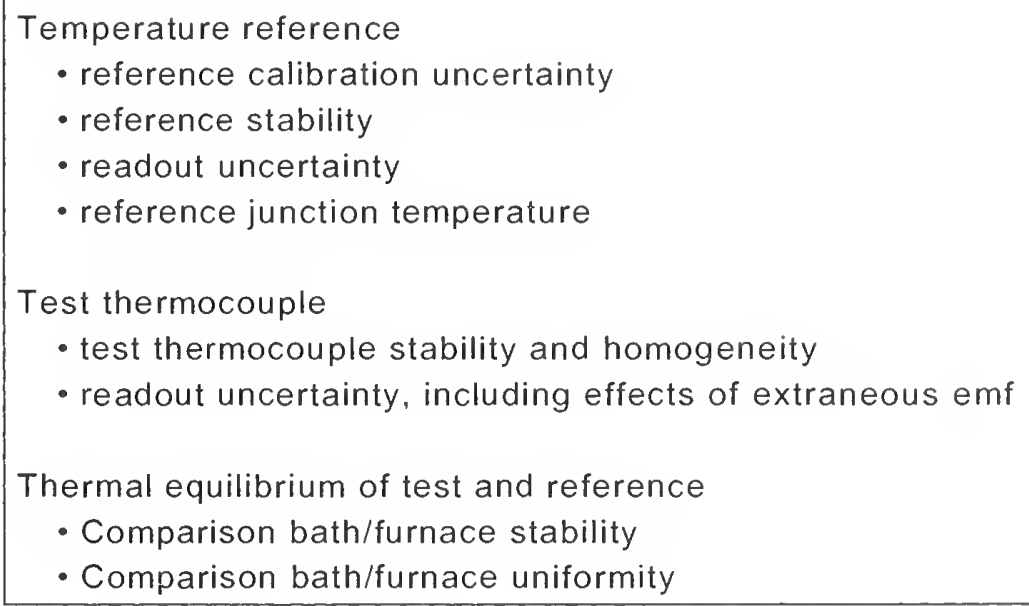




\section{Method for Evaluation of Uncertainty}

ISO Guide to the Expression of Uncertainty in Measurement

1. Evaluate uncertainty components by statistical analysis of data: Type A or

Evaluate by other methods (calculation, calibration cert., etc.): Type B

2. Express all uncertainties at the one standard deviation level.

Standard uncertainty $=u$.

3. Combine all uncertainties using the Law of Propagation of Errors, equivalent to root-sum-of-squares (RSS) in simple cases.

4. Expanded uncertainty $=U=k u_{c}$, where $k=$ coverage factor, often 2 . If uncertainties are not normally distributed, establish confidence limits for stated $k$ value.

Important point: RSS strongly weights only the few largest uncertainty components. Emphasize careful evaluation of these few components!

Uncertainty Budget for Type S TCs at Fixed Points

\begin{tabular}{|c|c|c|c|c|}
\hline Uncertainties in $\mu \mathrm{V}$ & $\begin{array}{c}\mathrm{Au} \\
\left.=1064^{\circ} \mathrm{C}\right)\end{array}$ & $\begin{array}{c}\mathrm{Ag} \\
\left(\approx 962^{\circ} \mathrm{C}\right)\end{array}$ & $\begin{array}{c}\mathrm{Sb} \\
\left(\approx 630^{\circ} \mathrm{C}\right)\end{array}$ & $\begin{array}{c}\mathrm{Zn} \\
\left(\approx 420^{\circ} \mathrm{C}\right)\end{array}$ \\
\hline \multicolumn{5}{|l|}{ Type B } \\
\hline Emf Measuring System & 0.05 & 0.04 & 0.03 & 0.02 \\
\hline Temperature of Liquidus Point & 0.03 & 0.02 & 0.08 & 0.01 \\
\hline Change in Liquidus Point & 0.10 & 0.09 & 0.06 & 0.06 \\
\hline Thermocouple Sheath Losses & 0.07 & 0.07 & 0.06 & 0.06 \\
\hline Reference Junction Temperature & 0.02 & 0.02 & 0.02 & 0.02 \\
\hline Total Type B & 0.14 & 0.12 & 0.12 & 0.09 \\
\hline \multicolumn{5}{|l|}{ Type A } \\
\hline Uncert. of Check-Standard & 0.43 & 0.35 & 0.38 & 0.27 \\
\hline Uncert. of Quadratic Function & 0.20 & 0.20 & 0.20 & 0.20 \\
\hline Total Type A & 0.47 & 0.40 & 0.43 & 0.34 \\
\hline Expanded Uncertainty, $U=2 u_{c}$ & 1.0 & 0.8 & 0.9 & 0.7 \\
\hline
\end{tabular}




\section{Care and Feeding of Thermocouples}

Noble Metal Thermocouples:

- Use at the same immersion at which the calibration was performed

- Protect from contamination by the furnace environment, using single lengths of alumina insulator when possible

- Protect from mechanical strain and kinks

Base Metal Thermocouples:

- Monitor drifts in base metal thermocouples by in situ tests

- Protect from contamination using alumina or silica tubes, or use mineral-insulated-metal-sheathed thermocouple wires.

- For each temperature environment to be measured, a new thermocouple should be made, and it should always be used at the same immersion.

- Obey the ASTM upper temperature limits for bare wire thermocouples.

The Difficulty of Recalibrating Used Thermocouples

- With use at elevated temperatures $\left(>200^{\circ} \mathrm{C}\right.$ to $\left.400^{\circ} \mathrm{C}\right)$, thermocouples become inhomogeneous.

- Calibration of a used thermocouple in a different apparatus often will produce meaningless results! Often, only in situ recalibration is meaningful.

- Noble metal thermocouples can be partially restored to a homogeneous state by annealing electrically or in a furnace. Base metal thermocouples are generally not reannealed.

- Any recalibration of a used thermocouple should include a check of the thermocouple homogeneity. (Example: test at different immersions.) 


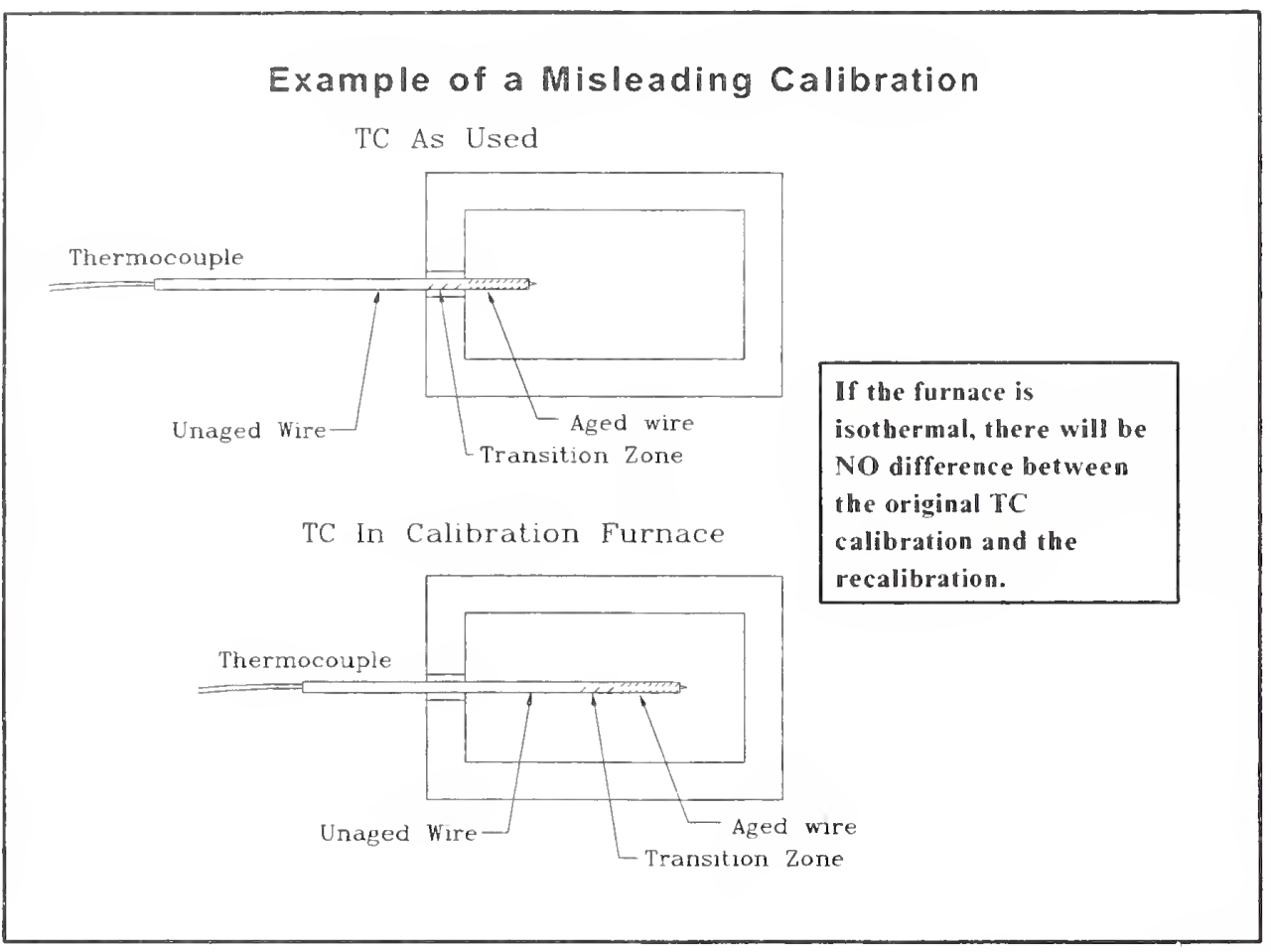

\section{Alternatives to Recalibration of Used Thermocouples}

Option 1. Recalibrate thermocouples in situ.

Example: a reference thermocouple is inserted into a furnace with a control thermocouple. The control thermocouple may be recalibrated without removal.

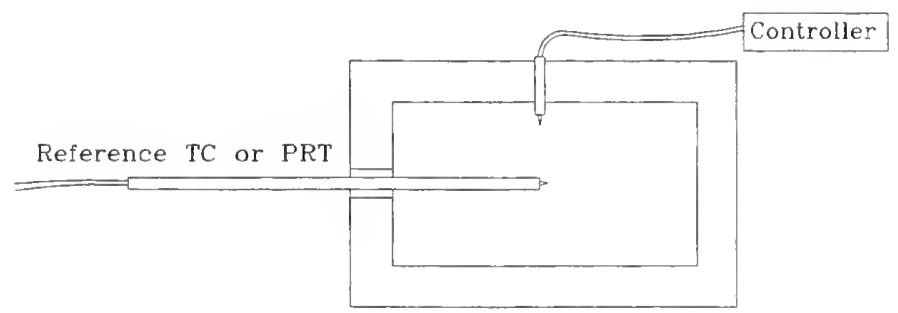




\section{Alternatives to Recalibration of Used Thermocouples}

Option 2. Periodic Replacement. Determine a typical drift rate of thermocouples in an application and replace thermocouples periodically.

Drift rate may be determined by:

- Finding similar cases documented in the literature,

- In situ calibrations,

- In situ comparison measurements between two thermocouples of the same lot, one of which is used and one of which is new.

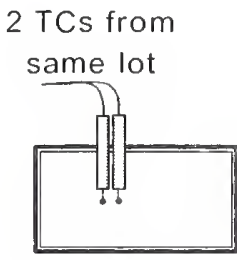

day 1

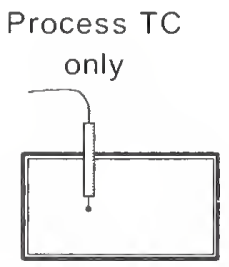

day 2 through 119
2 TCs again

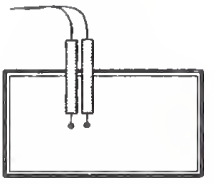

day 120

\section{Resources}

Books

- Traceable Temperatures, J. V. Nicholas and D. R. White (John Wiley, 1994)

- The Theory and Practice of Thermoelectric Thermometry, Vol. 3 of the Handbook of Temperature Measurement, R. Bentley (Springer, 1998)

- Manual on the Use of Thermocouples, ASTM, MNL-12 (ASTM, 1993)

Links

- ASTM standards and tables: www.astm.org

- NIST Thermometry Group : www.cstl.nist.gov/div836/836.05/home.htm

- General reference on thermometry: www.temperatures.com

Training

NIST Precision Thermometry Workshop, every March and October. Contact Andrea Swiger at andrea.swiger@nist.gov. 


\section{SURFACE TEMPERATURE MEASUREMENTS}

- KEN KREIDER

- THERMOMETRY GROUP, NIST

- OCTOBER 20, 2000

\section{NLS}

\section{Surface Temperature Measurements in Engineering}

\section{- PRODUCTION}

- hot rolling, forging, glass forming, plastic molding

- RTP of silicon wafers

- TEST AND EVALUATION

- gas turbine engines, diesel engines

- calibration of pyrometers

- APPLICATION AND OPERATION

- bearing surfaces, boiler tubes

- control 


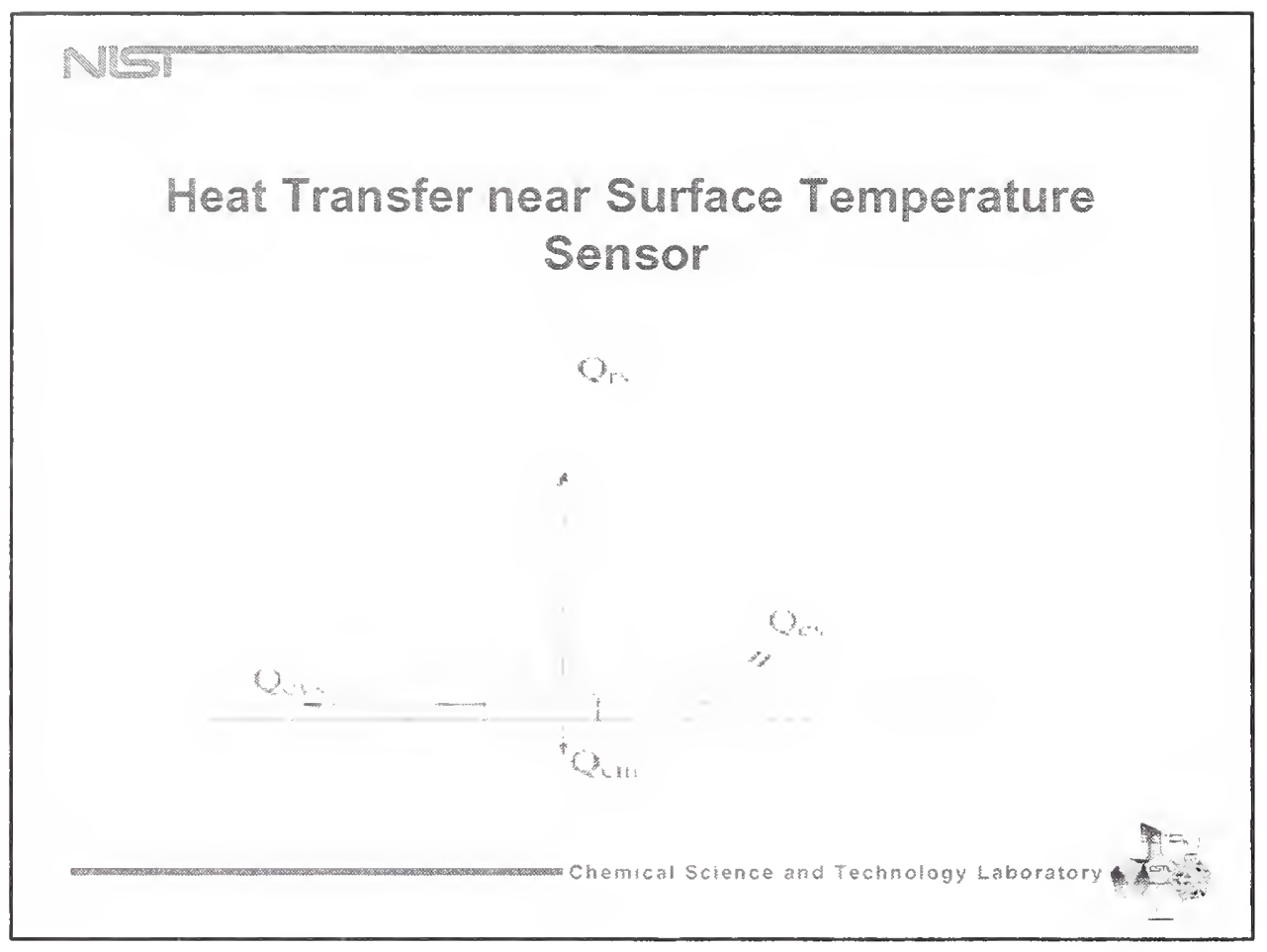

\section{Nem}

HEAT TRANSFER FROM SURFACES

- $Q_{c}=k A d T / d s$

- $Q_{C V}=h_{C} A \Delta T \quad h c=f(s, \angle)$

- $Q_{r a d}=(F \in A)\left(T_{s}{ }^{4}-T_{b}{ }^{4}\right) \quad \epsilon=f\left(x_{o x}, \delta_{r m s}, \lambda\right)$

B-2 


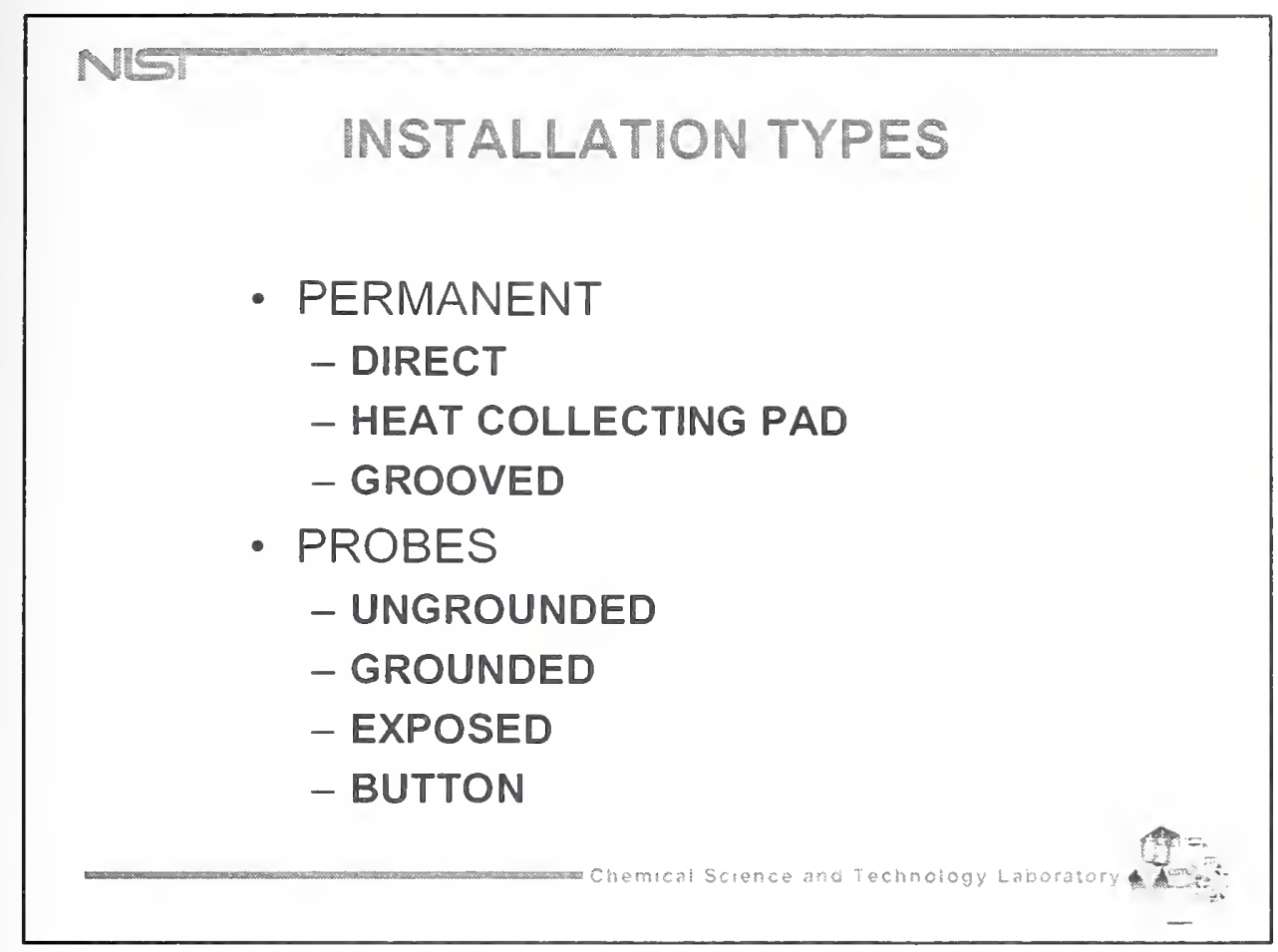

N 1 1

Thermocouple Probe with Auxiliary Heater

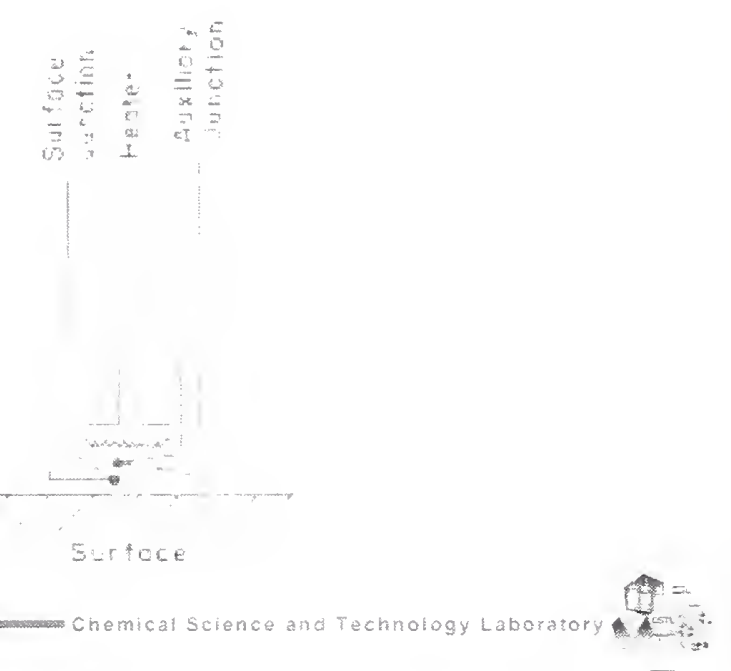

B-3 
NUST

Separated Thermocouple Junction

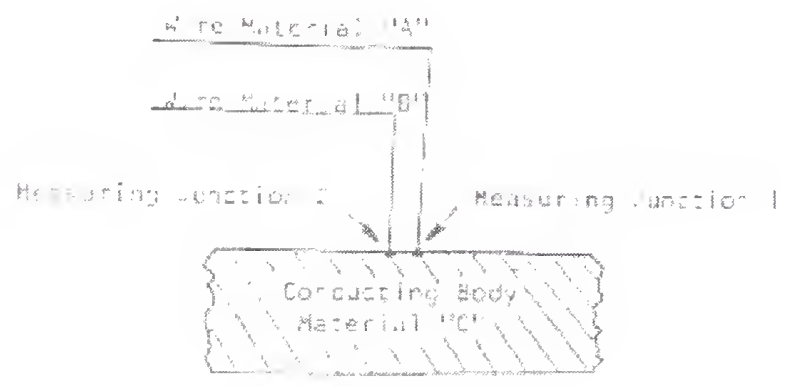

\section{NUST}

\section{SEPARATED JUNCTION}

- $e_{o}=e_{m}+\left(S_{1}-S_{2}\right)\left(T_{1}-T_{2}\right) / 2$

$-T_{1}$ and $T_{2}=$ junction temperatures

$-\mathrm{e}_{\mathrm{o}}=$ measured output

$-e_{m}=$ output if $T_{1}=T_{2}$

- $S_{1}, S_{2}=$ Seebeck coefficient of material $C$ versus materials $A$ and $B$, and Seebeck coefficient of thermocouple wires $A$ and $B$ 


\section{SOURCES OF ERROR}

- PERTURBATION ERROR

- EMISSIVITY

- CONDUCTION

- INSULATION

- CONVECTION

- DISPLACEMENT ERRORS

- OFFSET VS GRADIENT

- DISSIMILARITY OF MATERIALS

- TRANSIENT RESPONSE

- MASS CHANGE

- HEAT TRANSFER RATES

\section{PROCEDURES FOR MINIMIZING ERROR}

- USE SMALLEST POSSIBLE INSTALLATION

- USE ISOTHERM FOR TC WIRES FOR >20 D

- Locate Junction AT SURFACE

- MINIMIZE CHANGES IN CONVECTIVE AND RADIATIVE HEAT TRANSFER

- MINIMIZE TRANSIENT LAG

- MINIMIZE THERMAL RESISTANCE FROM SURFACE TO JUNCTION 


\section{NIST}

\section{THIN-FILM THERMOCOUPLES}

- SMALL SIZE

- FAST RESOLUTION (<1 $1 \mu s)$

- FINE SPATIAL RESOLUTION $(0.1 \mathrm{~mm})$

- LOW COST

- AUTOMATED PRODUCTION

- LOW MATERIALS COST

- COMPATIBLE WITH IC PRODUCTION

- MATERIALS COMPATIBILITY

- SAME FABRICATION TECHNOLOGY

- VOLTAGE OUTPUT

- SIMPLE INSTRUMENTATION-NO POWER REQUIREMENTS

\section{Nest}

\section{APPLICATIONS}

- GAS TURBINE BLADES AND VANES

- DIESEL ENGINE CYLINDER WALLS

- thermal CONVERTORS

- BEARINGS AND SEALS

- ELECTRONIC PACKAGE THERMAL MONITORS

- HEAT FLUX GAGES

- THERMOPILES

- CALIBRATION TOOLS FOR RADIOMETRIC MEASUREMENTS 


\section{LOW HEAT REJECTION DIESEL ENGINE}

ISSUES

- IN CYLINDER CONVECTIVE AND REDIATIVE HEAT TRANSFER

- CYCLIC TRANSIENT HEAT TRANSFER IN LAYERS NEXT TO COMBUSTION CHAMBER

- HEAT TRANSFER: PISTON / RING / LINER

- STEADY STATE HEAT TRANSFER

- TRANSIENTS IN WARM UP AND POWER CHANGES

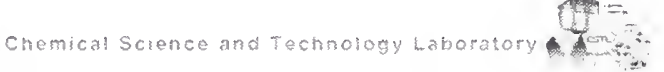

\section{NES}

Diesel Engine Sensor Plug

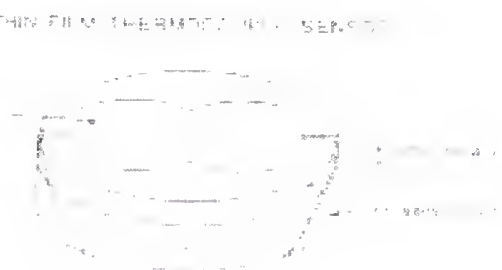




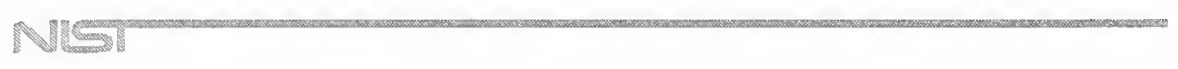

Heat Flux vs Crank Angle in Diesel Engine

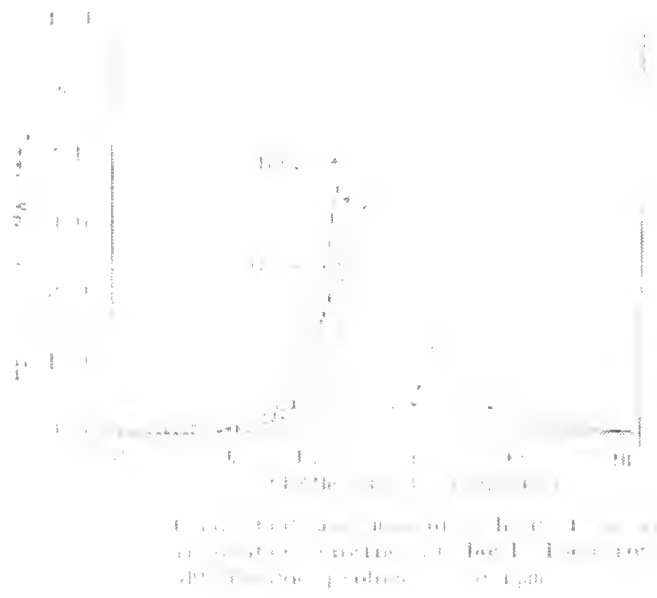

NUST

Swing Temperature Measured with Thin-film Thermocouple in Diesel Engine Cylinder

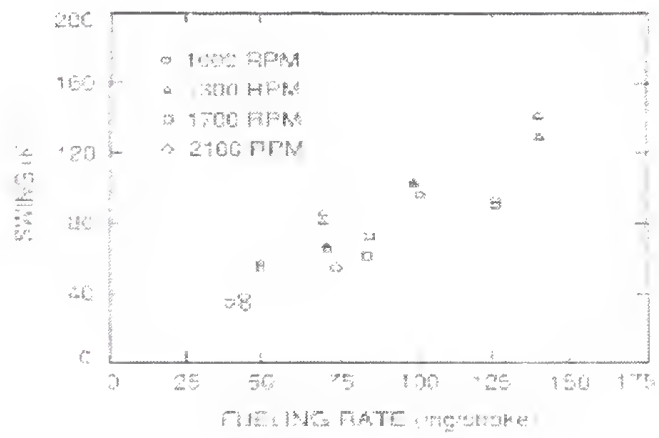

Chemical science and Jechnology Laboratory ton 
NLSt

THIN-FILM THERMOCOUPLE TRANSIENT THERMAL RESPONSE

- tFtC JUNCTION ON SUBSTRATE $\left(\mathrm{ZrO}_{2}, \mathrm{Al}_{2} \mathrm{O}_{3}\right.$, etc. $)$

- EXIMER LASER (ns) ON $1 \mathrm{~mm}^{2}$ JUNCTION

- TRACK ON CR OSCILLOSCOPE

- DETERMINE THERMAL CONDUCTIVITY AND DIFFUSIVITY OF SUBSTRATE MATERIAL

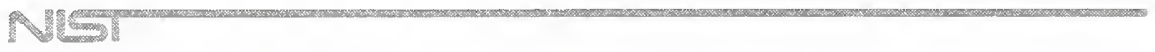

Thin-film Thermocouple Time Response on Aluminum Oxide 
Thin-film Thermocouple Time Response $\mathrm{ZrO}_{2}$

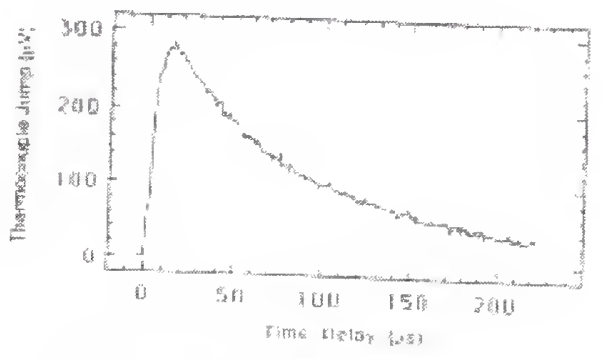

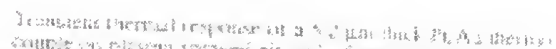

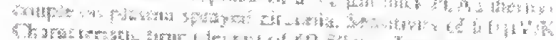

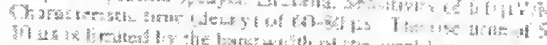

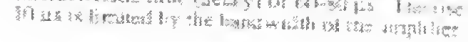

chemicat scier

and

\section{NESI}

\section{RAPID THERMAL PROCESSING}

\section{ADVANTAGES}

COMPATIBILITY WITH CLUSTER TOOLS

FABRICATION CYCLE TIME

PROCESS REPEATABILITY

REDUCED FOOTPRINT

\section{REQUIREMENTS}

WAFER TEMPERATURE UNIFORMITY ABSOLUTE TEMPERATURE CONTROL 


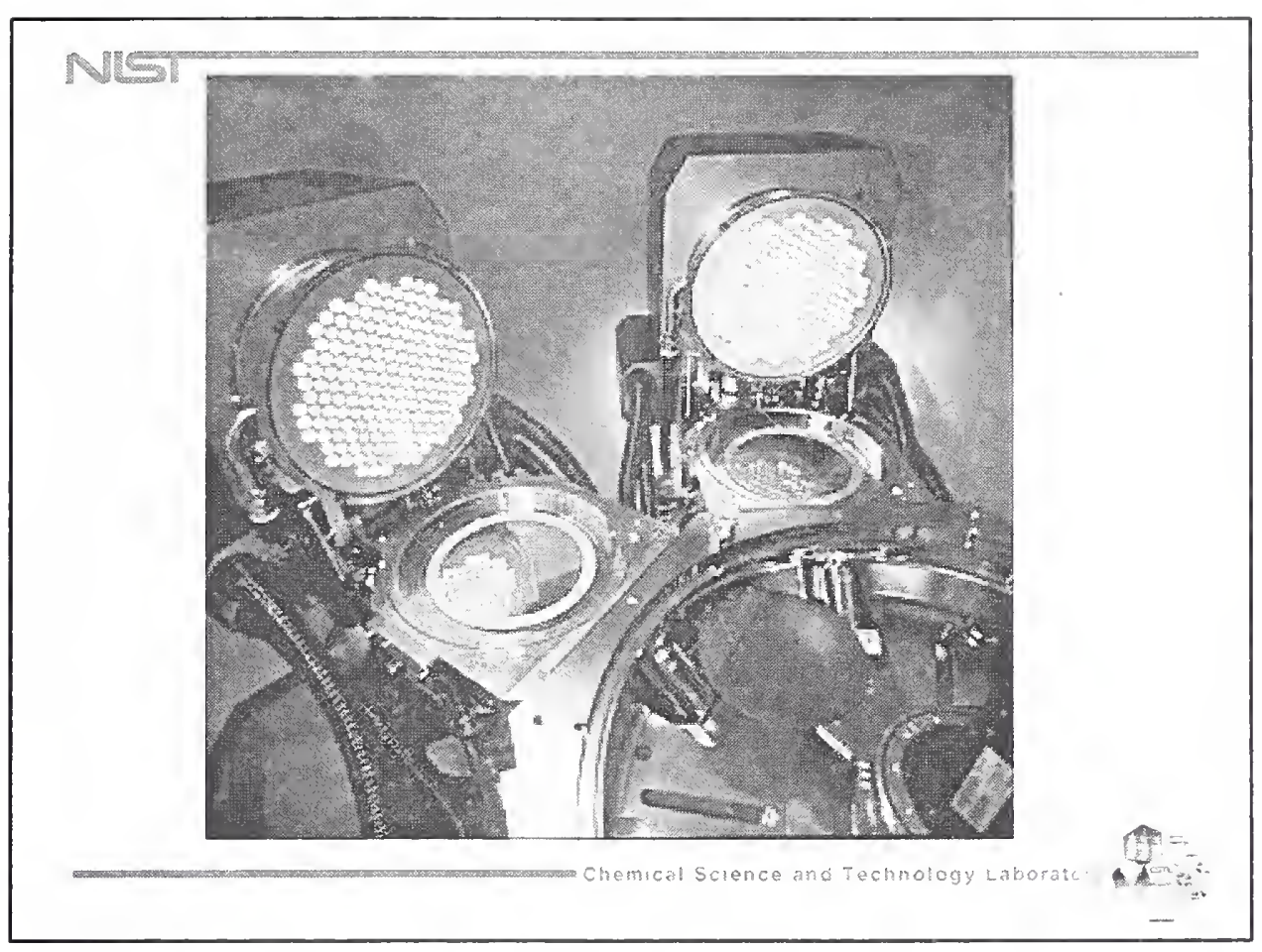

\section{NUST \\ THIN-FILM VERSUS WIRE THERMOCOUPLES}

\begin{tabular}{|c|c|c|c|}
\hline & thin=7im & & wire \\
\hline junction volume & $2 \times 10^{-5}$ & $\mathrm{~mm}^{3}$ & $10^{-2}$ \\
\hline profile & $10^{-3}$ & $\mathrm{~mm}$ & 0.5 \\
\hline attachment & $2 \times 10^{-7}$ & $m^{3}$ & 1 \\
\hline$\Delta T_{900}$ & $<1^{\circ} \mathrm{C}$ & & $3.6^{\circ} \mathrm{C}$ \\
\hline
\end{tabular}


NEST

Calibration Wafer with Wire/Thin-film thermocouples

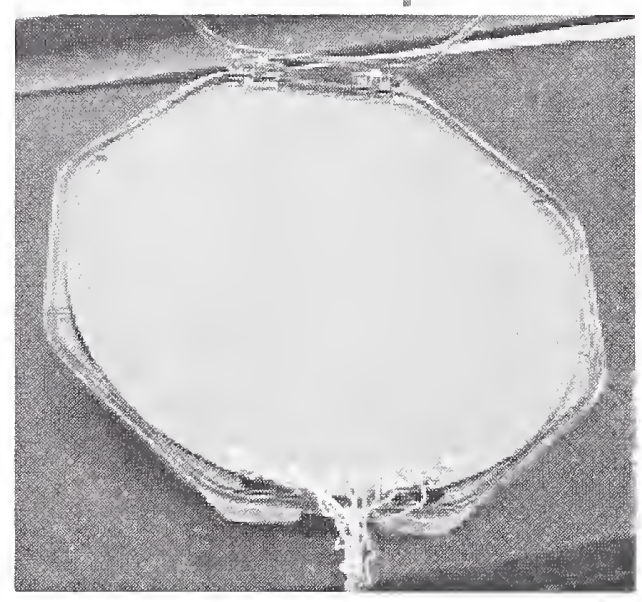

NUSI

\section{WAFER SURFACE TEMPERATURE MEASUREMENT}

\section{UNCERTAINTY $k=1$}

- Pt/Pd wire thermocouple $u_{\mathrm{c}}=1{ }^{\circ} \mathrm{C}$

- $S$ for thin-film thermocouple $u_{c}=3 \% \times 10^{\circ} \mathrm{C}$ 


\title{
Relationship between Thermocouple and
} Radiation Thermometer Measurements

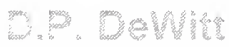 \\ Ophical Temperature and Source Group \\ Optra Techrology Division. Pi \\ MST - Samershurg. Wh
}

Workshop on

Temperature Measurement

of Semiconductor Waters

Using Thermocouples

RTP 2000 Conference

September 19, 2000

\section{Overvew}

Objectives: fundamentals of RTs, model-corrected measurements, LPRT calibration, comparison of RT \& TC; about good practice

1. The Measurement Problem: getting $T_{\text {rad }}$ from $T_{\lambda}$

Blackbody calibration, measurement equation

Model-corrected RT measurements, $T_{\text {rad }}$

2. Radiation Modeling: three idealized reactor cases

3. Light-Pipe RTS

Calibration against blackbodies, uncertainties

Characterization for use in RTP environment

4. NIST Test Bed Experiments: comparing $T_{t c}$ and $T_{\text {rad }}$

5. Recommendations for Good Practice using RTS

6. References and Bibliography 


\section{The Measurement Problem}

- Radiation thermometer, RT - a radiometer calibrated to indicate temperature of a blackbody, $T$.

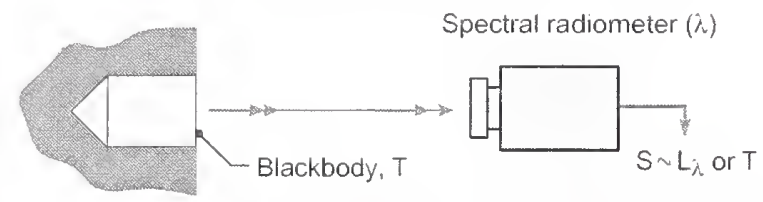

- Spectral radiance temperature, $T_{\lambda}$-indicated temperature when viewing a real target experiencing irradiation from the surroundings.

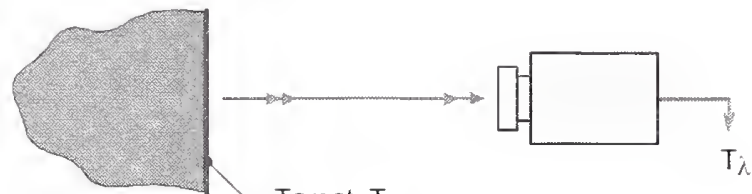

Target, T, $\varepsilon$,

1. The Measument problem - ThE

- Temperature measurement equation, TME - relates $T_{\lambda}$ to $T$.

$L_{\lambda}\left(\lambda, T_{\lambda}\right)=\varepsilon_{\lambda} L_{\lambda, b s}(\lambda, T)+($... reflected irradiation ...)

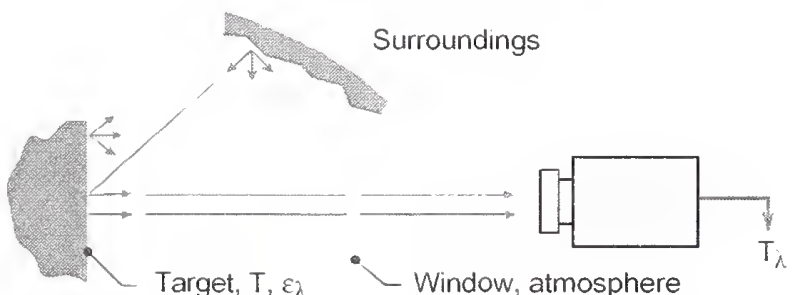

$L_{\lambda}$ - spectral radiance, $W /\left(m^{2}-\mu m-s r\right)$

$L_{\lambda, \mathrm{Esib}_{0}}(\lambda, T)=c_{1} \lambda^{-5}\left[\exp \left(c_{2} /(\lambda T)\right) \cdot 1\right]^{-1}$

$\varepsilon_{\lambda}$-spectral emissivity

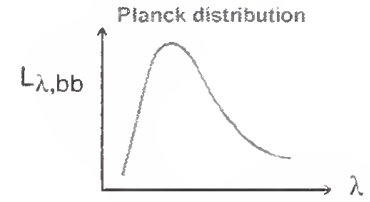




\section{The Radiation Environment}

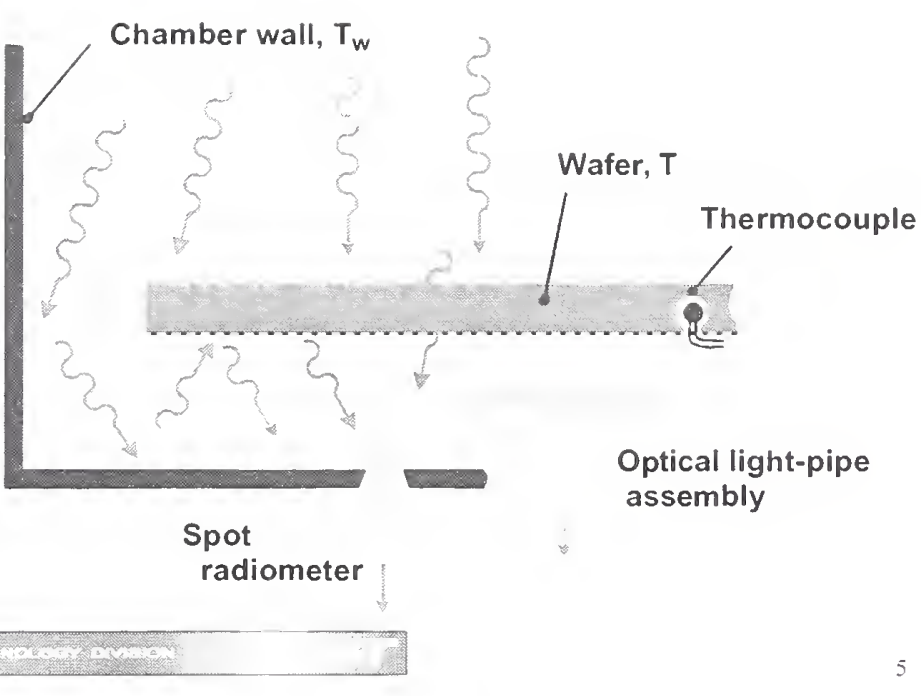

1. The Measurement Problem - Meknodology

- Characterizing the Radiation Environment: specifying the irradiation due to emission, reflection, stray radiation.

- Thermal Modeling: predicting the spectral radiance exitent from target reaching $R T$ in terms of wafer properties and radiation environment; three limiting cases to explore.

- Freely radiating - Cold reflective walls - Hot emitting walls

- Model-Corrected RT Measurements: using the TME with thermal radiation model(s) to determine wafer temperature and uncertainty of the measurement.

- Calibrating RT with a TC Measurement: for conditions of the calibration, $T_{\lambda}=T_{t c}$; for other conditions, require the TME. 


\section{Radiation Modeling: TMEs, idealized reactors}

- Radiation thermometer, RT - a radiometer calibrated to indicate temperature of a blackbody, T. For other conditions or targets, indicates spectral radiance temperature, $T_{\lambda}$.

- Freely radiating target - cold surroundings; $T_{\lambda}$

$$
\frac{1}{\mathrm{~T}}=\frac{1}{\mathrm{~T}_{\lambda_{2}}}+\frac{\lambda_{e}}{\mathrm{C}_{2}} \ln \left(\varepsilon_{\lambda_{i}}\right)
$$

$c_{2}=14,388 \mu m-K$, second radiation constant

$\lambda_{\text {eff }}=0.95 \mu \mathrm{m}, \mathrm{RT}$ effective wavelength

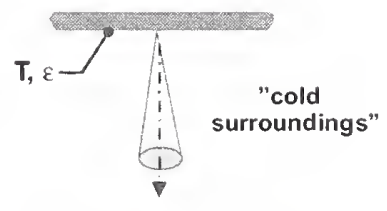

$$
L_{\lambda}\left(\lambda, T_{\lambda}\right)=\varepsilon_{\lambda} L_{\lambda, b}(\lambda, T)
$$

Case: $T=1000 \mathrm{~K}=727{ }^{\circ} \mathrm{C}, \varepsilon=0.67$, find $\mathrm{T}-\mathrm{T},=29 \mathrm{~K}$

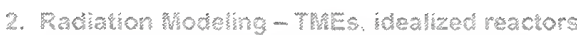

- Cold, reflective wall (shield), $T_{\lambda}$ $\frac{1}{\mathrm{~T}}=\frac{1}{\mathrm{~T}_{i}}+\frac{\lambda_{\mathrm{e}}}{\mathrm{C}_{2}} \ln \left(\varepsilon_{\mathrm{eff}}\right)$

$$
\varepsilon_{\mathrm{eff}}=\frac{\varepsilon}{1-(1-\varepsilon) \rho_{\mathrm{S}}}
$$

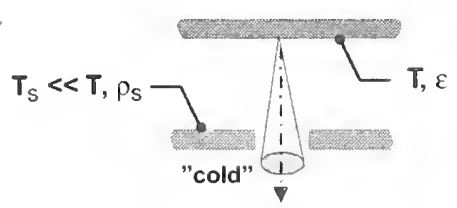

Case: $T=1000 \mathrm{~K}=727^{\circ} \mathrm{C}, p_{\mathrm{s}}=0.99, \varepsilon=0.67$,

find

$$
\varepsilon_{\text {eff }}=0.995 \quad T-T_{\lambda}=0.3 \mathrm{~K}
$$

- Hot, black wall (shield), $T_{\lambda}$

$L_{\lambda, b}\left(T_{\lambda}\right)=\left[1-\frac{1 / \varepsilon-1}{1 / \varepsilon+1 / \varepsilon_{s}-1} \mid 1-\frac{L_{\lambda, b}\left(T_{s}\right)}{L_{\lambda, b}(T)}\right] L_{\lambda, b}(T)$

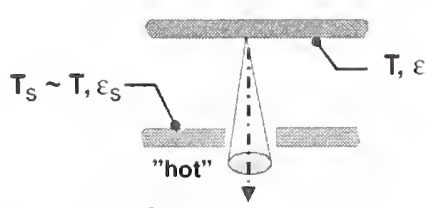

Case: $T=1000 \mathrm{~K}, \varepsilon=0.67 ; T_{\mathrm{s}}=990 \mathrm{~K}, \varepsilon_{\mathrm{s}}=0.95 \mathrm{find}$

$$
\mathrm{T}-\mathrm{T}=3 \mathrm{~K}
$$




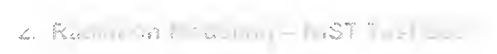

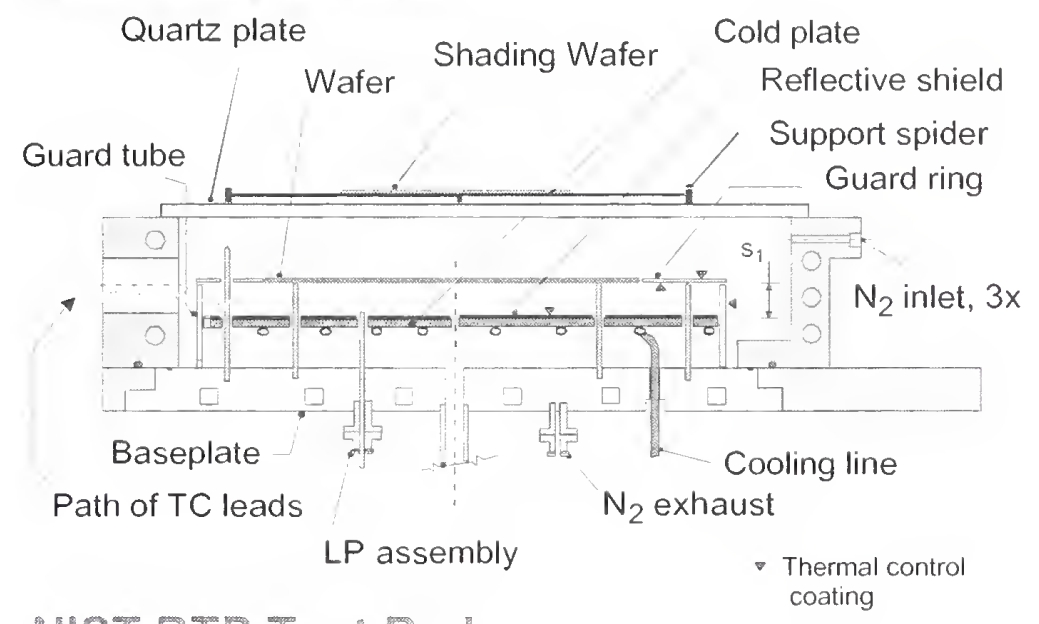

NIST RTP Test Bed

2. Radration hoseing - Mrst rest bed

Five-Region, 24-Zone Enclosure Model

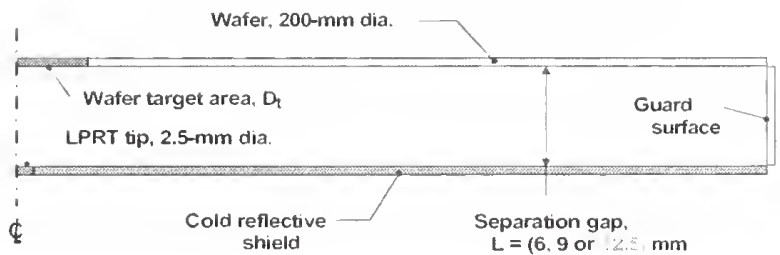

Target - LPRT Configuration

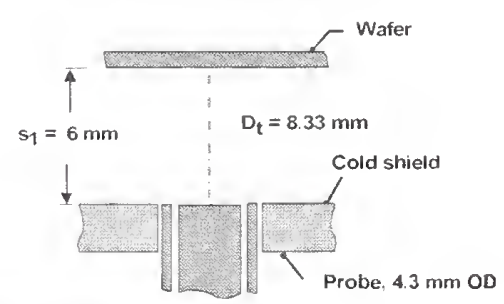

Model Assumptions:

1. Uniform radiosity on surfaces

2. Diffuse or specular shield

3. Prescribed uniform temperatures

for wafter, guard, edge ....

4. Target diameter, $D_{t}$, function of gap distance

5. Wafer effective emissivity,

$\varepsilon_{\text {eff }}=J_{t} / E_{b t}$ 
2. Radiation Modeling-NIST Test Bed

Silicon spectral emissivity (with thermal oxide)
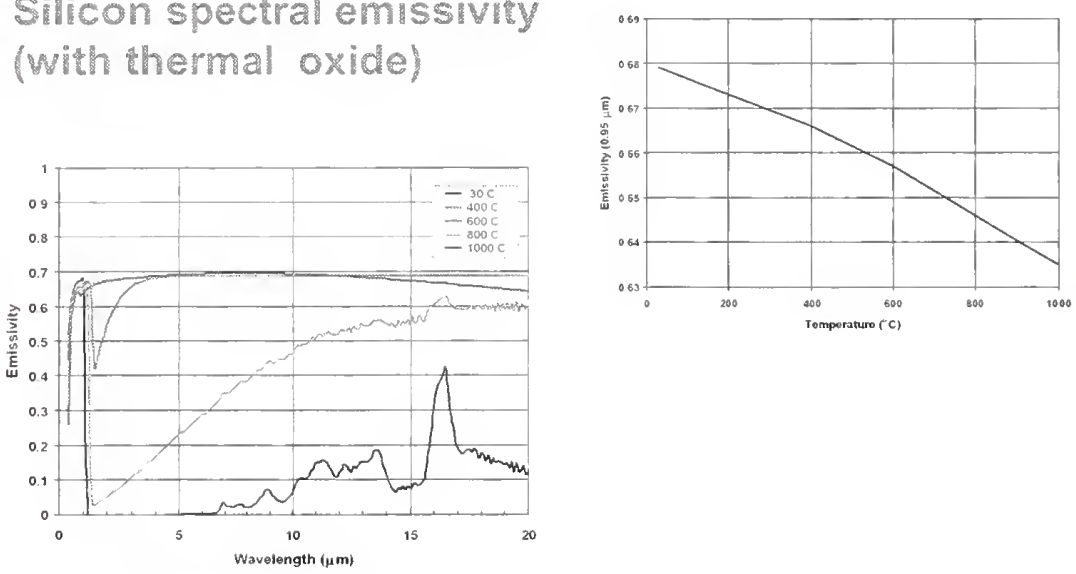

\section{Light-Pipe Radiation Thermometers Technology Issues}

Calibration of LPRTs against NIST Blackbody

- Remarkable discrepancies in factory calibrations

- Differences between hot and cold LPS

\section{Thermal Characterization}

- Calibration vs. application conditions (hot - cold)

- LP tip - wafer interaction, temperature disturbance

\section{Spatial Characterization}

- Thermal effects on field-of-view (FOV)

- Benchmarking FOV effects 
3. in Pine RTS - intio

The NIST Sodium Heat-Pipe Blackbody (Na-HPBB)

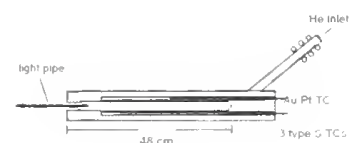

Uncertainties in LPRT Calibrations

$$
\text { Factor }
$$

$B B$ radial uniformify

$B B$ length uniformity

LPRT noise

LPRT short-term dritt

Total $(k=1)$

$u(K)$

0.01

0.03

0.30
LPRT calibration shifts (1 yr)

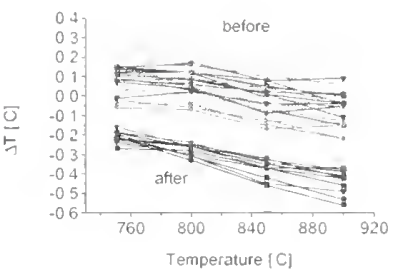

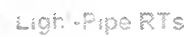

Hot Vs. Cold Light-Pipe RT Calibration

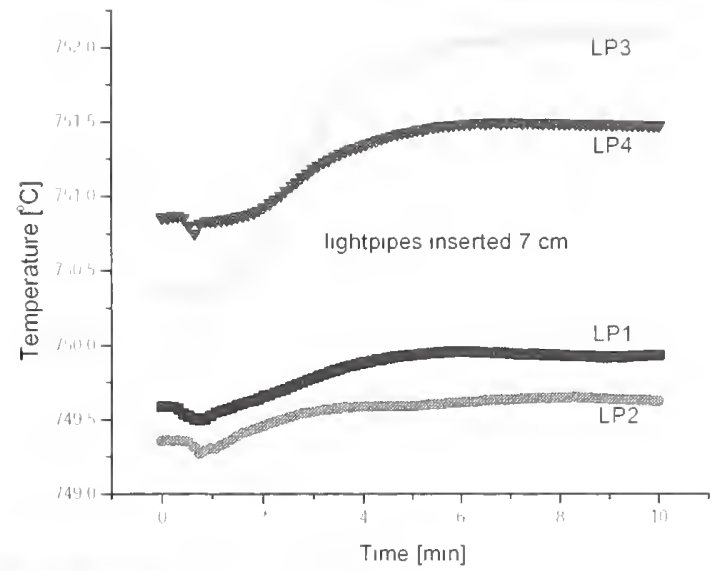




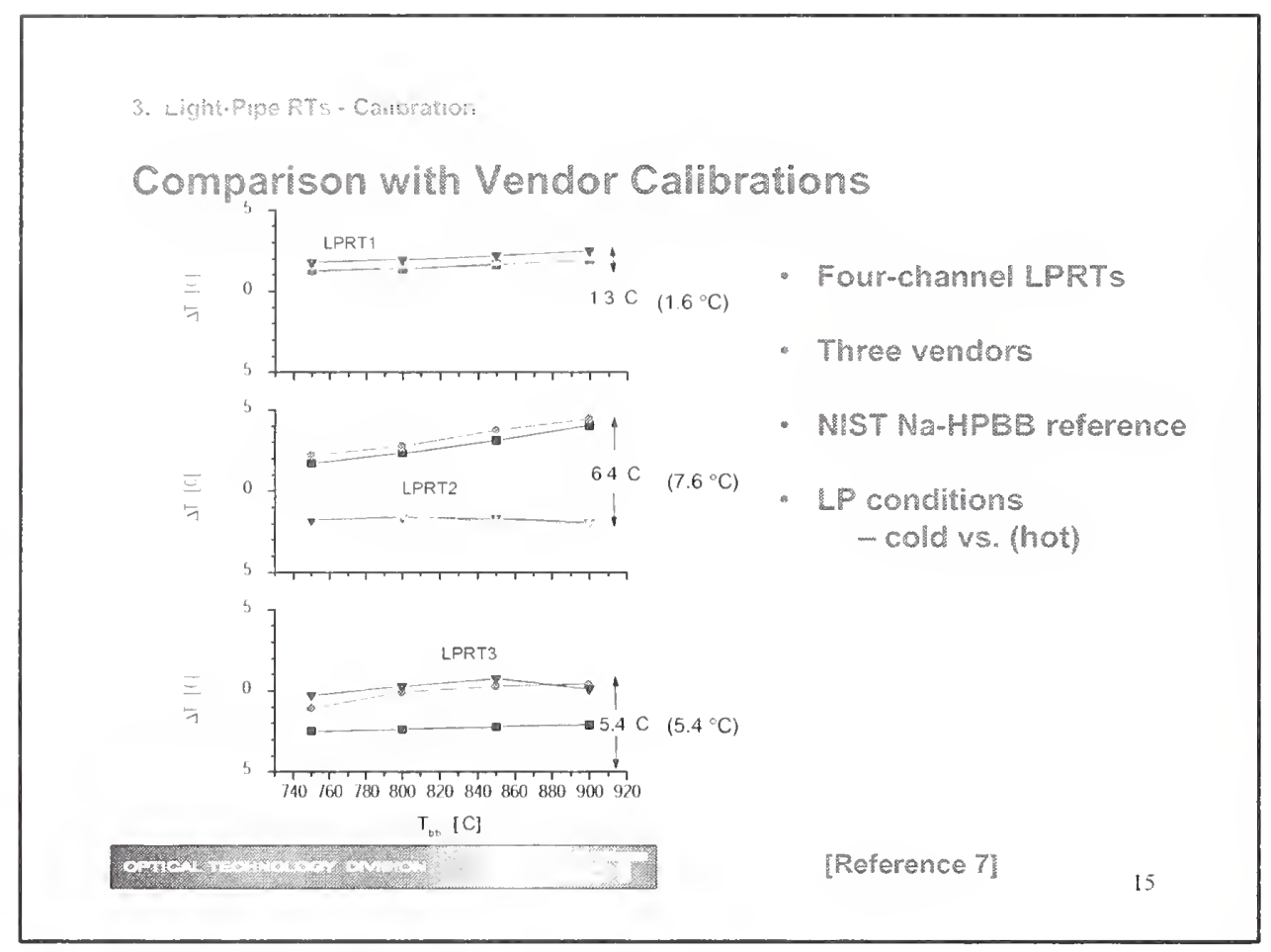

4. NST Test Bed Experiments - Objectives

Development and demonstration of thin-film/wire thermocouple (TFWTC) Test Wafer

In-situ calibration of LPRT using Test Wafer

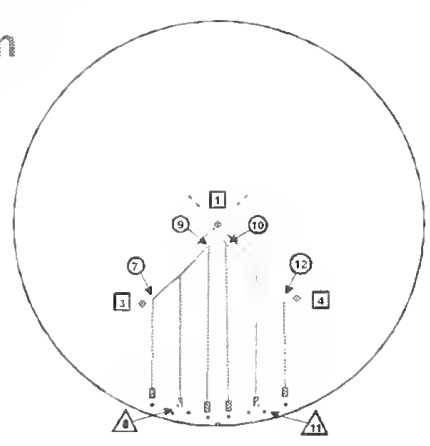

Comparison of temperature measurements by TFTC and Model-Corrected LPRT 


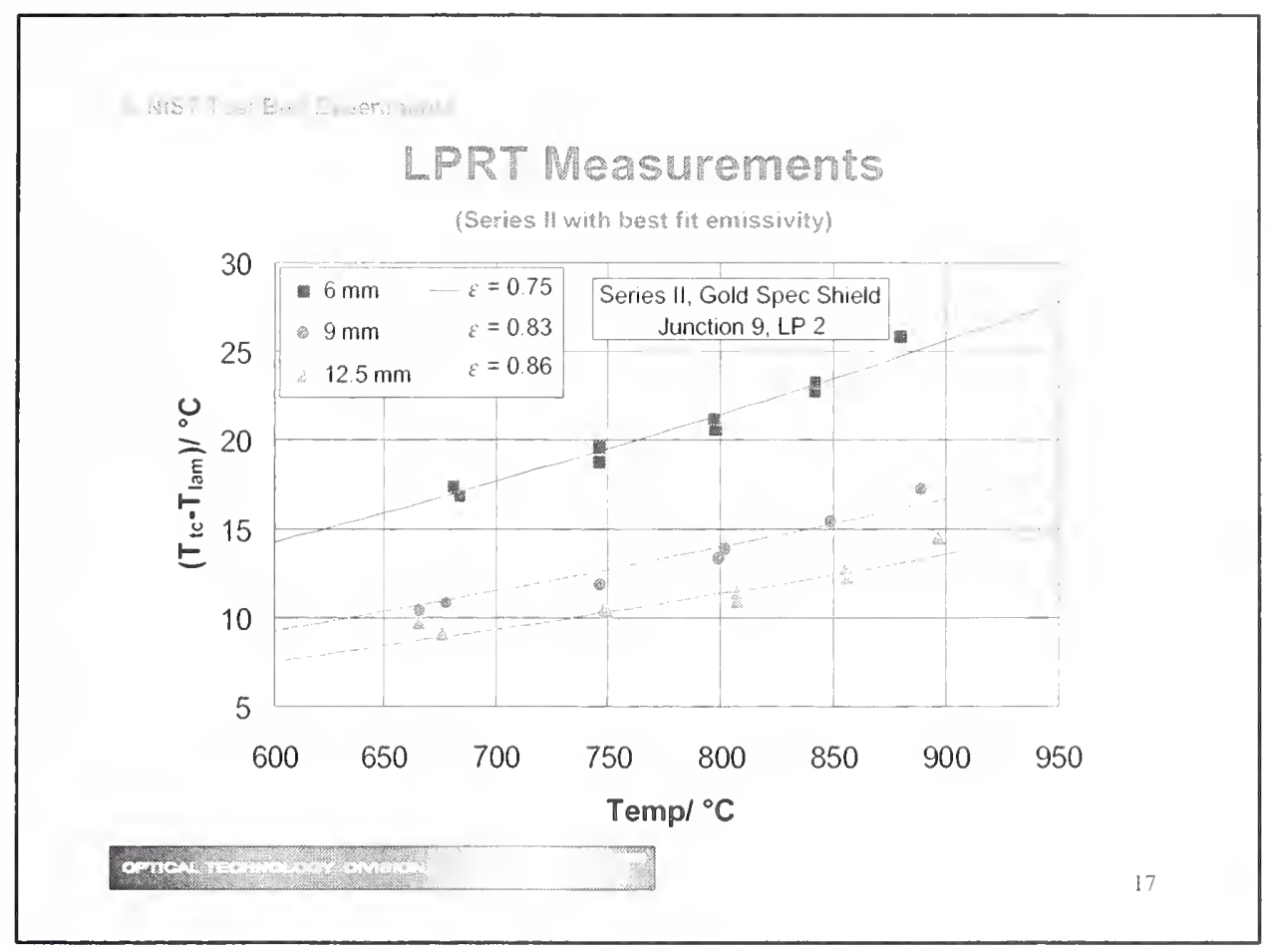

In Situ Calibration of LPRTS
Temperature Uncertainties $(k=1)$

Component

TFWTC calibrations $\left(10^{\circ} \mathrm{C}\right)$

TC emf measurements

LPRT measurements

Wafer temperature fluctuations

Wafer temperature drift

Junction/target temp difference

Total $u_{c}\left({ }^{\circ} \mathrm{C}\right)$

0.3

0.1

0.1

0.4

0.1

2.0

2.1 


\section{Model-corrected LPRT Measurements}

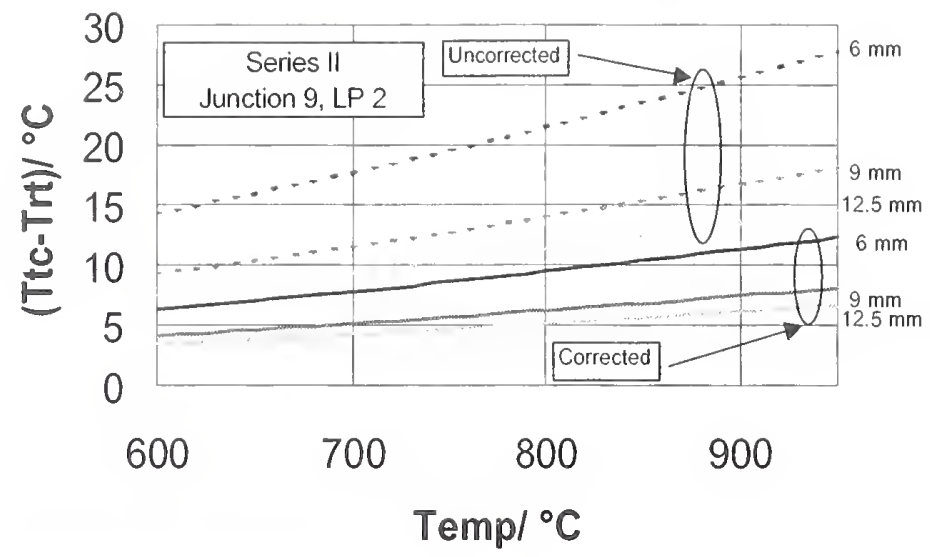

Comparison of TFWTC and LPRT Measurements Temperature Uncertainties $\left({ }^{\circ} \mathrm{C}, \mathrm{k}=1\right)$

LPRT

TFTC

Callibration

Effective emissivity

Junction/target

temperature

difference

Temperature

fluctuations

Temperature drift

LPRT display

Subtotal

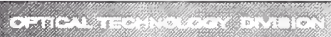

0.2 TFTC $\left(10^{\circ} \mathrm{C}\right)$

3.0 Pd/Pt TC TC emf

2.0

0.4

0.1

0.1

3.5
0.1

0.3

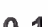

0.1

0.3 
4. Nist Ros. Bu: Experments

\section{Summary - Calibrating Against TC}

- NIST Test Wafer

- Benchmark calibrations of TFWTC and LPRT

$\begin{array}{cc}\text { Calibration } & 4\left(^{\circ} \mathrm{C}\right) \\ \text { TFWTC }\left(10^{\circ} \mathrm{C}\right) & 0.3 \\ \text { LPRT } & 0.2\end{array}$

- Test Bed measurement (present) uncertainties
NIST TFWTC technology
$0.3^{\circ} \mathrm{C}$
In-situ LPRT calibration
$2.1^{\circ} \mathrm{C}$
Model corrected, blackbody calibrated LPRT $3.5^{\circ} \mathrm{C}$

- Thermal modeling for effective emissivity

Transferring calibrations to applications

Establishing uncertainties

\section{Recommendations for Cood Practee}

(1) Calibrate the RT under same conditions as application.

- LP used hot or cold; temperature gradient

- Characterize blackbody for gradients

- Identify traceability artifact

(2) Characterize the radiation environment.

- Formulate the Temperature Measurement Equation (TME)

- Emissivity of wafer - bare: oxide. ....roughness

- Surroundings of wafer - hot/cold walls hot, shields, stray light

- Sensor placement - interaction with wafer. operating temperature 


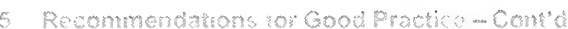

(3) Make model-corrected measurements, establish uncertainties.

- RT calibrated against blackbody; limits of uncertainties known

- Develop radiation model of the characterized radiation environment

- Seek first-order models based upon geometries amenable to analysis

- Establish realistıc, first-cut uncertainty estimates

- Identify largest contributing factors to uncertainty

- Design and perform experiments to validate model(s), and hence establish confidence in uncertainty estimates

(4) Use in-situ calibration with TC to establish reliability of RT measurements.

- Characterize RT under blackbody conditions to assure proper operation

- Establish limits of error to traceable TC artifact

- Identify the conditions under which the in-situ calibration is performed

- Establish limitations of calibration - emissivity variability, chamber conditions

\section{References}

[1] Dewitt, D.P. and G.D. Nutter (Eds.), Theory and Practice of Radiation Thermometry, Wiley Interscience, 1988.

[2] Short Course, Temperature Measurement by Radiation Thermometry, Optical Technology Division. NIST, http:/physics.nist.gov.Divisions/Div844/rtsc.html

[3] Tsai, B.K. and D.P. DeWitt, "ITS-90 Calibration of Radiometers Using Wire/Thin Film Thermocouples in the NIST RTP Tool: Effective Emissivity Modeling," Proc. of $7^{\text {th }}$ int. Conf. On Adv. Thermal Processing of Semiconductors, RTP'1999; (H. Kitayama, et al., eds), p 125, 1999

[4] Meyer, C.W., et al , ITS-90 Calibration of Radiometers Using Wire/Thin Film Thermocouples in the NIST RTP Tool Experimental Procedures and Results," Proc. of $7^{\text {th }}$ intl. Conf. on Adv. Thermal Processing of Semiconductors, RTP'1999, (H. Kitayama, et al., eds), p 136, 1999.

[5] Multi-RAD, PC software, optical and radiative properties of semiconductor materials, Private communication, Dr. J.E. Hebb, Eaton Corp.. Sept 15, 1997. 
[6] Lovas, F.J B. BK Tsal, and C.E. Gbson. "Meetng RTP Temperature Accuracy Requirements: Measurement and Caltbrations at NIST," Mat Res. Soc Symp Proc., v 525, p 127, 1998

[7] Tsai, B.K., C.W. Meyer and F.J. Lovas, "Characterization of Light-Pipe Radiation Thermometers for the NIST Test Bed. "Proc. of $\delta^{\text {th }}$ Inth. Conf. on Adv Thermal Processing of Semiconductors, RTP'2000. (B. Lojek, et al. eds). September 2000.

[8] Kreider, K.G., et al. "Calibratıon of Light-pipe Radiation Thermometers in an RTP Tool at 1000 "C", to be

[9] Kreider, K.G., et al., "Calibration of Light-pipe Radiation Thermometers in an RTP Tool at 1000 "C", to be published in Proc. of $8^{\text {it }}$ Intl. Conf. on Adv Thermal Processing of Semiconductors, RTP'2000, (B. Lojek, et al, eds). September 2000 . 

TOTAL

SOLUTIONS

\section{RTA T/C and RT Measurements}

B. E. Adams

Applied Materials, Santa Clara, CA

Workshop on

Temperature Measurement

of Semiconductor Wafers

Using Thermocouples

RTP 2000 Conference

September 19, 2000

\section{OVERVIEW}

1. RTP Hardware

The Measurement Environment

2. Temperature Measurement Problems

In-Situ Scales

Ripple

Emissometer

3. Lightpipe Pyrometer Calibration

Hot Calibration Issues

Cold Calibration Issues

4. Why Traceability?

Cost

Portability

5. Bridging to ITS-90 - modeling wafer, chamber, pyrometer interactions

6. Recommendations

7. References and Bibliography 


\section{RTP Hardware}

- Variations

- Cold wall / hot wall

- wafer rotating or stationary

- single arc lamp, linear lamps, concentric lamp arrays

- single sided or dual sided heating

- Generic features

- non thermal equilibrium conditions

- non contaminating environment

- single wafer processing

Linear Lamps, Dual Sided Heating, Rotating Wafer STEAG 3000 RTP System

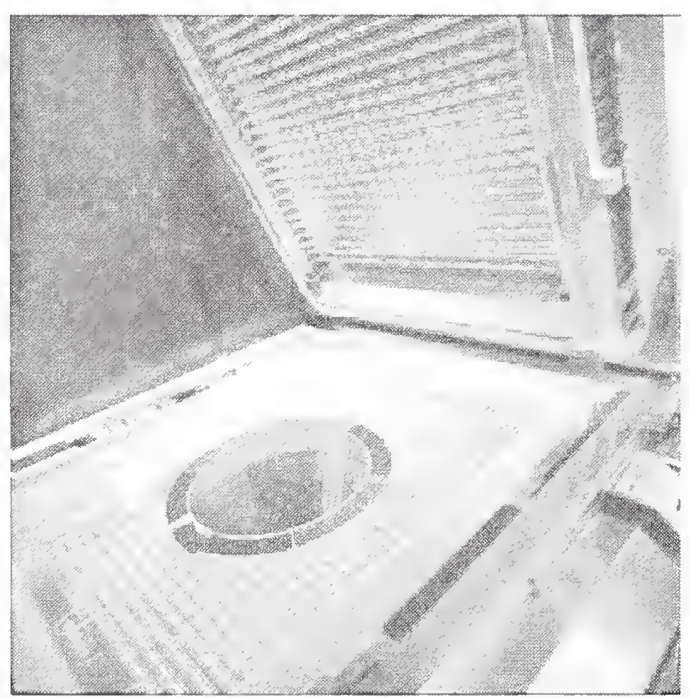

D-2 


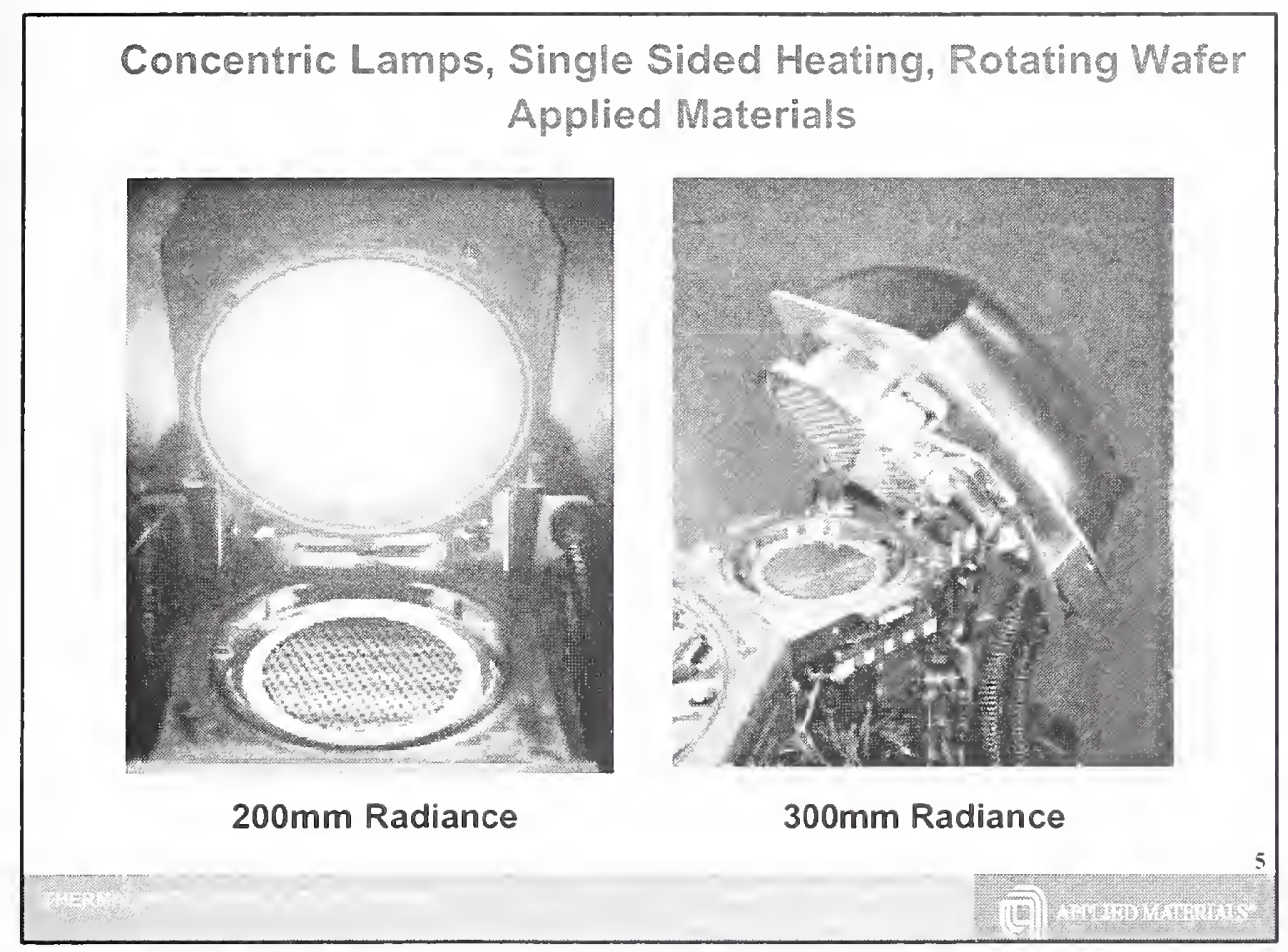

\section{Radiance Centura Temperature Control System} High speed, Closed-Loop, Real-time, Multi-point Control

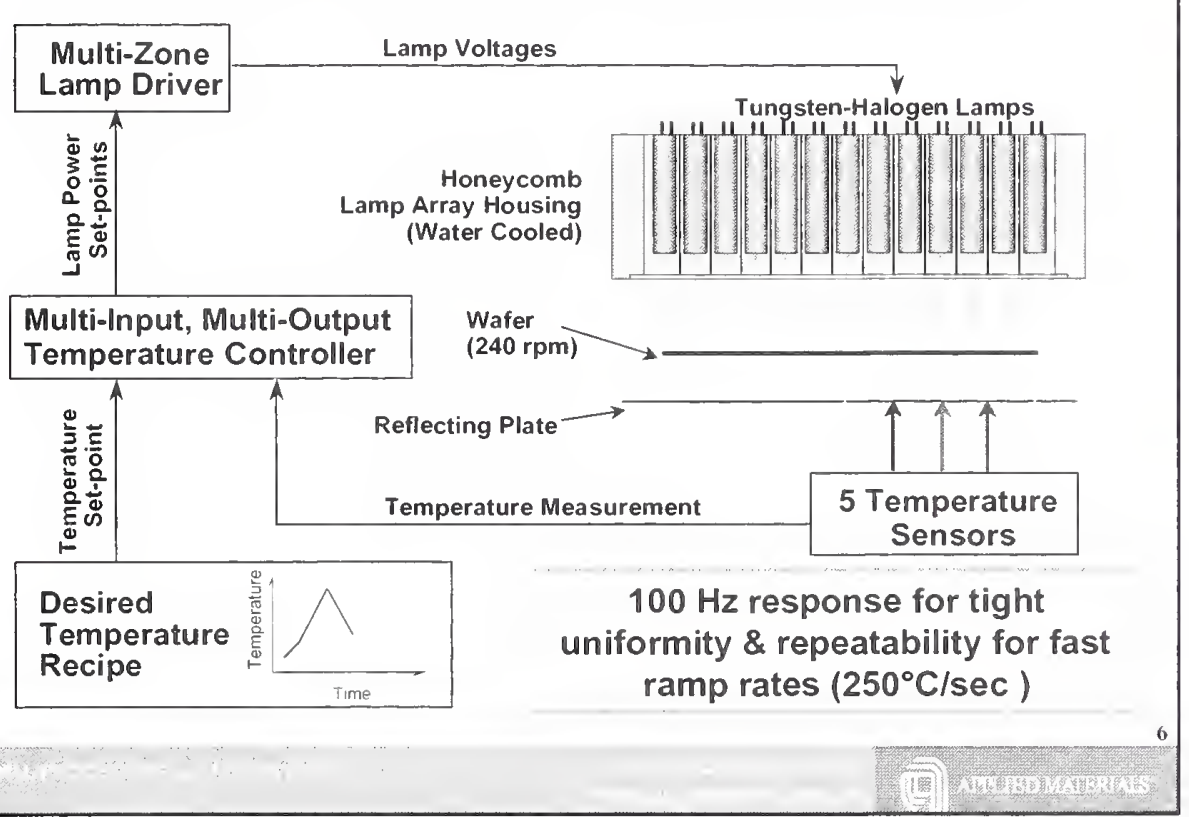




\section{Radiance Centura Magnetically-Levitated Wafer Rotation}
Mag-lev Suspension: Rotation is closed-loop controlled

Rotor support cylinder, edge ring and wafer

Backup power brings rotor to gentle halt

Rotor does not contact any chamber parts while in motion

Fast acceleration \& deceleration

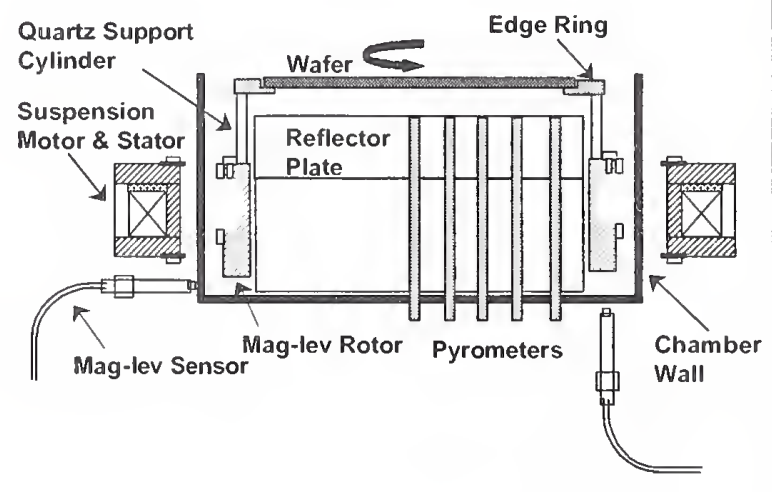

Magnetic-levitation offers clean and fast wafer rotation for improved process results \& easier serviceability

\section{Thermocouple Calibrations}

T/C - Great under isothermal conditions

- Calibrations get very complex with temperature gradients

- Radiative coupling differs for thermocouples and silicon

- Spectral issues (wafer transparent, $t / c$ opaque for $50 \%$ of the energy spectrum)

- Heat conduction to or from the leads

- Thermal isolation from the wafer by the binders

Net result is that traditional T/C wafers are limited in accuracy $\left(5^{\circ} \mathrm{C}\right)$ 


\section{Historical Problems of RTP Temperature Measurement}

Variability of wafer optical properties

- wavelength

- temperature

- view angle

- film stack

- film thickness

- dopants

- roughness

* Lamp Radiation

Wafer rotation and contamination issues

Emphasis on REPEATABILTY and CONTROL

Temperature Error for a 10\% Uncertainty in Emissivity

\begin{tabular}{|c|c|c|c|c|c|}
\hline \multicolumn{7}{|c|}{ Measurement Wavelength $\mu \mathrm{m}$} \\
\hline Temp ${ }^{\circ} \mathrm{C}$ & 0.95 & 1.7 & 2.4 & 3.4 & 5 \\
\hline 300 & 2 & 4 & 5 & 8 & 11 \\
\hline 500 & 4 & 7 & 10 & 14 & 21 \\
\hline 700 & 6 & 11 & 16 & 22 & 33 \\
\hline 900 & 9 & 16 & 23 & 33 & 48 \\
\hline 1100 & 12 & 22 & 31 & 45 & 66 \\
\hline
\end{tabular}




\section{Process Temperature Scales}

aTO $1100^{\circ} \mathrm{C}, 60 \mathrm{sec}$, yields $0.828+/-0.015 \mathrm{~A} /{ }^{\circ} \mathrm{C}$

RTA $1050{ }^{\circ} \mathrm{C}, 20 \mathrm{sec}$, As $1 \mathrm{E} 1640 \mathrm{KeV}, \mathrm{w} / 10 \% \mathrm{O}_{2}$, yields $-0.35 \mathrm{Ohms} / \mathrm{Sq} /{ }^{\circ} \mathrm{C}$

We use these virtually every day all over the world

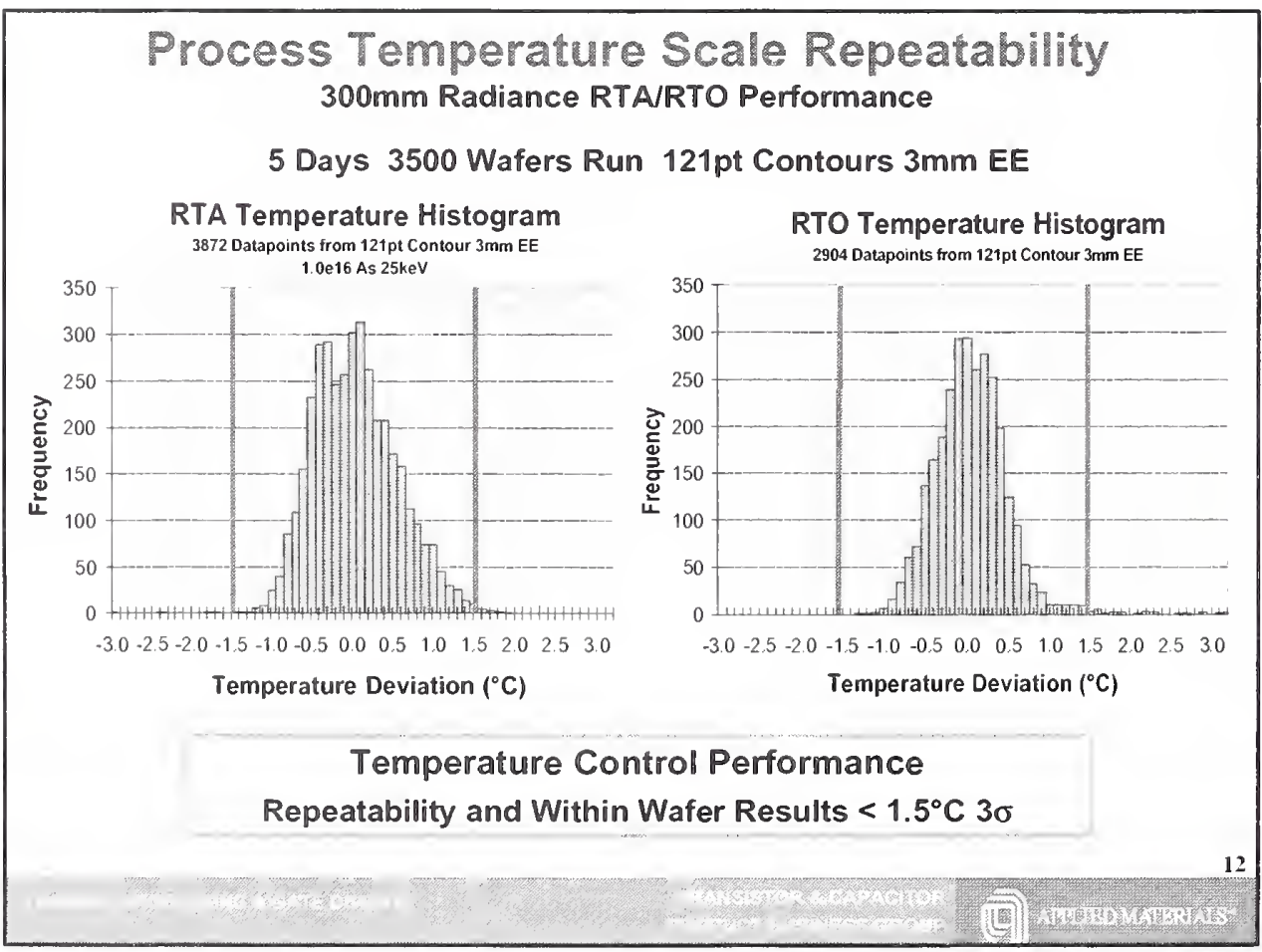

D-6 


\section{Process Temperature Pros and Cons}

Advantages

- industry standard - Historically Repeatability has been more important to the processing industry than Accuracy.

- process temperature repeatable worldwide within $5^{\circ} \mathrm{C}$

- within 1 fab / RTP supplier $-1^{\circ} \mathrm{C}$

- compatible materials $\left(\mathrm{O}_{2}\right.$ sometimes an exception)

- may identify non-temperature related processing problems

Disadvantages

- slow, not real time

- single point for a process cycle

- very costly

- end user dependent

- not easily traceable to freeze point standard - Accuracy is becoming more important, Portability of recipes between tools, between fabs, between vendors

\section{Schematic of External Configuration for Ripple Pyrometry}

(wafer exitance) $\mathrm{I}_{\mathrm{W}} \rightleftarrows \longrightarrow \mathrm{I}_{\mathrm{L}}$ (wafer irradiance)
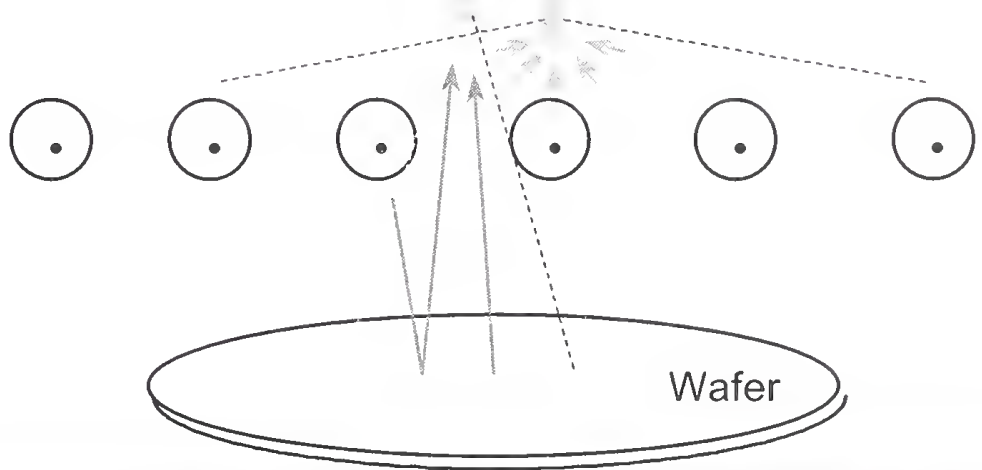


\section{The Virtual Blackbody Cavity}

Uniformly Heated Open Cavity of Any Shape or Material

Perfect Reflecting Mirror $\longrightarrow$

Virtual Image; Creating the Optical Equivalent of a Closed Isothermal

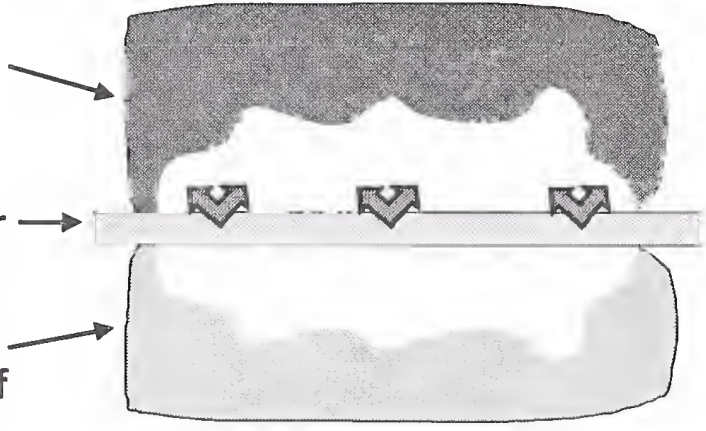
Cavity

The Conditions are met for Blackbody radiation

\section{Pyrometer Surrounded by a Reflector Plate}

Depending on the reflectivity of the plate, $R, \varepsilon_{\text {True }}$ is enhanced to $\varepsilon_{A}$

For values of $\mathrm{R}$ approaching 1 (i.e. $100 \%$ reflection), $\varepsilon_{A}$ approaches 1

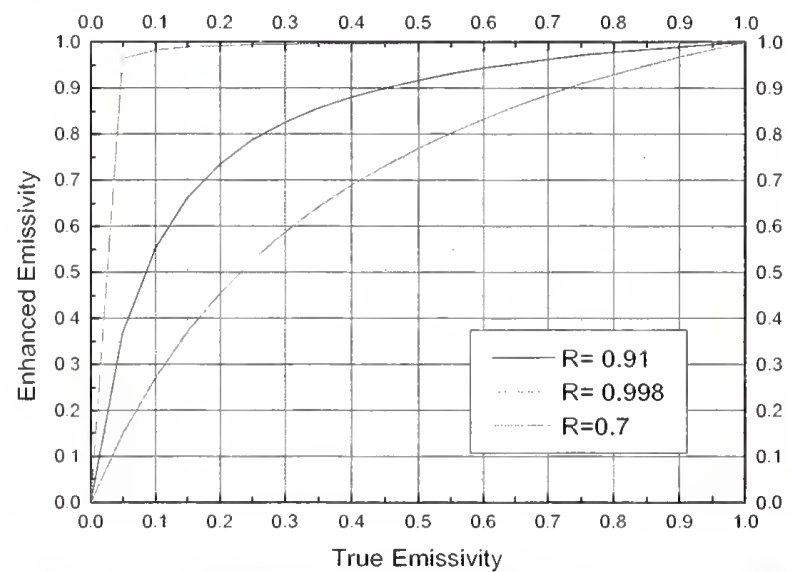




\section{Lightpipes / Optical Cables}

E. Connect / Disconnect

Dependence of Cable Position, Polish

- Very Wide Field of View

- Calibration Source must be close to L/P

- Emissivity and uniformity must be known over wide angles

- Cold Calibrations

- Characterize Target Radiation

霝 Hot Calibrations

- Thermal Interaction with the Furnace

- Contamination

- Characterize Emissivity

\section{The Uncertainties of Hot Calibrations}

- NIST Type S Uncertainty

- Emissivity of blackbody

- Cone/TC heat Transfer

- Added Heatflow

- Short Term Drift

- Long Term Drift

- TC Hysteresis

- Contamination

- Self Emission

- Length Uniformity

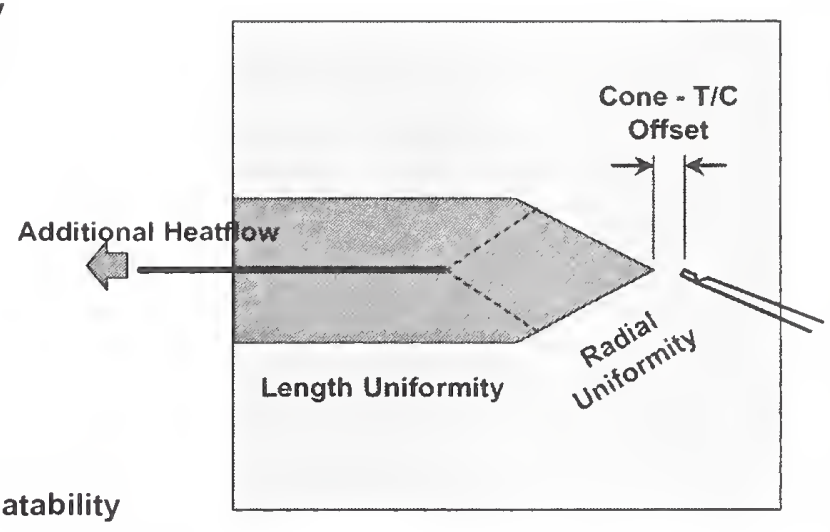

- Lightpipe Position Repeatability 


\section{Cold Calibration Source}

The TempMatch ${ }^{\circledast}$ tool is a portable transfer standard used for in-situ calibration of Optical Fiber Thermometers (OFT). This radiant source is a combination of LEDs, filters, and diffusers optically coupled to faithfully reproduce the blackbody spectrum for a single temperature over a limited bandwidth. The output intensity is feedback controlled for stability, and is nearly Lambertian for angles within the numerical aperture of the OFT. This tool is used to determine the OFT sensor factor (aperture correction) after installation and at periodic calibration intervals. Errors introduced due to the transfer standard only increased the total accuracy error of the OFT

measurement from $\pm 1.2^{\circ} \mathrm{C}$ to $\pm 1.75^{\circ} \mathrm{C}$. This performance is demonstrated to be sustained for a large population of instruments over a year's period of

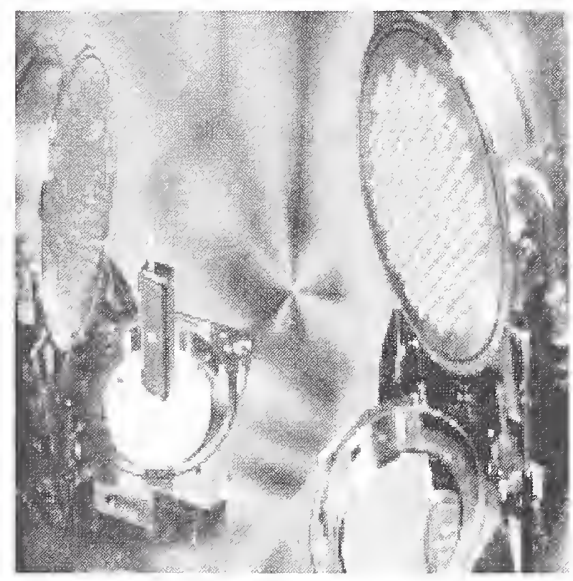
operation.

\section{Why Traceability, and not just better Resolution?}

Better Process Control, Higher Yields

Portability of Process Recipes

- Limits of process temperature scales

- Cost

- Time

Moore's Law

- Shorter process times

- Higher ramp rates

- Greater Temperature Accuracy 


\section{Accuracy Viewed from Different Points Along the Chain}

NIST

- Pyrometer Manufacturer (within pyrometer companies)

- RTP Manufacturer (between pyrometer companies)

End User (systematic errors between RTP companies)
0.1 C Type ST/C

$3.0 \mathrm{C}$

$6.0^{\circ} \mathrm{C}$

$30 \cdot 0$

Traceable Chain and Process Measurements

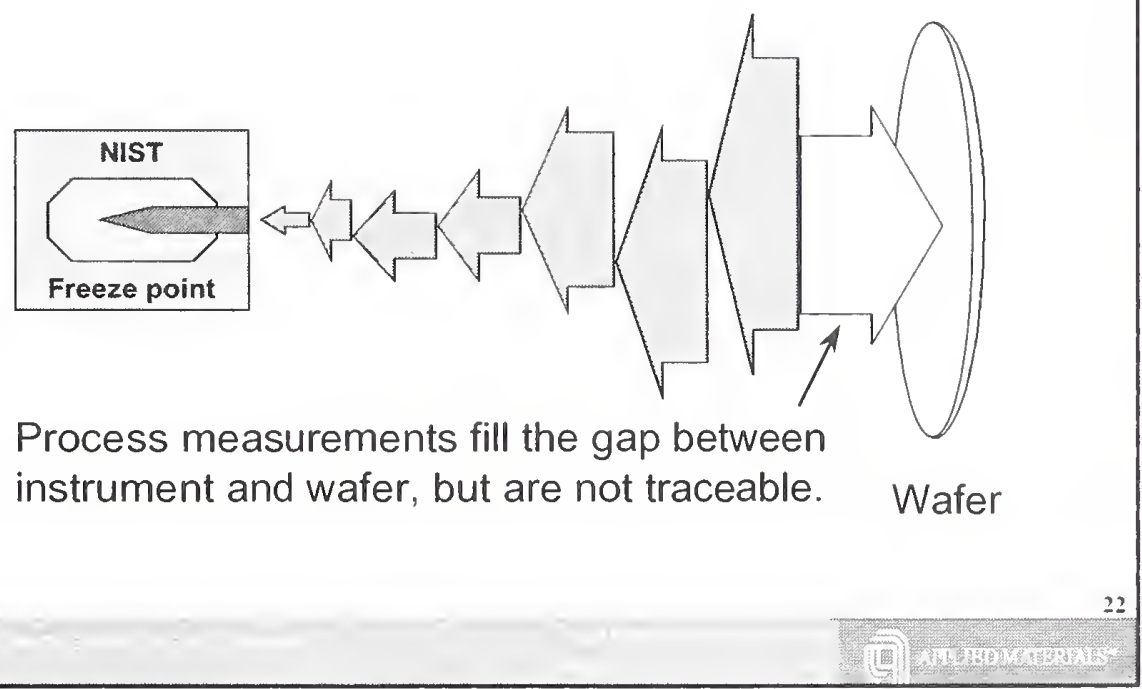




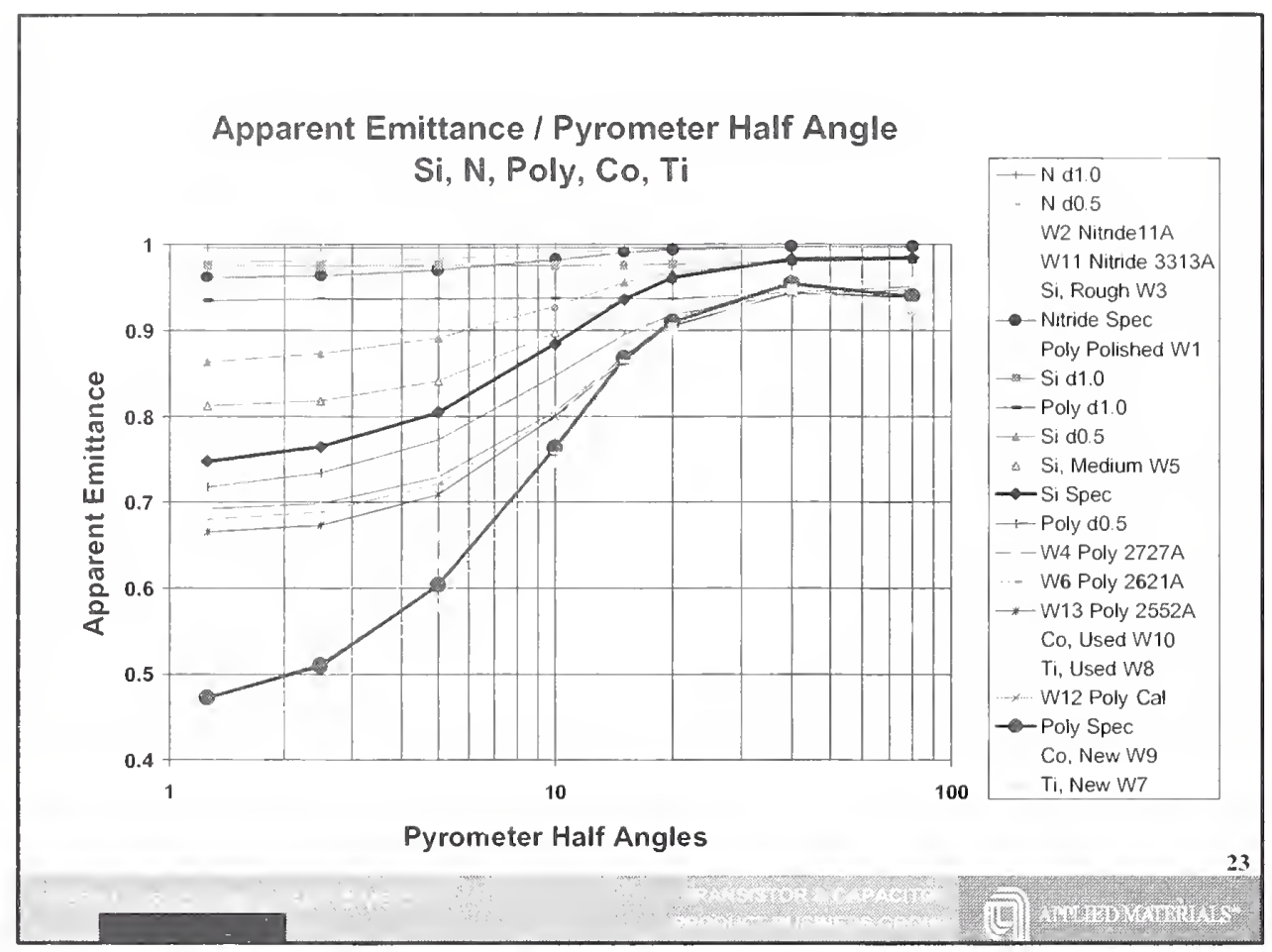

The Effect of Pyrometer Reflectance on the Apperant Emittance of Polished Polysilicon ( $e=0.4$ ), Model with reflector plate $(R=0.97)$, pyro diameter to wafer gap $=10$

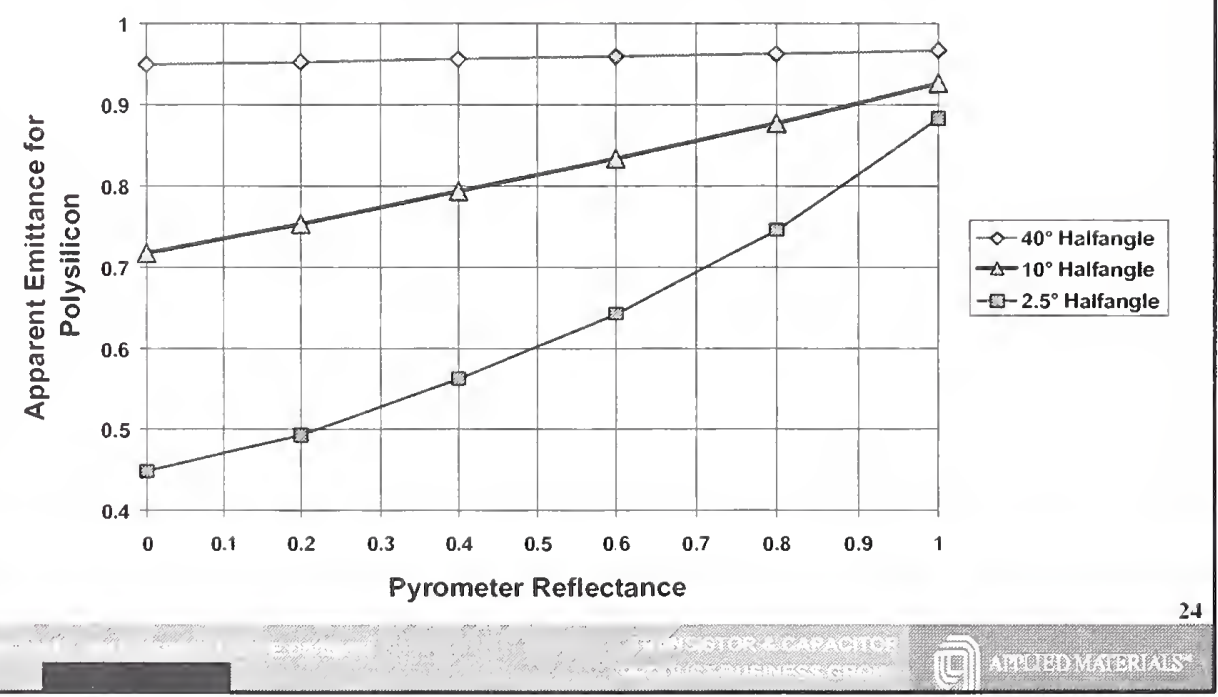

D-12 


\section{Recommendations}

1. Develop an understanding of the heat transfer issues involved in your method of calibration

2. ANSI/NCSL Z540 Standard (1994)

Documentation for Calibration Laboratories

Traceability, Uncertainty Analysis

3. Use real time in-situ emissivity measurements to determine wafer temperature.

4. Don't ignore the effect of the pyrometer on the measurement

5. Common problems and measurement error

Inadequate heat transfer model for the application

Not routinely verifying calibrations with NIST traceable standards

Inadequate monitor wafer quality (cleaning of recycled wafers)

Contamination of optical components

Operator errors

\section{References and Bibliography}

Temperature Measurement Issues in Rapid Thermal Processing ,DeWitt D.P., Sorrell F.Y., Elliott J.K.,, Mat. Res. Soc. Proc., 470, edited by Riley, Gelpey, Roozeboom, Saito, MRS, San Francisco, 1997, pp 3.15

whe Challenges of Temperature Measurement in the Semiconductor Industry. B. E. Adams, TEMPMEKO'99, J. F. Dubbeldam and M. J. de Groot. Eds., Vol 1, p.3, NMI Van Swinden Laboratorium - Delft, The Netherlands (1999).

Rapid thermal Annealing and Oxidation of Silicon Wafers with Back-Side Films Fiory A.T.,, Mat. Res. Soc. Proc., 470, edited by Riley, Gelpey, Roozeboom, Saito, MRS, San Francisco, 1997, pp $49 . .56$

I Advances in Temperature Measurement and Control for RTP, Peuse B., Yam M., BahI S.,. Proc. 5th Intl. Conf. Adv. Thermal Processing of Semiconductors, edited by Fair, Green, Lojek, Thakur, RTP'97, New Orleans, 1997, pp 358..365

Emissometer U.S. Patents 5660472, 5755511 European EPA0612862,

Calibration of OFTs in Production. R. R. Dils, RTP'99, (get full paper from Sekidenko Inc.)

I Determining the Uncertainty of Wafer Temperature Measurements Induced by Variations in the Optical Properties of Common Semiconductor Materials. B. E. Adams, A. Hunter, M.Yam and B. Peuse, ECS'2000 



\title{
MEASUREMENT OF WAFER SURFACE TEMPERATURE USING THERMOCOUPLES AND TEMPERATURE CALIBRATION OF RTP EQUIPMENT
}

\author{
B. Lojek \\ ATMEL Corporation \\ BAD DATA LOOK AS BELIEVABLE AS GOOD DATA \\ allas \\ WAFER TEMPERATURE MEASUREMENT MATTERS!
}

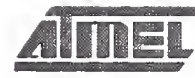

NIST

COLORADO SPRINGS

GAITHERSBURG (09/19/00)

WHY IS IT IMPORTANT TO KNOW WAFER TEMPERATURE ? and

WHY IS MATCHING THE SHEET RESISTANCE NOT GOOD ENOUGH?

MOST PHYSICAL MECHANISMS INVOLVED IN ANNEALING, DIFFUSION, AND OXIDATION EXHIBIT A VERY STRONG TEMPERATURTE DEPENDENCE. (For example, a change of approximately $80^{\circ} \mathrm{C}$ results in a change of diffusivity of common Si dopants, about one order of magnitude).

A WRONG CONCLUSION ABOUT PHENOMENA MAY BE DRAWN IF ACTUAL WAFER TEMPERATURE IS NOT KNOWN.

IN A MULTI FAB MANUFACTURING ENVIRONMENT, MISSING KNOWLEDGE OF ACTUAL PROCESSING TEMPERATURE INCREASES THE COST AND TIME OF TECHNOLGY TRANSFER

THE SHEET RESISTANCE MEASUREMENT CAN LEAD TO ERRONEOUS RESULTS FOR SHORT ANNEALING TIMES AND ARE FAIRLY INSENSITIVE FOR LONG TIME ANNEALING. THE MATCHING OF SHEET RESISTANCE DOES NOT GUARANTEE THAT OTHER MATERIAL PROPERTIES ARE THE SAME.

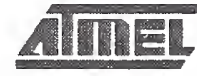

COLORADO SPRINGS

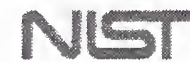

GAITHERSBURG (09/19/00) 
TYPICAL INSTRUMENTATION SETUP FOR WAFER TEMPERATURE MEASUREMENT

$T_{W}$ REQUIRED "DVM" SENSITIVITY

\begin{tabular}{c|c|c} 
TC & SEEBECK COEFFICIENT $[M V P C]$ & "DVM" SENSITIVITY FOR 0 $1{ }^{\circ C}[\mu V]$ \\
\hline$K$ & 40 & 40 \\
$R$ & 7 & 07 \\
$S$ & 7 & 07
\end{tabular}

CONTACT RESISTANCE

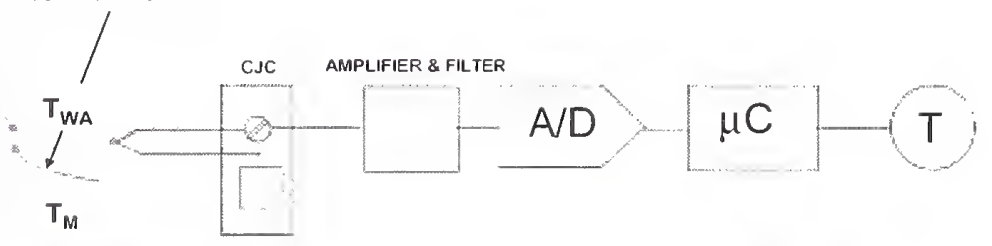

WAFER TEMPERATURE HIERARCHY:

$T_{W}$ - UNDISTURBED WAFER TEMPERATURE - THE TEMPERATURE OF THE WAFER WHEN NO DISTURBANCE ARISES FROM THE MEASUREMENT PROCEDURE

$T_{\text {WA }}$ - AVALABLE WAFER TEMPERATURE - WAFER TEMPERATURE WHEN TRANSDUCER AND MEASUREMENT SYSTEM ARE IN PLACE

$T_{A}$ - ACHEVED WAFER TEMPERATURE - THE WAFER TEMPERATURE SENSED BY TRANSOUCER

$T_{M}$ - OBSERVED WAFER TEMPERATURE - THE WAFER TEMPERATURE INDICATED BY MEASUREMENT SYSTEM

T - CORRECTED WAFER TEMPERATURE - THE WAFER TEMPERATURE AFTER APPLYING ALL CORERECTION (LINEARIZATION, INTERPOLATION etc.)

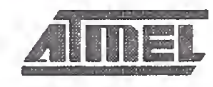

COLORADO SPRINGS

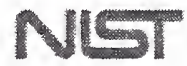

GAITHERSBURG $(09 / 19 / 00)$ 


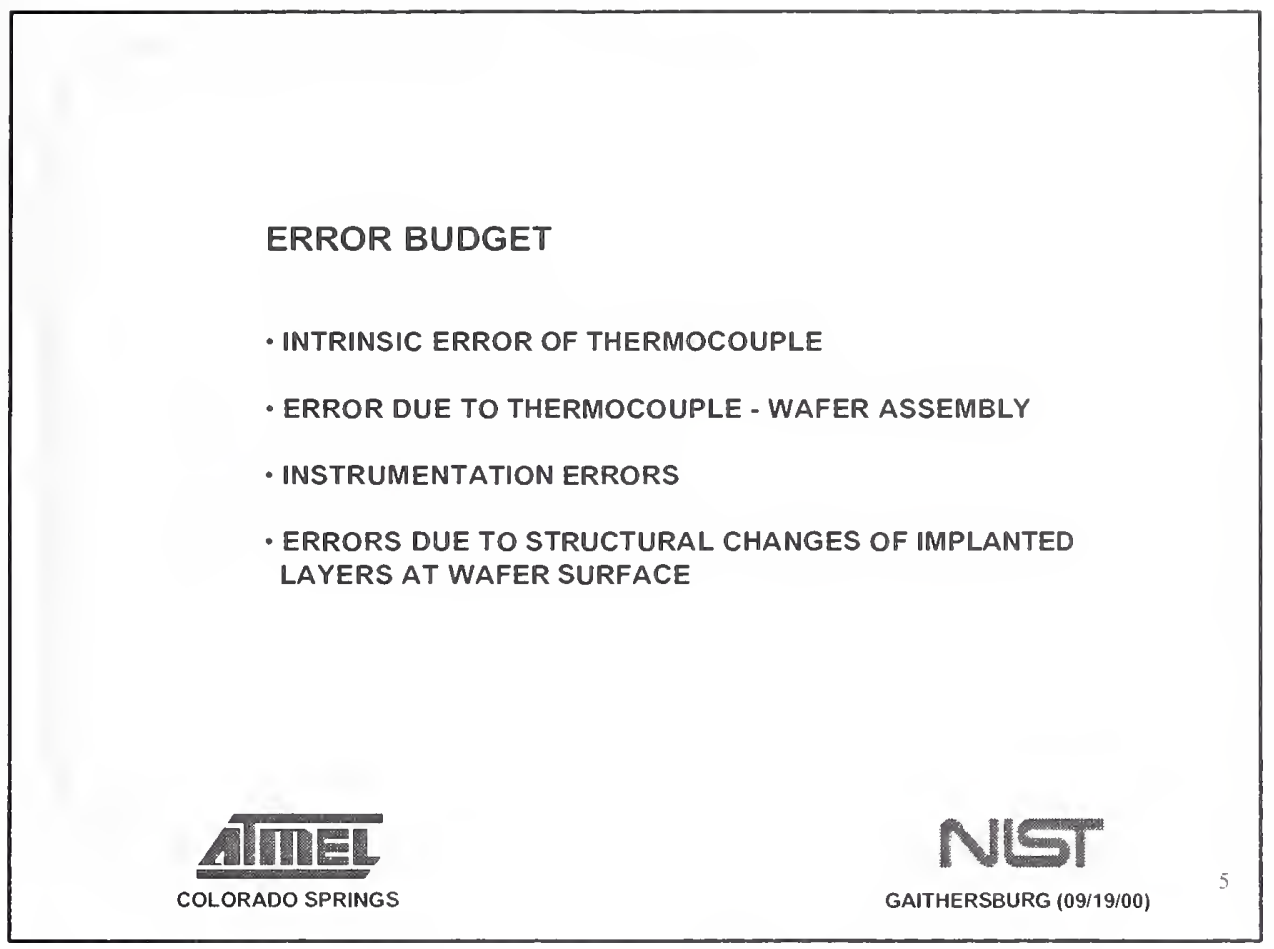

THE PERTURBATION OF THE WAFER TEMPERATURE DUE TO DIFFERENT THERMAL CONDUCTIVITY IN THE CAVITY

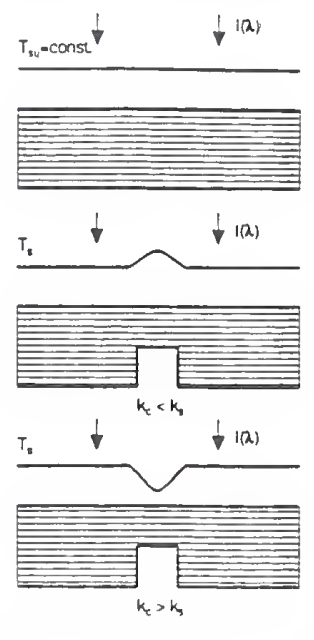


THERMAL CONTACT RESISTANCE $R_{t c}$

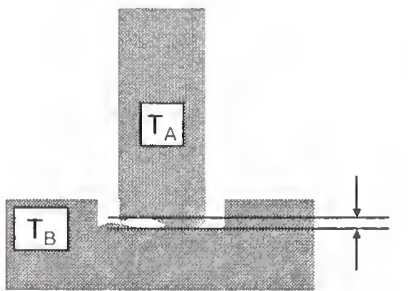

DUE TO SURFACE ROUGHNESS, TWO BODIES TOUCH AT ONLY A FEW DISCRETE SPOTS.

COMPONENTS OF $\mathrm{R}_{\mathrm{tC}}$ :

1) SOLID TO SOLID CONDUCTION AT SPOTS IN CONTACT

2) RADIATION IN THE VOID SURFACES CREATED BY THE CONTACT

THE CONTACT RESISTANCE IS DOMINANT THERMAL RESISTANCE WHEN HIGH THERMAL CONDUCTIVITY MATERIALS ARE INVOLVED IN CONTACT. TYPICAL MAGNITUDE OF $R_{\mathrm{tc}}$ FOR TC WIRE WITH DIAMETER $80-100 \mu \mathrm{m}$ IS 800-5000 ${ }^{\circ} \mathrm{C} / \mathrm{W}$. SUCH MAGNITUDE OF $R_{\text {tc }}$ RESULTS IN $4-20^{\circ} \mathrm{C}$ DIFFERENCE BETWEEN AVAILABLE WAFER TEMPERATURE AND ACHIEVED WAFER TEMPERATURE.

[T.Borca-Tasiuc et al UCLA, 1998, B.Lojek, RTP'95]

"CLASSICAL" TC (WIRE DIAMETER $80 \mu \mathrm{m}$ )
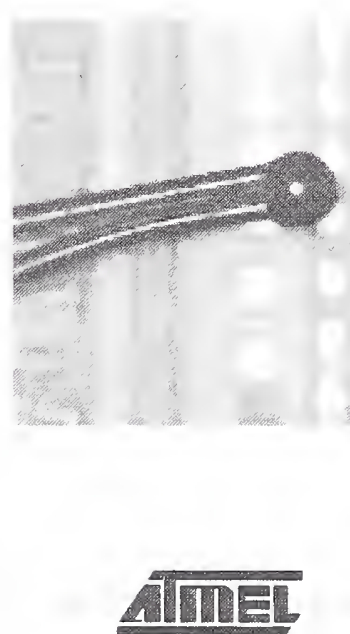

COLORADO SPRINGS
TC WITH FLAT BEAD MINIMIZING THERMAL COTACT RESISTANCE

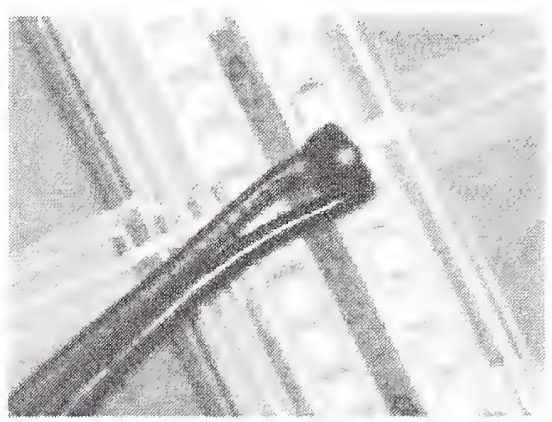


FOR MOST PC BASED TEMPERATURE ACQUISITION BOARDS, THE ERROR ASSOCIATED WITH COLD JUNCTION COMPENSATION IS BY FAR A DOMINANT INSTRUMENTATION ERROR

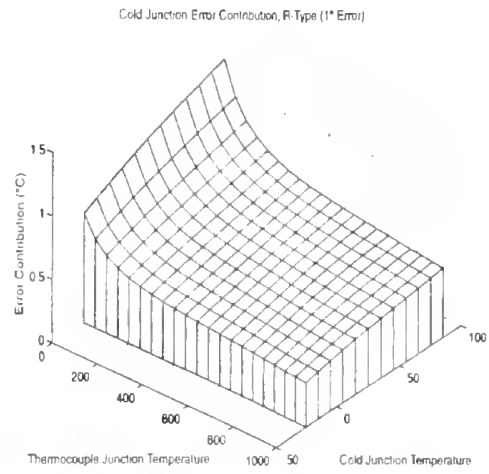

TC TEMPERATURE ERROR ASSUMING

$+1.0 .5^{\circ} \mathrm{C}$ ACCURACY IN CJC TEMPERATURE

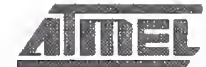

COLORADO SPRINGS

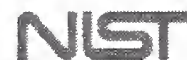

GAITHERSBURG (09/19/00)

\section{POWER ABSORBED BY WAFER DEPENDS ON THE REFLECTIVITY AND ABSORPTION OF THE WAFER}

Absorbed power for uniformly doped wafer of thickness $t_{w}$ is given by:

$P_{a b_{s}}=\int_{\lambda=1}^{\lambda}\left(1-R(\lambda) U_{0}(\lambda)\left[1-\operatorname{expt}\left(\frac{\alpha \lambda)}{t_{w}}\right)\right] d \lambda\right.$

IN RANGE OF WAVELENHGTH 0.4 to $1.5 \mu \mathrm{m}$, RYSTALIZATION FROM $\alpha$-Si TO c-SI IS ACCOMPANIED BY A NON-REVERSIBLE REFLECTIVITY DECREASE. 
IMPACT OF IMPLANTED LAYERS ON THE WAFER TEMPERATURE MEASUREMENT (As 1E14@20keV)

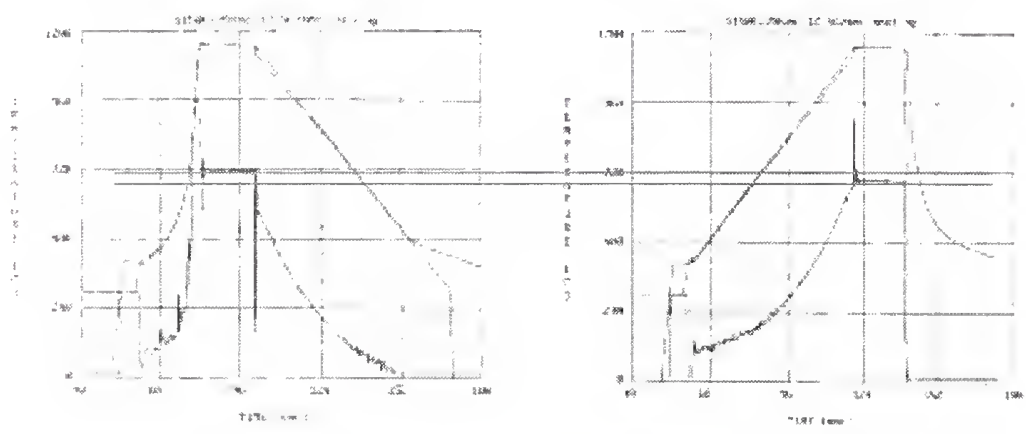

FOR GIVEN CALIBRATION DATA, SET-POINT POWER IS FUNCTION OF THE HEATING RATE. (Calibration data has been acquired for heating rate $12.5^{\circ} \mathrm{C} / \mathrm{sec}$, therefore the run with faster heating rate indicate a wrong temperature at set point)

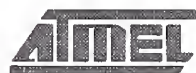

IMPACT OF IMPLANTED LAYERS ON THE WAFER TEMPERATURE MEASUREMENT

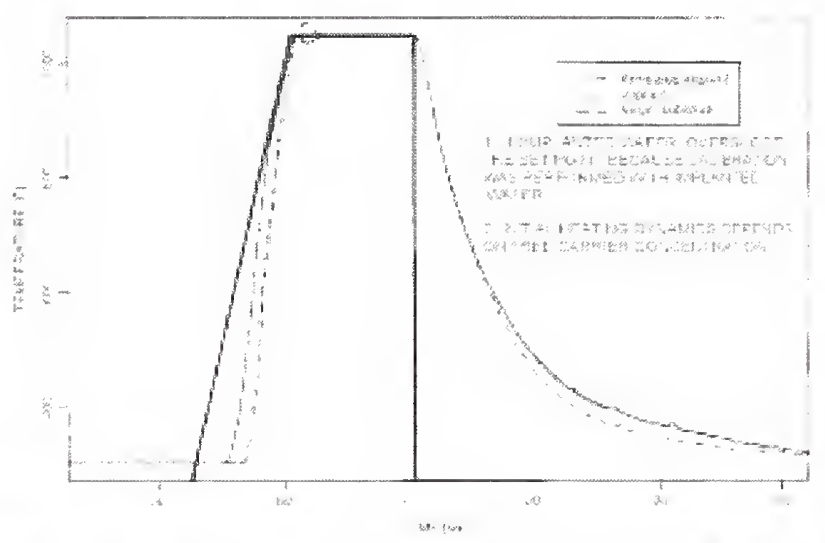


IMPACT OF IMPLANTED LAYERS ON THE WAFER TEMPERATURE MEASUREMENT

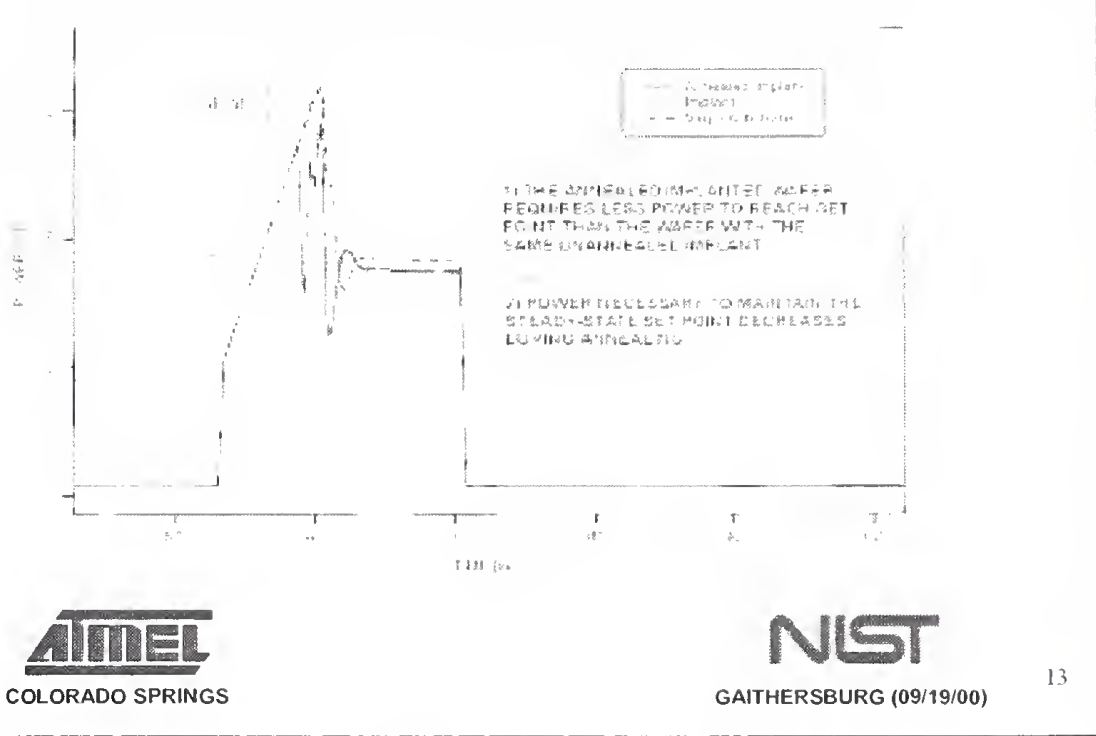

IMPACT OF IMPLANTED LAYERS ON THE WAFER TEMPERATURE MEASUREMENT

RAMP $50^{\circ} \mathrm{C} / \mathrm{seC}$ FROM $400^{\circ} \mathrm{C}$ TO SET PONT TEMPERATURE WITH 30 SEC ANNEAL (AS IMPLANT 1E $16 @ 20 \mathrm{keV}$ )

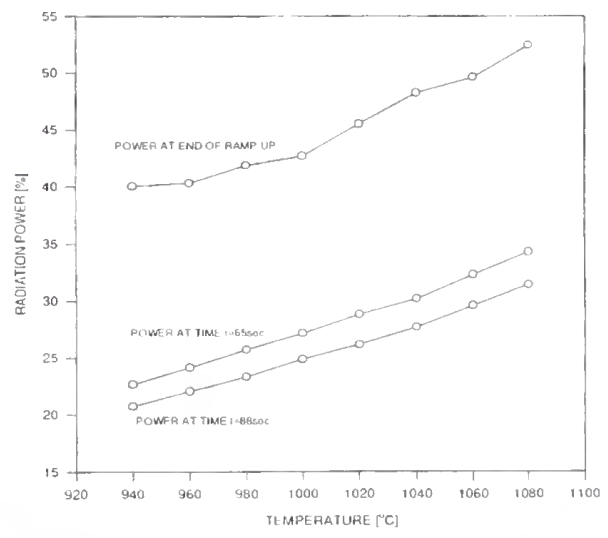


TEMPERATURE CALIBRATION OF RTP SYSTEM USING WAFER WITH EMBEDDED TC

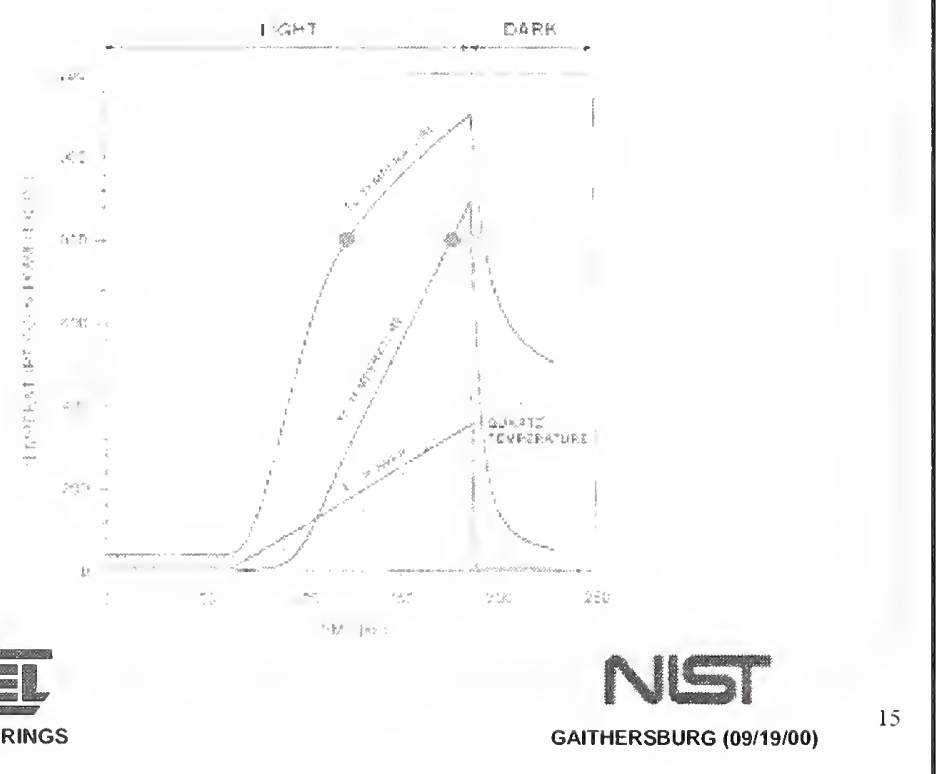

TEMPERATURE CALIBRATION OF RTP SYSTEM USING WAFER WITH EMBEDDED TC
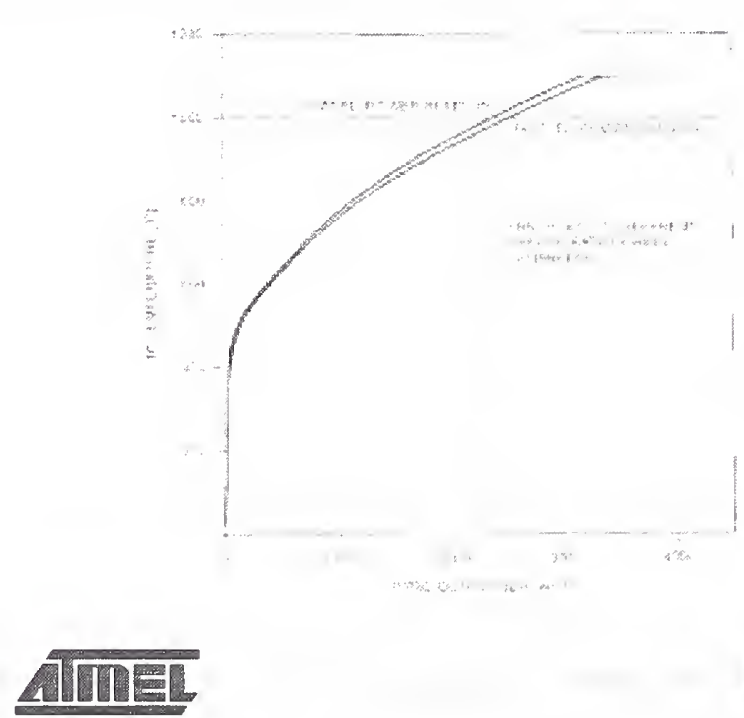


\section{CONCLUSIONS WHAT CANNOT BE MEASURED. CANNOT BE CONTROLLED!}

- tC CALIBRATION SHOULd BE PERFormed UNDER tHe SAME CONDITIONS AS THE RECIPE, WHERE CALIBRATION DATA IS USED

- calibration waFer should be used only once

- calibration wafer should be identical to the product WAFER

- IF "INAPPROPRIATE" WAFER IS USED FOR CALIBRATION (FOR EXAMPLE, REPEATEDLY ANNEALED WAFER, DIFFERENT SUBSTRATE, POORLY DESIGNED TC, etc.) THE TEMPERATURE MEASUREMENT ERROR MAY BE AS LARGE AS $20-30^{\circ} \mathrm{C}$

- DIGITAL ELECTRONICS INSTRUMENTATION HAS CREATED AN ILLUSION THAT VERY ACCURATE THERMOCOUPLE THERMOMETRY IS RELATIVE EASY AND ROUTINE MEASUREMENT

- THE THERMOCOUPLE SURFACE TEMPERATURE MEASUREMENT OF THE WAFER WHICH IS NOT IN THERMAL EQUILIBRIUM WITH SURROUNDING AMBIENT IS A CHALLENGING PROBLEM WHERE SPECIFIC PHENOMENA (i.e. TC INSTALLATION, TC CONTACT RESISTANCE, WAFER PROPERTIES, etc.) DETERMINE ACCURACY OF MEASUREMENT

- If PROPERLY EXECUTED, THE TC TEMPERATURE MEASUREMENT IS VERY ACCURATE (IF NOT THE MOST ACCURATE) METHOD OF SURFACE TEMPERATURE MEASUREMENT OF THE WAFER UNDER THERMAL NON-EQUILIBRUIM CONDITIONS 



\title{
Thermal Characterization of Batch Furnaces using Thermocouple Instrumented Wafers
}

Cole Porter and Karl Williams

Silicon Valley Group, Thermal Systems Division

\author{
Workshop on \\ Temperature Measurement \\ of Semiconductor Wafers \\ Using Thermocouples \\ RTP 2000 Conference \\ September 19, 2000
}

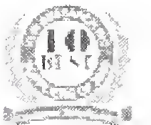

\section{Overview}

- What

- Batch Furnace configuration

- Batch furnace temperature measurement

- Why

- Thermal stresses in Si

- Process chamber vs. wafer temperature

- Heat transfer in batch furnace

- How

- T/C wafer configuration

- T/C wafer installation

- Issues

- Conclusions

- References 


\section{Batch Furnace Configuration}

- High purity dual-wall quartz tube process chamber

- Wafer fixture "boat"

- $\quad$ Pedestal, supports the wafer boat.

- Process chamber positioned vertically inside the heater element

- Gas injection is via MFC through manifold assembly

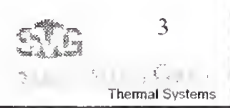

\section{Temperature control}

- Furnace temperature is monitored and controlled via "profile" thermocouples located inside the process chamber in each of five control zones of the heater element

- Profile thermocouples provide an approximation of the wafer stack temperature

- $\quad$ "Spike" thermocouples are positioned outside of the quartz process chamber in close proximity to the element windings in each of the five control zones

- Spike thermocouples provide an approximation of the heater element temperature 


\section{Batch Furnace Configuration}

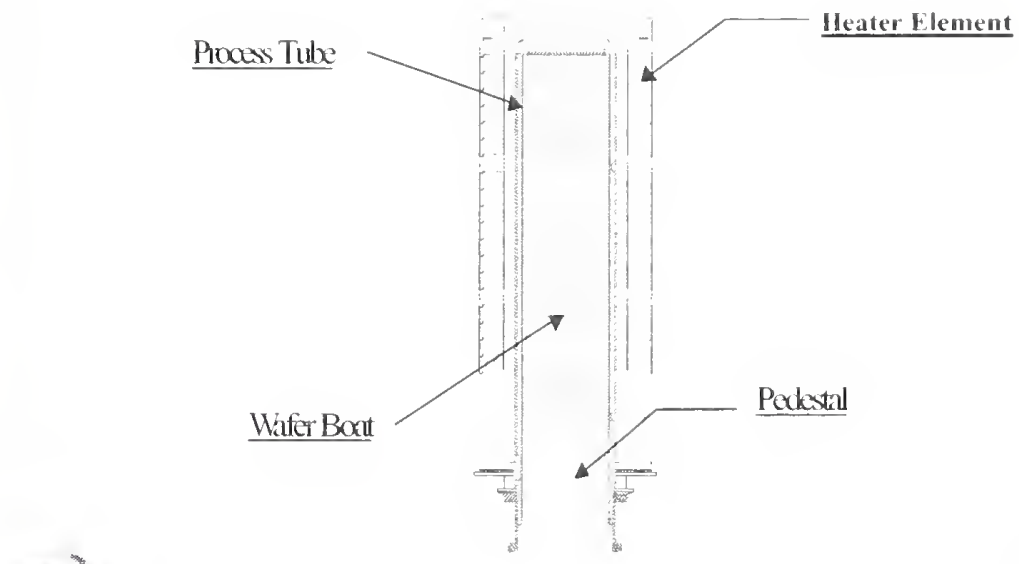

\section{Thermal stress}

- Rapid Vertical Processor (RVP) furnace systems can ramp at rates in excess of $75^{\circ} \mathrm{C} / \mathrm{min}$

- In a batch furnace, ramp rates in this range can thermally stress wafers causing slip and wafer warpage

- A critical effect during fast-ramp processing is the radial delta temperature (RDT) within each wafer during ramp up and ramp down

- During ramping conditions, wafer edges will heat and cool at a higher rate than wafer centers 


\section{Slip Curve}

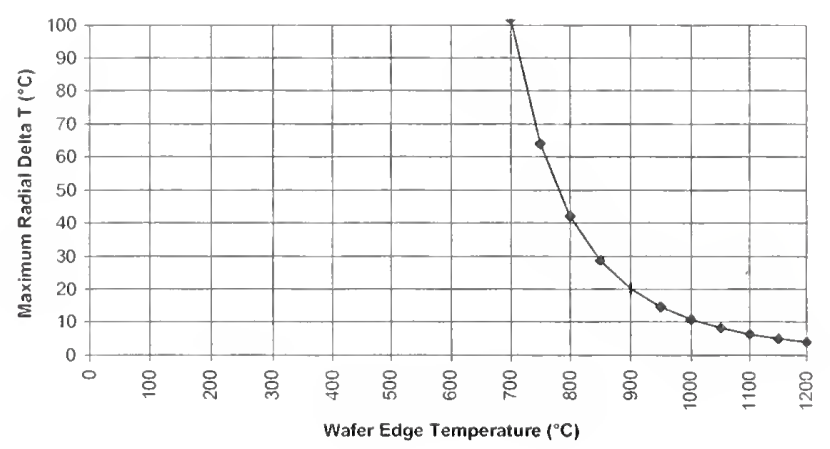

\section{Wafer temperature, process}

\section{RDT/Slip curve}

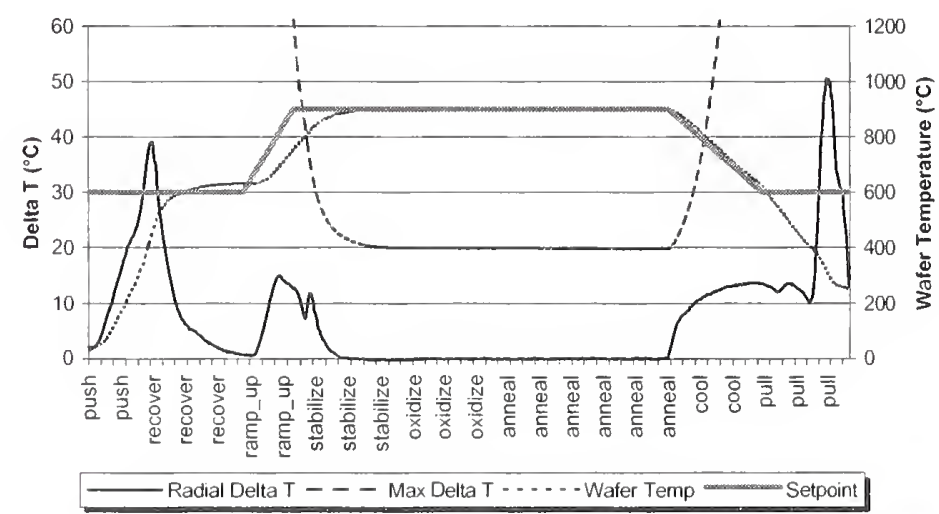




\section{Thermal stress, Si}

- Thermal stress must be held below the plastic deformation limit of Si

- Slip dislocations may be generated resulting in lower device yields

- The maximum allowable Radial Temperature Delta (RDT) that will produce slip in $\mathrm{Si}$ is well known and documented

- RDT Slip limits decrease as temperature is increased

- The use of $t / c$ wafers to understand actual wafer temperatures in this case is a very important tool

- The knowledge gained using $\mathrm{t} / \mathrm{c}$ wafers feed into the final product, process chamber and recipe design

\section{Profile $t / c$ vs wafer temperature}

- Under ramping conditions the profile $\mathrm{t} / \mathrm{c}$ signal can be far from actual wafer temperatures

- Profile $t / c$ to wafer temperature errors can be as large as $100^{\circ} \mathrm{C}$ under fast ramping conditions

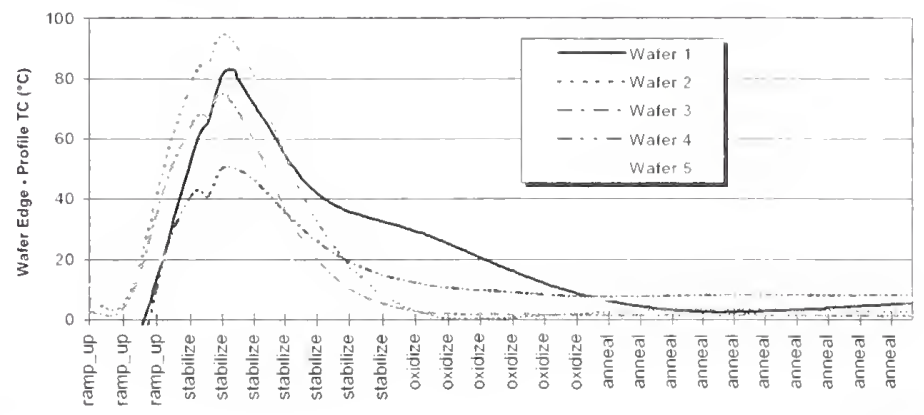




\section{Batch Furnace heat transfer}

- At higher temperatures heat transfer is predominantly via radiation

- Path is from heater to the absorbing wafer stack

- Passes through the semitransparent quartz where the profile $t / c$ is positioned.

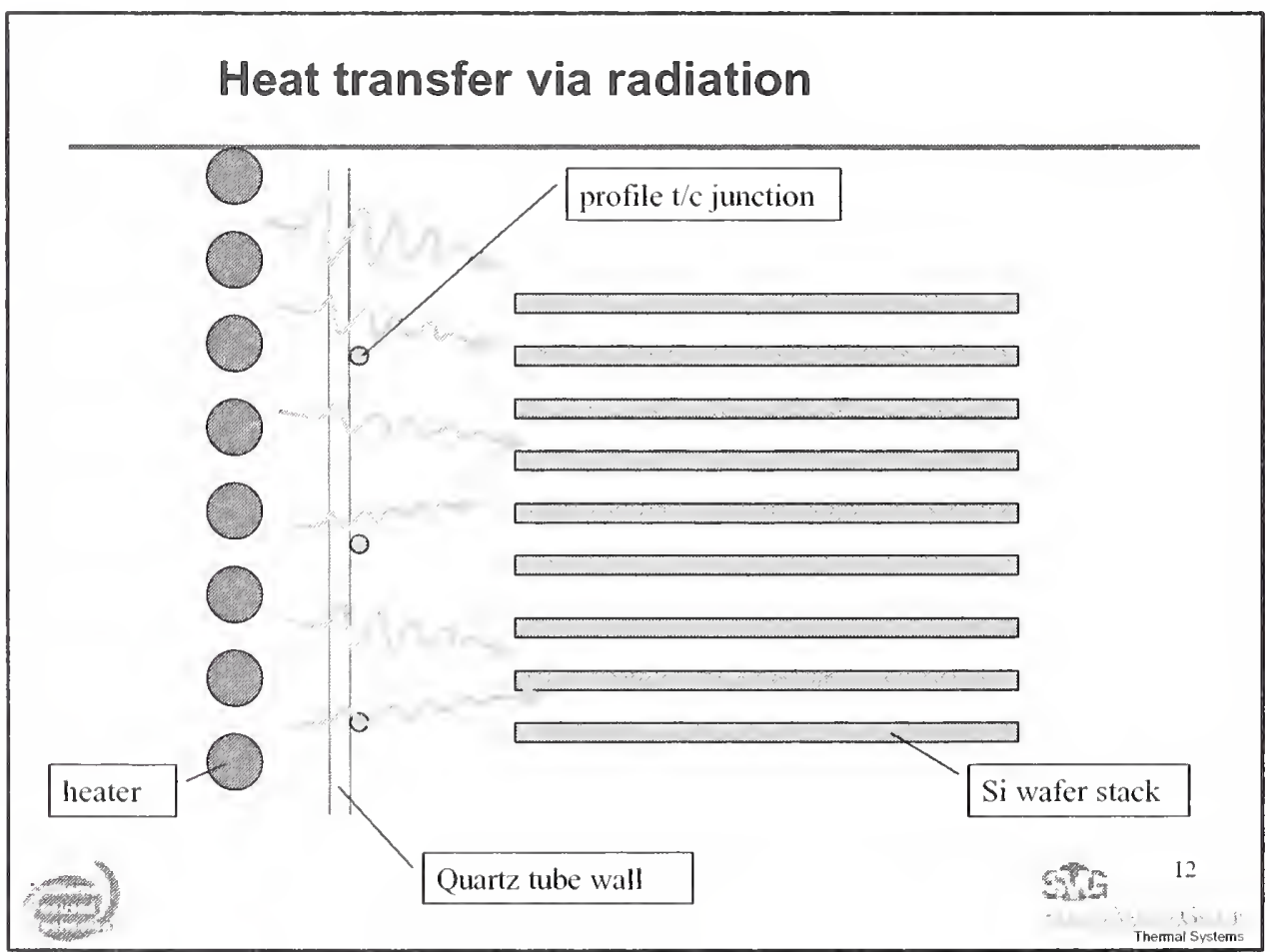




\section{T/C wafer configuration}

- T/C placement

- 2 center $2 @ 6 m m$ from edge

- 1 center and 1 edge is monitored

- Extra center and edge provide redundancy

- Wafer positioning in wafer stack

- Optimal locations to represent product wafer population

- 5 wafers used

- Spaced equidistant within the product zone

- All other slots occupied with filler wafers

\section{T/C location on wafer}

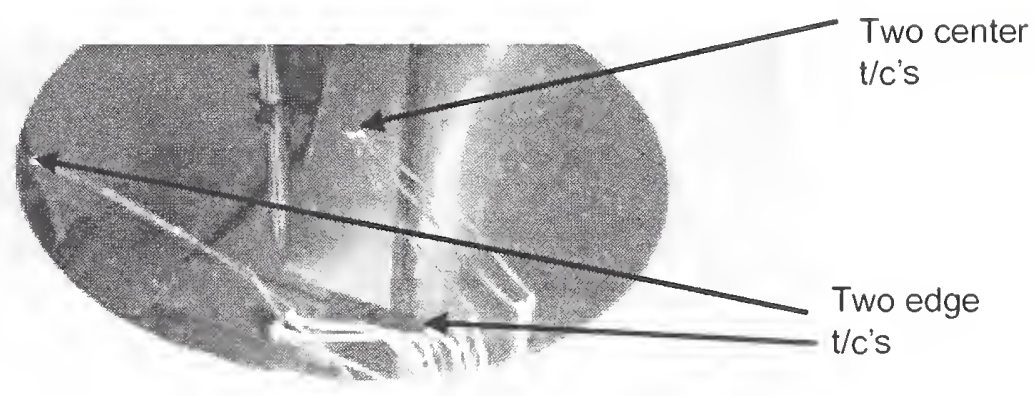




\section{T/C wafer, wire configuration}

- Harnessing/wire insulation

- Micro quartz tubing at wafer surface

- Stress relief posts at wafer edge

- Silica braided insulation from wafer edge to bottom of reactor chamber

- Polyimide tape insulation at area of door seal

- Teflon tubing insulation up the mini connectors

- Braided silica over-sleeving

\section{T/C wafer, wire configuration}

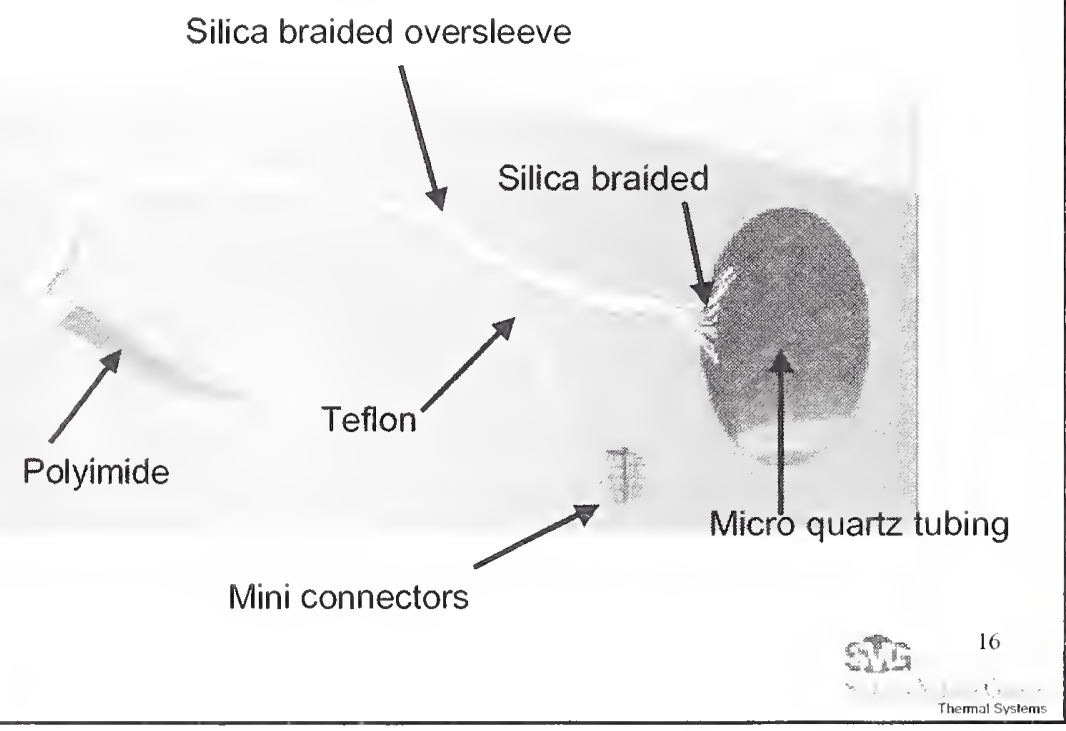




\section{T/C wafer, substrate and signal}

- Wafers

- Prime quality $\langle 100>$

_ $>7000$ A thermal oxide, prevents platinum wire breakage due to Pt-Si silicidation

- Signal processing

- $\mathrm{Cu}$ t/c extension wire harnessed from mini connectors to signal conditioners

- On board AD signal conditioners convert millivolt signal to 0-5 volt

- $0-5 \mathrm{~V}$ signal processed in temp control board

\section{T/C wafer, signal path}

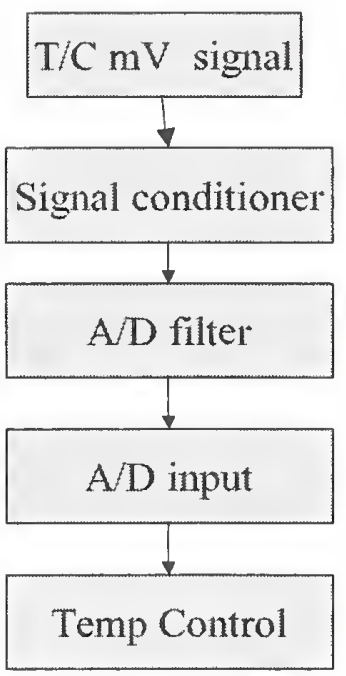




\section{T/C wafer, installation}

- Installation

- Wafer installed in empty boat slot using tweezers

- Edge t/c's positioned away from wafer support rail

- Wire leads are positioned vertically against wafer stack

- Silica braided string used to secure leads against boat rails

- Polyimide flat cable positioned across 'o' ring surface

- Leads are secured using polyimide adhesive tape outside chamber

- Strain relief fasteners applied to teflon section of leads at door surface

\section{T/C wafer, installation}

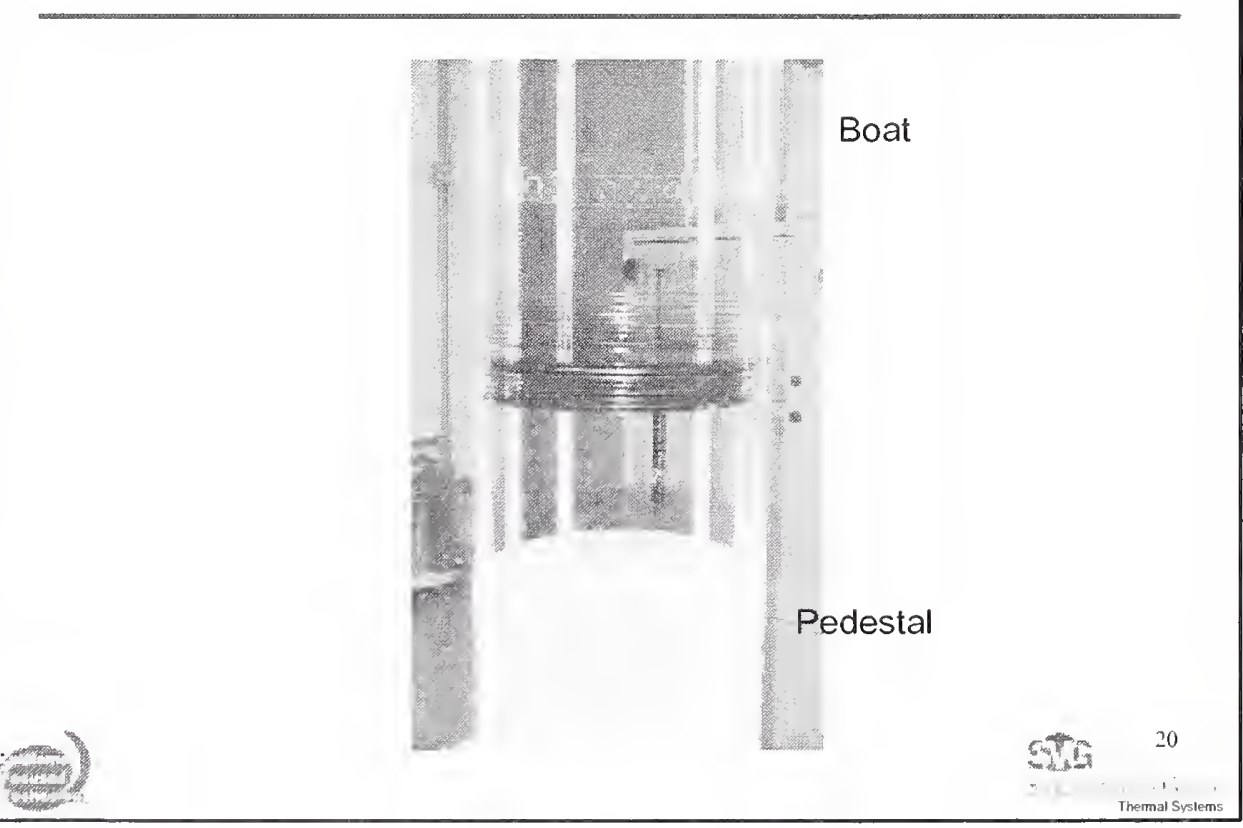




\section{T/C wafer, installation}

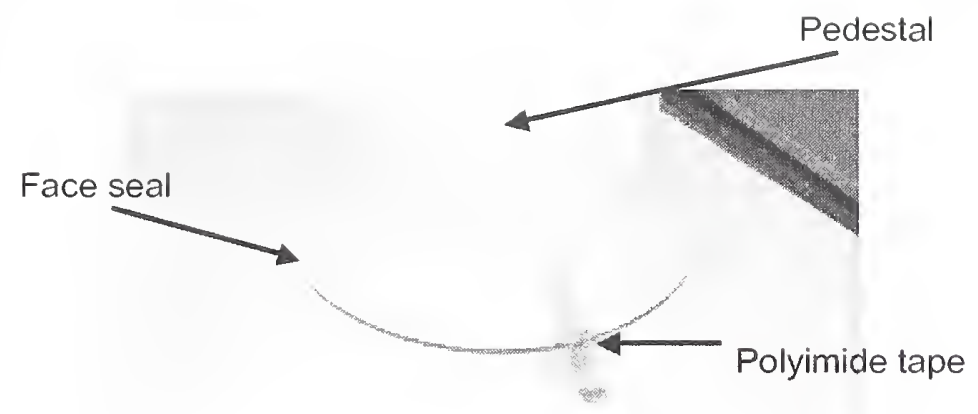

sests

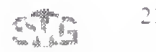

\section{T/C wafer, issues}

- High temp Insulation material

- Particle generation, abrasion

- Lifetime

- Reliability

- Handling

- Wafer breakage during shipping

- Container

- Wafer support

- Wafer size

- Shipper 


\section{T/C wafer, issues}

- Signal noise

- Wire routing within process chamber

- Filtering

- High temp $>1050^{\circ} \mathrm{C}$

- Type B?

- Reliability?

- Longevity?

\section{Conclusions}

- T/C wafers are a valuable tool for batch furnace diagnostics

- Furnace chamber thermal characteristics are understood

- Profile $t / c$ vs wafer temperature error is known

- Transient wafer dynamics are measured real time

- Thermal stress is characterized

- T/C wafer configurations for up to $1050^{\circ} \mathrm{C}$ processing established and reliable

- Future

- $>1050^{\circ} \mathrm{C}$

- insulation

- packaging 


\section{References}

I Christopher Ratliff, Cole Porter, Allan Laser, Anthony Dip, Rapid Vertical Processor for Fast-Ramp Diffusion and Oxidation Applications, RTP 97 Conference

2 Robert H. Nilson and Stewart K Griffiths. Sandia National Laboratories, Scaling Batch Processes for Large Wafer Diameters, Second Large Diameter Wafer Thermal Issues Conference, Sept. 1996 
. 


\section{Computer-Besed Temperture Megsurement Systems}

Pakil Damle Groun Wanager

1. Hot ong

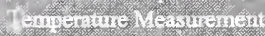

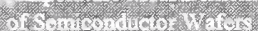

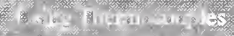

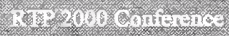

\section{Agenda}

1 Compurer-basted measurement of Thernegeveles:

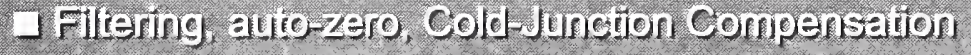

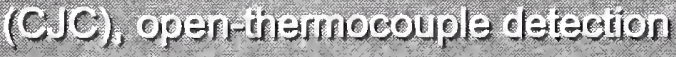

Jhe rigni connecivisy is importent

1 Solvitare nakes the cliterenes

a Computer-gasod inirared vision systents

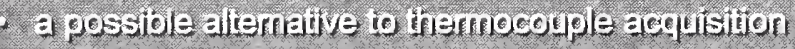




\section{Computer-Based Approach}

1 Compuler-eased aperoach is very common

- PCl bearels (in elestitep PC)

- USB (fistruments external to the PC)

- PXIICompactPCI (neelular instrumentis)

$\beth$ Commercially available high-reseluiten A to D cenverters

- Driven oy consumer electronics in

uersable, fast, low cost

¿Challenges

- Same pitialls as other systems

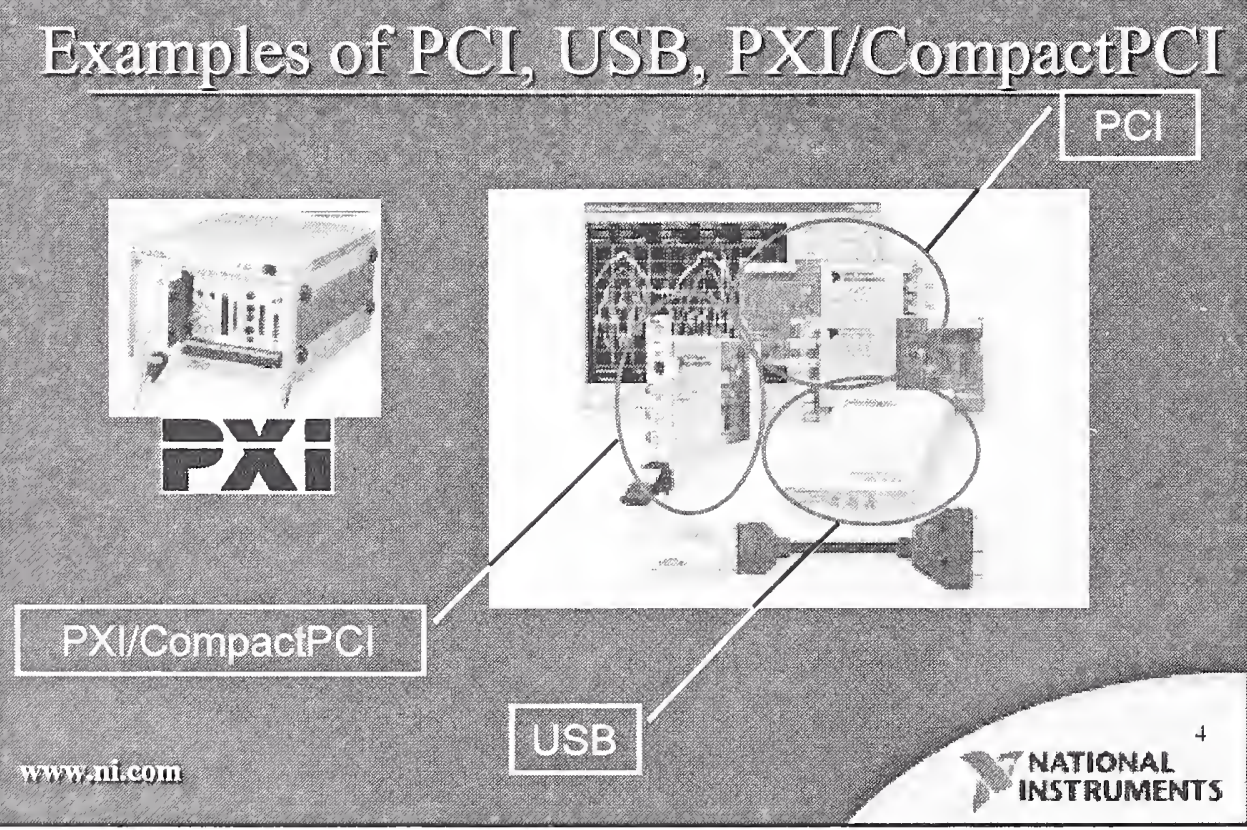




\section{Fillering}

¿Pro-dighizing nilering is necessary

- to eliminate high-ireefeney neise

- io eliminate pewerline neise

- to aveíe aliasing

בPost-digitzing fillering in sorivare

- can improve guality of measurenents

- caninet replace pre-ejigitzing hardyare illening

\section{Cold Junction Compensalion}

Thermecouples nake relaivg measurements

- Cuc converis then inte abselite measuremenis

1 CJC senser must be at same temperature as cold junction

- System must be in tsethermal with themeeouple cenineters

IErrors realing OJC senser

- Measurement errors will afiect CJC

- This must bo taken into aceount 


\section{Offset and Gain Enrors}

- Error due to ofiset and gain errors in amplifier

- Impossieje to eliminate cemelerely

- Use autezere

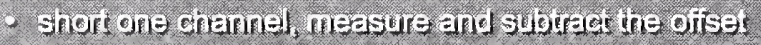

- Compensales for elrits over tine

- Check the cemmon mede voltage of the themecouple

- If too hifin, you have to change instrument

- Converter with iselated frontenel will hele

\section{Open-Thermocouple Detection}

-Check your thermoeousle

- If it is open, your measurements are incorrect

LHow are open thermocouples detected?

- Measure the thermocievele resistanes - If it ls ree hijh, chances are the inermocouple is broken 


\section{Connectivity}

uChoose the right eoninesivity

- Minitelegs (ine is money)

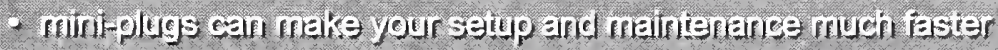

- Mejelar terminal elociss

- Provide bost mainenances operaidens
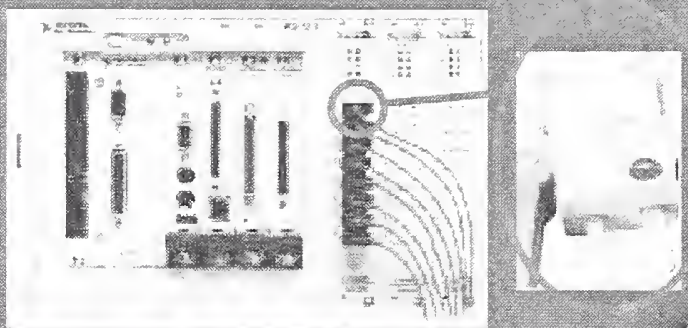

\section{Soliware}

- Soriware is core to the applieation

- A measurement-oriented anguage proveles

- hitenter connseijor

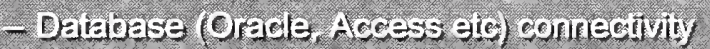

- Heasurenent intelligenag"

- Great analysis iunetens

ב Vleasurement-oriented languages

- LabVIEWm ier ejaphical ajereach

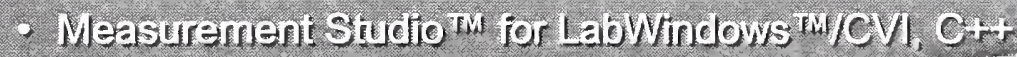
Visural Easic 


\section{Vision-Based Systems - An Altemative-}

¿Visionfeased systems

- Can provide an alternalive solvitor

- Rjeent technelogiteal breakthreughs for cameras

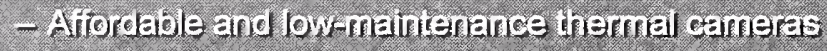

- Map the enitre wafer(s) at once (eefivalent of 76:000 therniecouples rearl bo itmes; al secenid)

- Same sofintere aperreach (LabVIEW or Measurement Studiom )

- nis.cominnate

\section{Vision Systems - Examples -}

siramile le

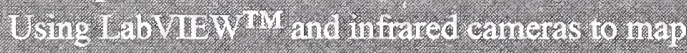

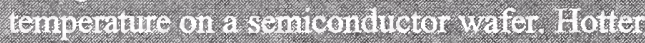

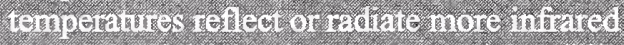

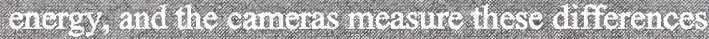
and olisplay them in waty ning colors

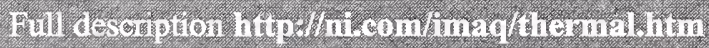

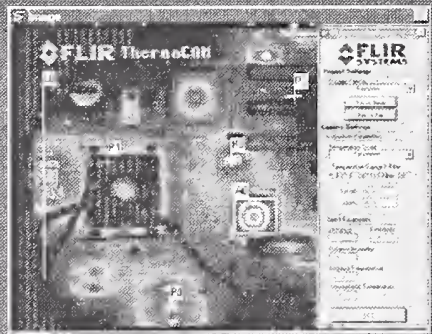

is minte 2

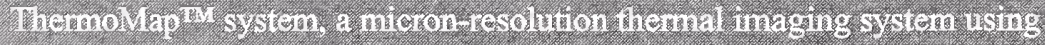

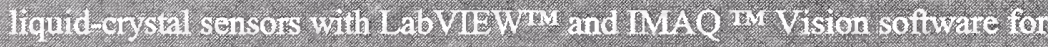

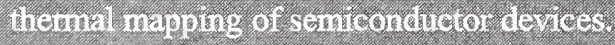

Sointon toverloged of Tempronic Corp

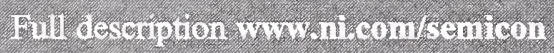




\section{Conclusions}

$\square$ Thermegetple measurenents are easily mable vith cemputer-based approats

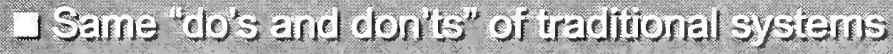

I The right cenirectivisy is impertant

$\triangle$ Seliware makes the ofitierence

\lrcorner Vision-besed systens can provicle an interesting allemalive 


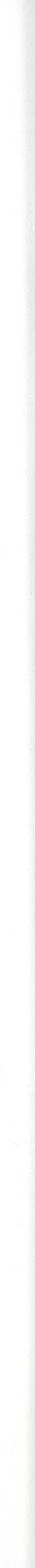




\title{
Instrumentation Issues
} for

Thermocouple Measurements

\author{
Tom Hayden \\ Manager of Sales Training and Support \\ Keithley Instruments, Inc.
}

Cleveland, $\mathrm{OH}$

Workshop on

Temperature Measurement

of Semiconductor Wafers

Using Thermocouples

RTP 2000 Conference

September 19, 2000

\section{Instrumentation for Temperature}

Major sources of error in most systems

- Sensor and Thermal Contact with Subject (covered elsewhere in conference).

- Cold Junction Reference Error $\left(0.1^{\circ}\right.$ to $\left.5.0^{\circ} \mathrm{C}\right)$

- Noise Pick-Up - mostly $60 \mathrm{~Hz}\left(0.01^{\circ}\right.$ to $\left.0.2^{\circ} \mathrm{C}\right)$

- $V$ to T Conversion Errors $\left(0.02^{\circ}\right.$ to $\left.0.4^{\circ} \mathrm{C}\right)$

- V Measurement Errors $\left(0.1^{\circ}\right.$ to $\left.2.0^{\circ} \mathrm{C}\right)$

Note: Individual error sources are rarely specified - usually just the sum. 


\section{Instrumentation for Temperature}

Additional Problems with Rapid Thermal Measurements

- Thermal Latency in Sensor (covered elsewhere in conference).

- Measurement Latency

\section{Instrumentation for Temperature}

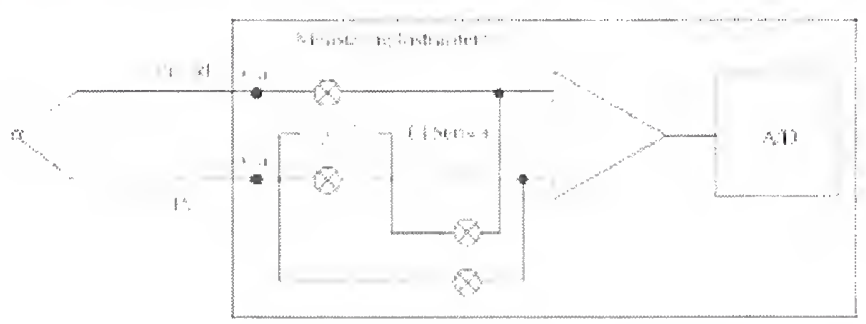

- CJ Sensor - typically Thermistor, Semiconductor Sensor or RTD

- Sensor accuracy is typically $0.1^{\circ}$ to $0.2^{\circ} \mathrm{C}$

- Additional errors can be due to gradient between sensor and actual junction

- Can be minimized by isothermal bars/blocks and/or removal from sources of heat 


\section{Instrumentation for Temperature}

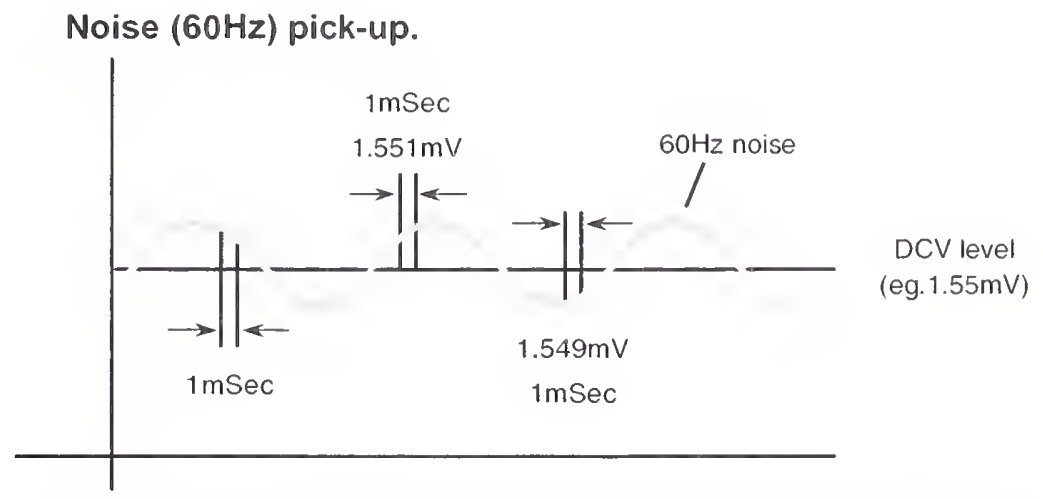

1) With type $K \mathrm{~T} / \mathrm{C}\left(40 \mu \mathrm{V} /{ }^{\circ} \mathrm{C}\right)$, just $1 \mu \mathrm{V}$ noise $=0.025^{\circ}$ error

2) With type $R$ or $S\left(11-13 \mu \mathrm{V} /{ }^{\circ} \mathrm{C}\right), 1 \mu \mathrm{V}=0.08^{\circ} \mathrm{C}$

$1]$

\section{Instrumentation for Temperature}

$60 \mathrm{~Hz}$ Noise Rejection

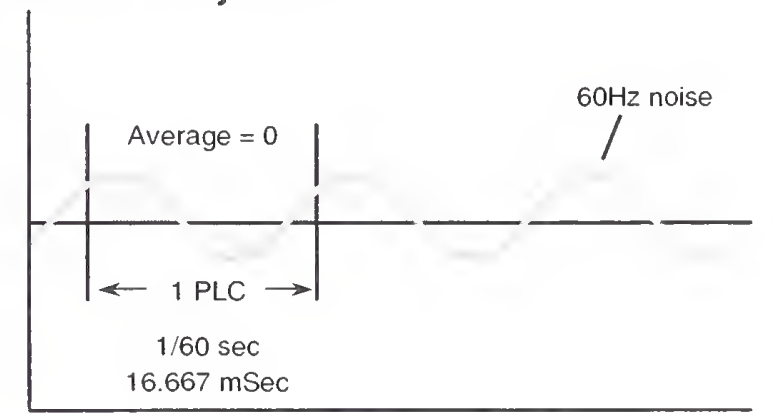

Line cycle integration ( $16.66 \mathrm{mSec}$ increments) can reduce this error by $60-80 \mathrm{db}(1000-10,000$ to 1$)$.

Common method used in $90+\%$ of multimeters and some A/D Boards. 


\section{Instrumentation for Temperature}

Voltage to Temperature Conversion Errors

ITS-90 \& IPTS-68 Typo K Thermocouple Performance

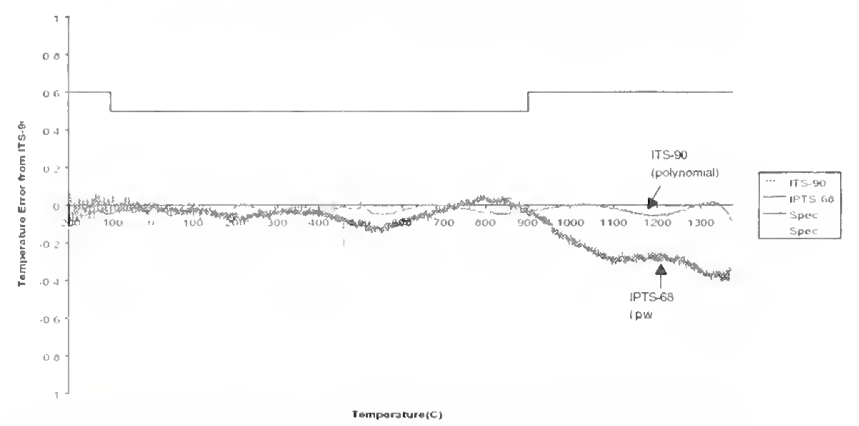

- Many methods: look up table, piecewise linear, polynomial

- Piecewise linear can be $0.02^{\circ} \mathrm{C}$ to $0.2^{\circ} \mathrm{C}$ depending on how many segments

- IPTS-68 vs. ITS-90 can add $0.1^{\circ} \mathrm{C}$ to $0.4^{\circ} \mathrm{C}$ additional conversion error especially above $900^{\circ} \mathrm{C}$

\section{Instrumentation for Temperature}

Volts Measurement Errors

- Type R, S Thermocouples are 11 to $13 \mu \mathrm{V} /{ }^{\circ} \mathrm{C}$

- Type $\mathrm{K}$ Thermocouple is $\sim 40 \mu \mathrm{V} /{ }^{\circ} \mathrm{C}$

- Most measurements are done on a $100 \mathrm{mV}$ range

- A good 6-1/2 digit DMM has about a \pm 50 ppm of range spec (plus a \pm 50 ppm of reading)

- This translates to about $5-6 \mu \mathrm{V}$ of error over the 0 to $10 \mathrm{mV}$ range of input signals

- This corresponds to about $0.5^{\circ}$ with $\mathrm{R} / \mathrm{S}$ and $0.12^{\circ} \mathrm{C}$ with $\mathrm{K}$ 


\section{Instrumentation for Temperature}

Additional errors for Rapid Thermal Measurements

Measurement Latency

- 0 to $1000^{\circ}$ in $5 \mathrm{sec}=0.2 \% \mathrm{mSec}$

- A $17 \mathrm{mSec}$ measurement (1PLC for good, accurate measurement)

- $17 \times 0.2=3.4^{\circ}$ ramp during each measurement

- Reading will be approx AVERAGE temp over this time which should be approximately equal to the specific temperature about $8-10 \mathrm{mSec}$ before the end of the reading.

1 


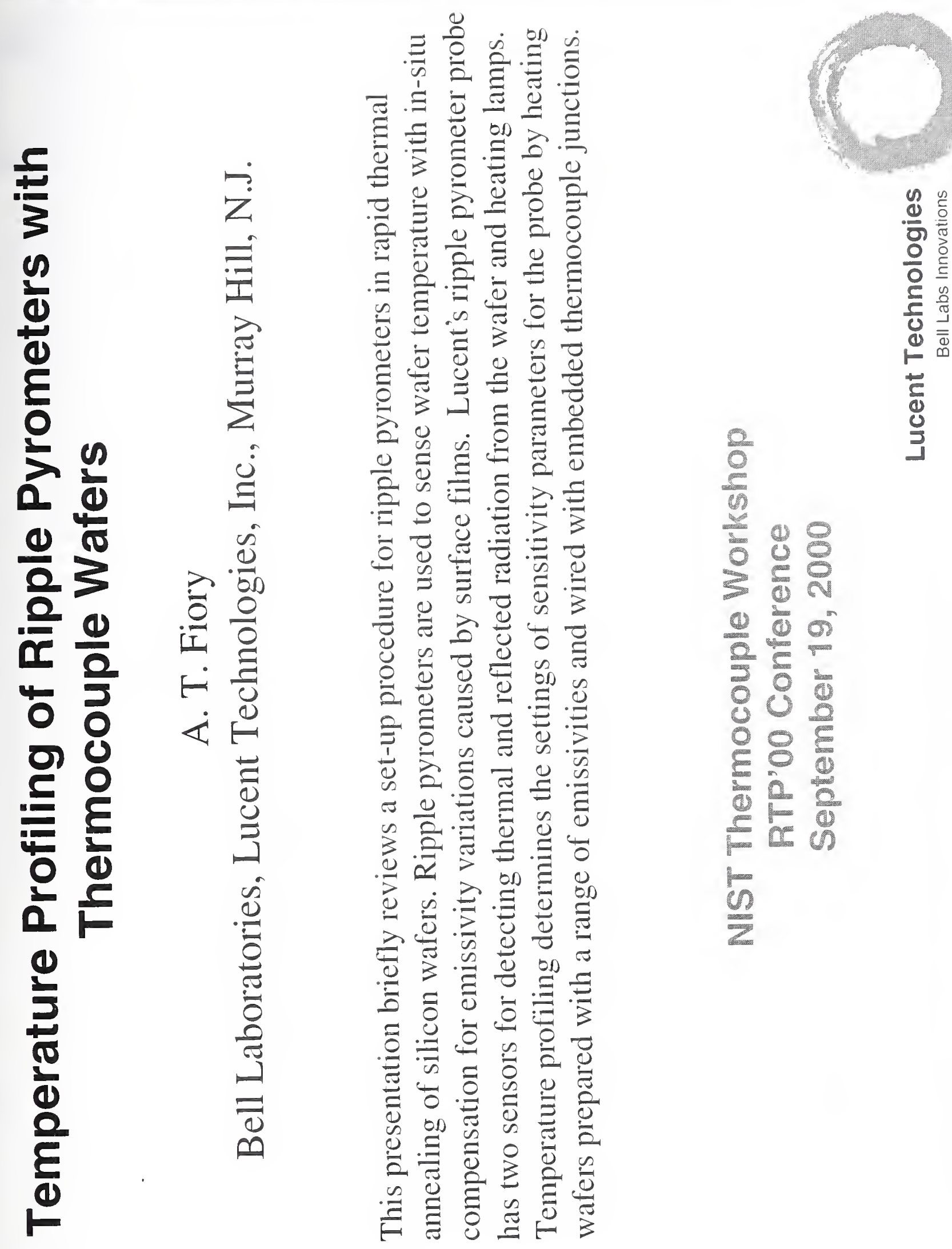

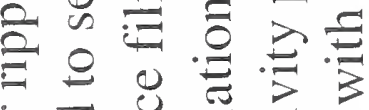

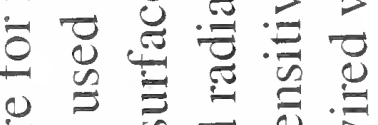

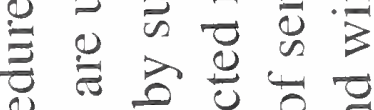

บ

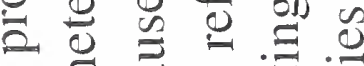

छ

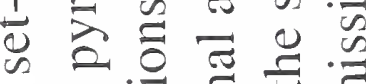

$\sigma$ 늘 先

文言焉导

$\frac{1}{6}$

$-00$

(1) $00^{2}$

$2=$

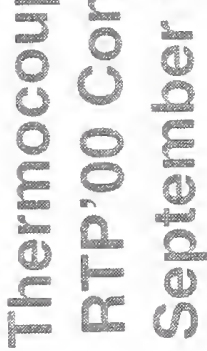

12 


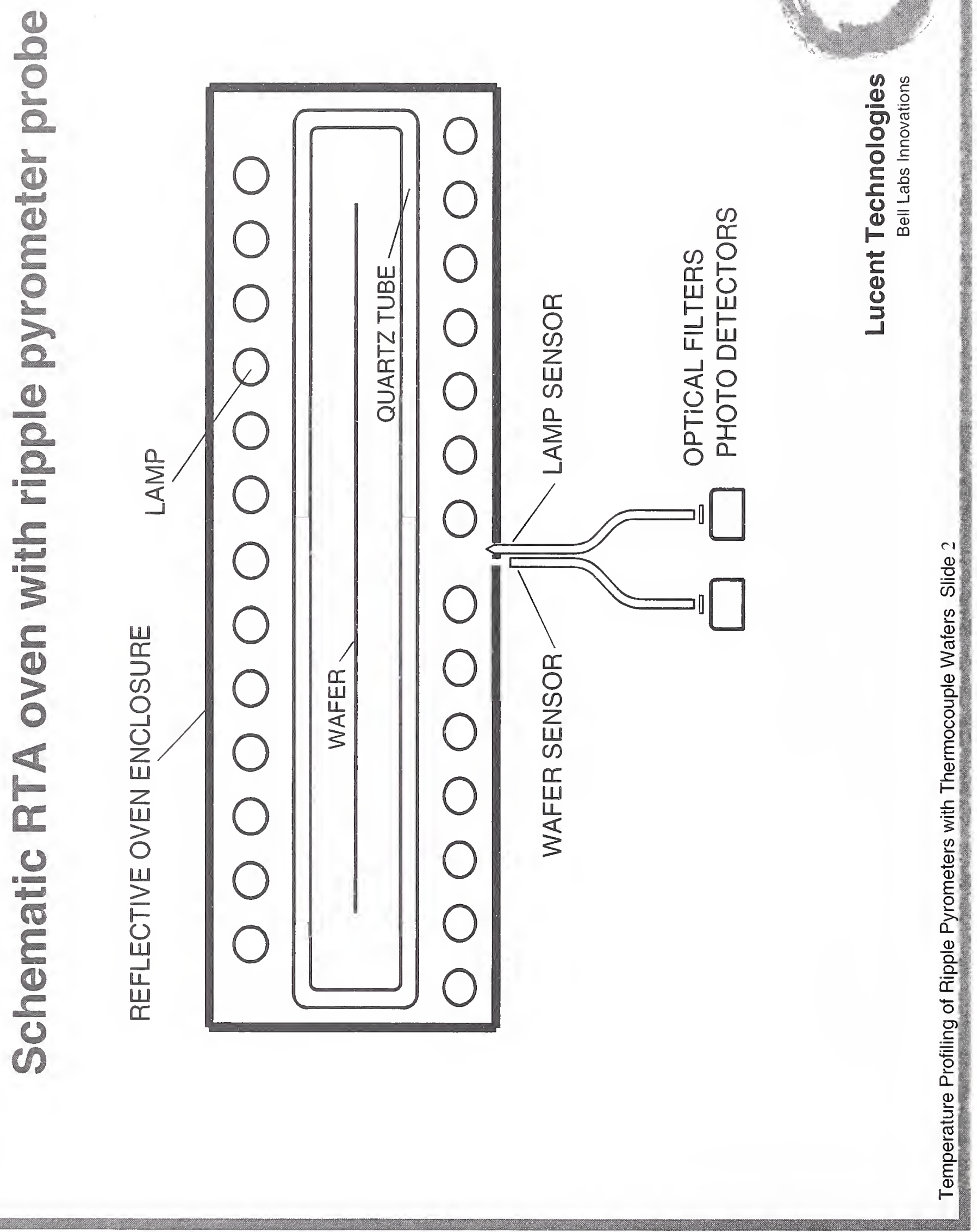




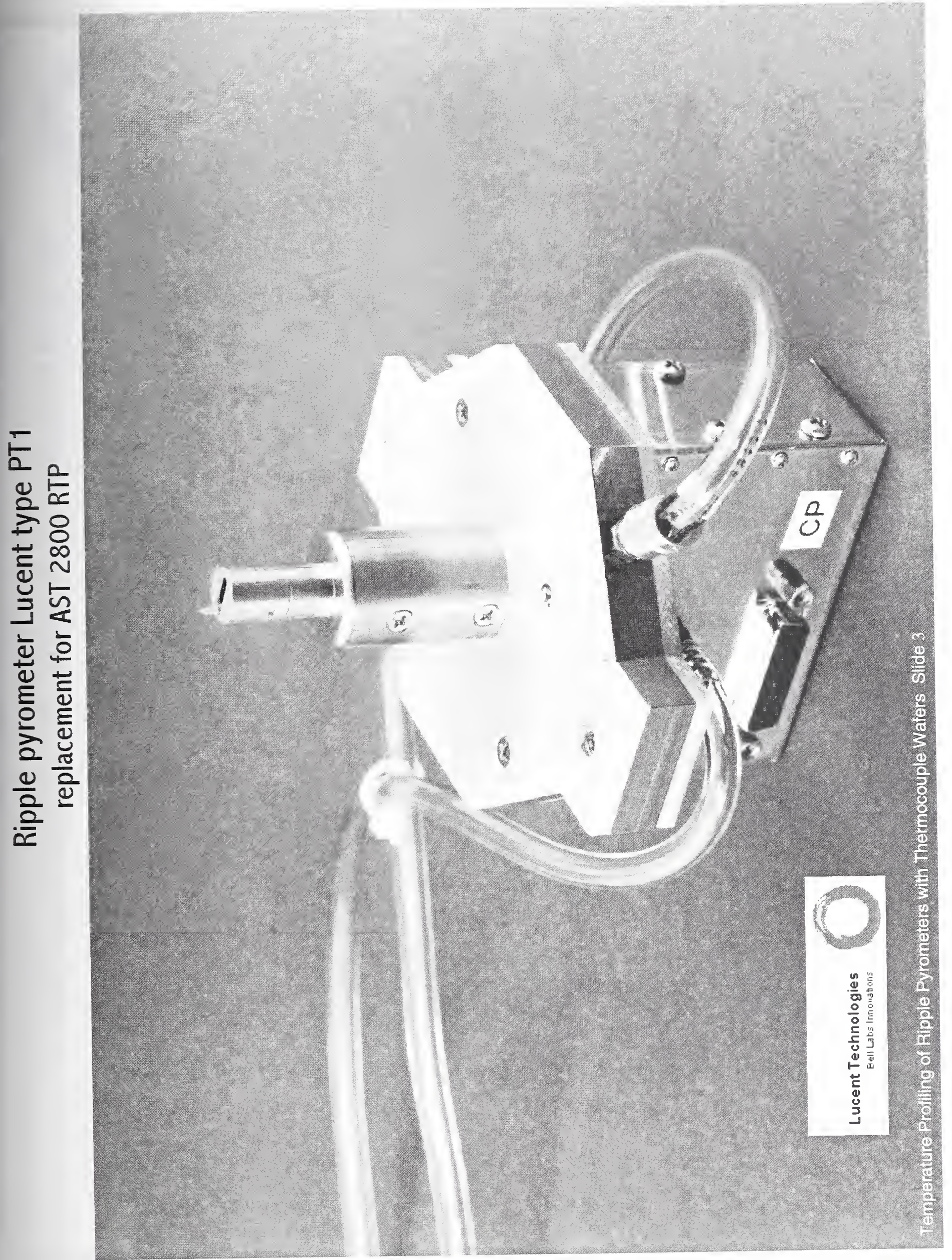




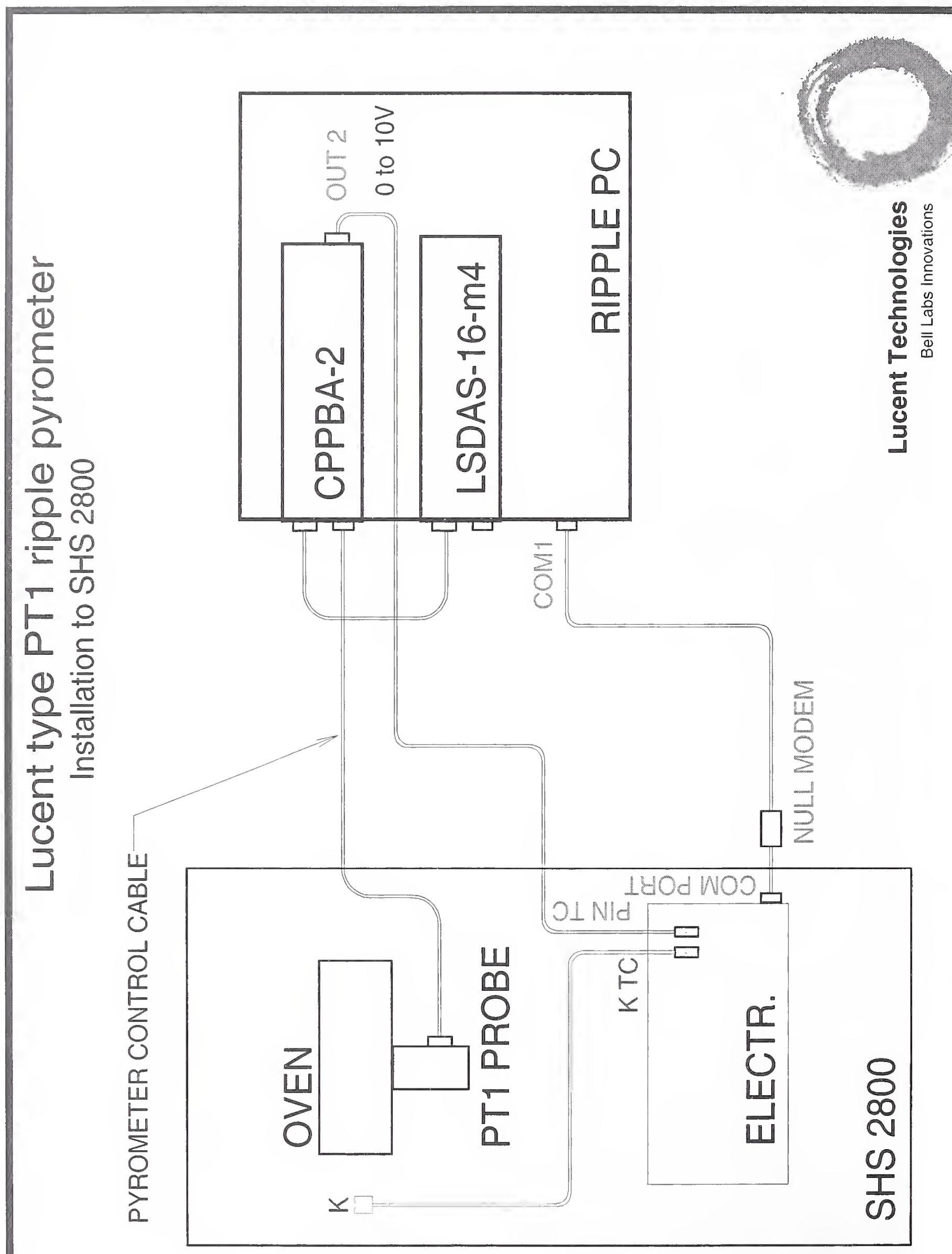



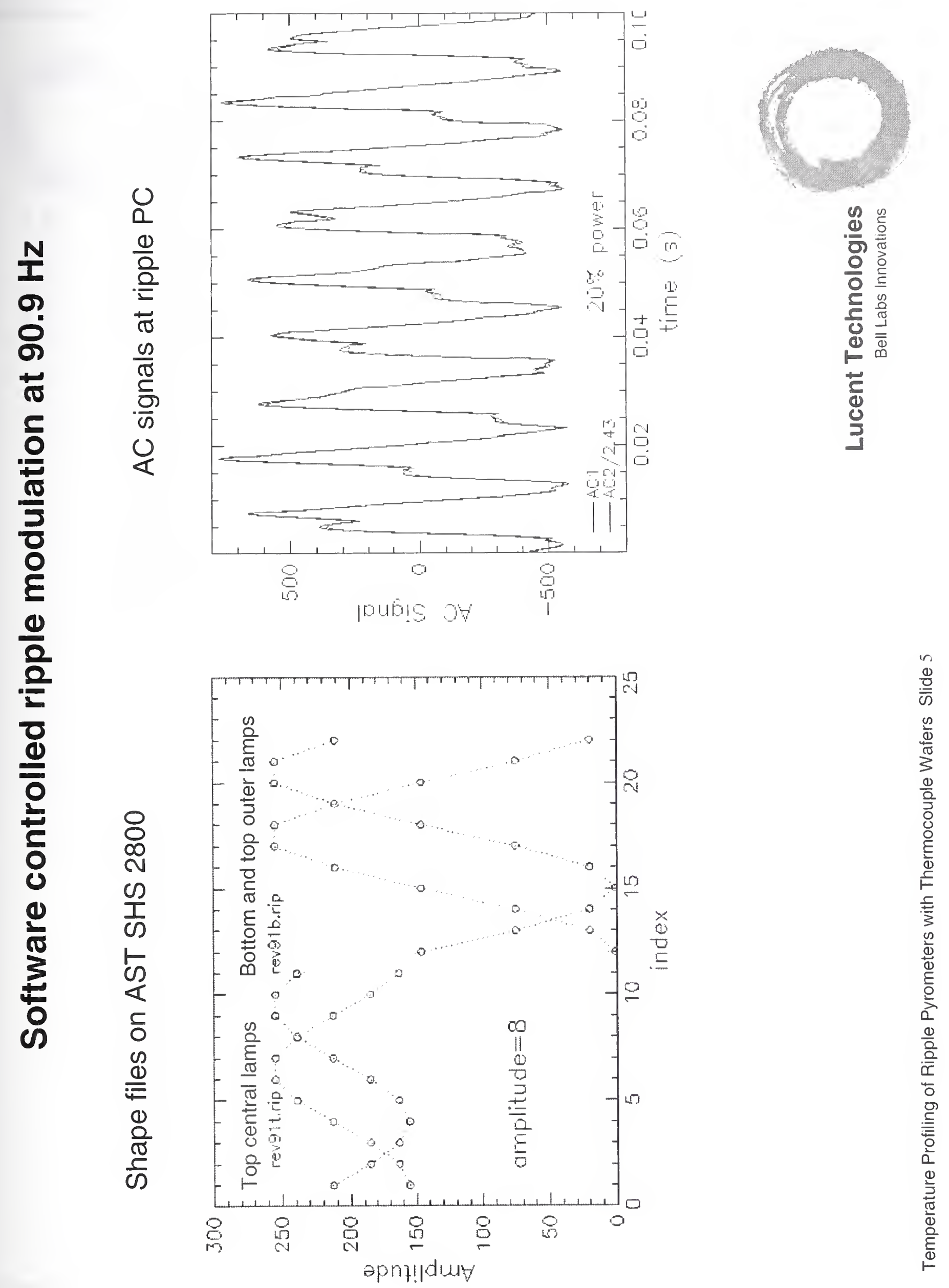


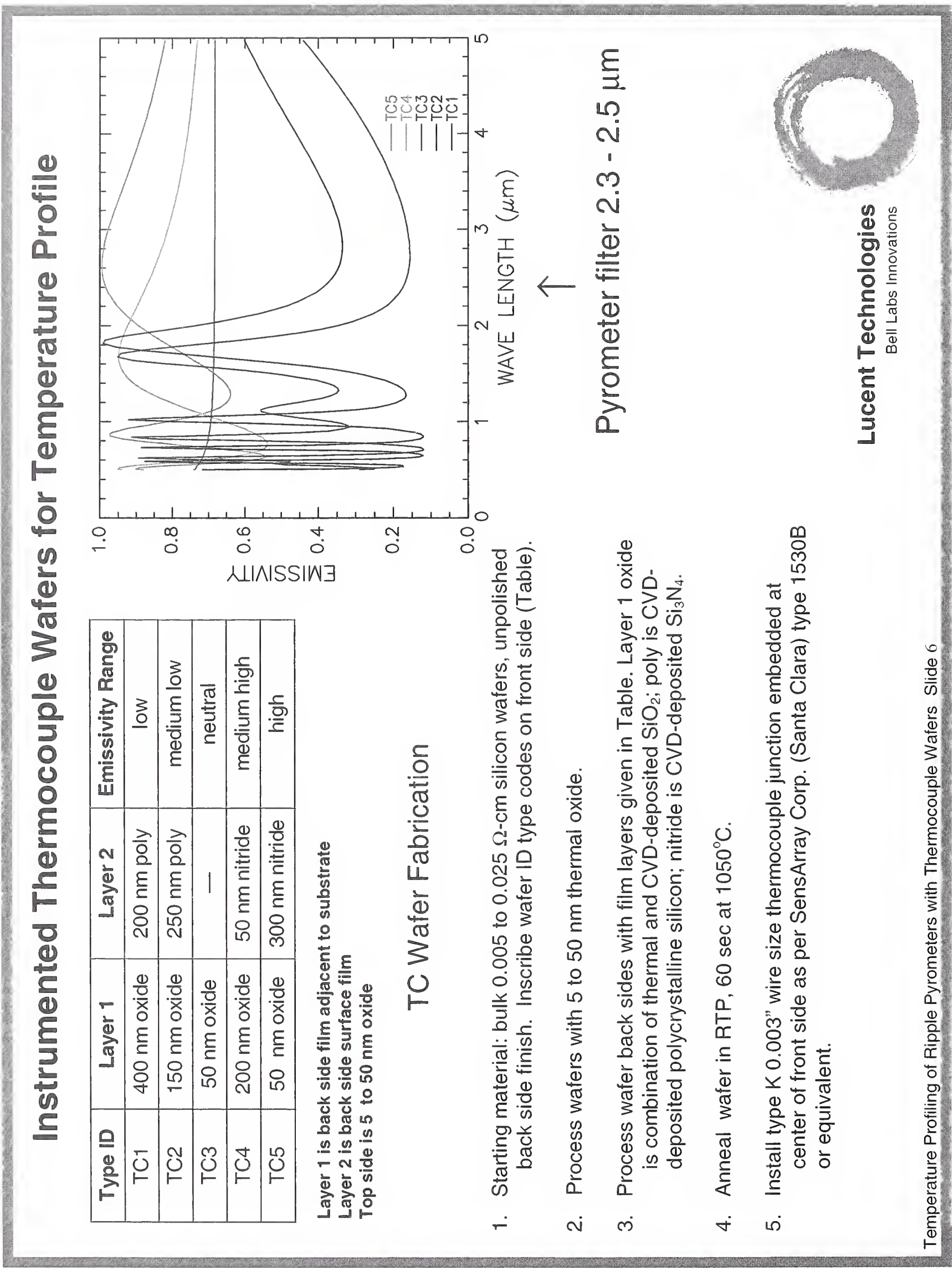




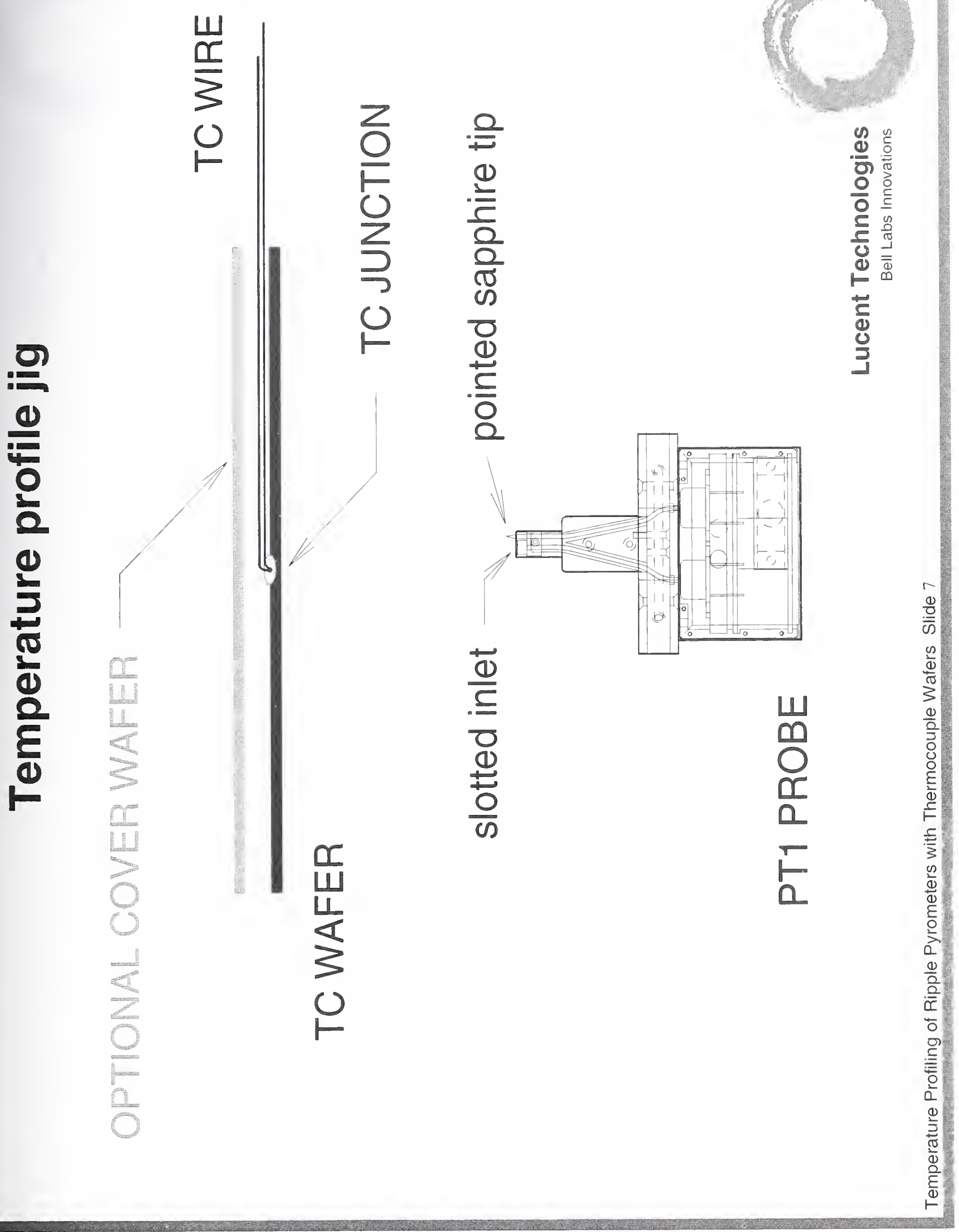



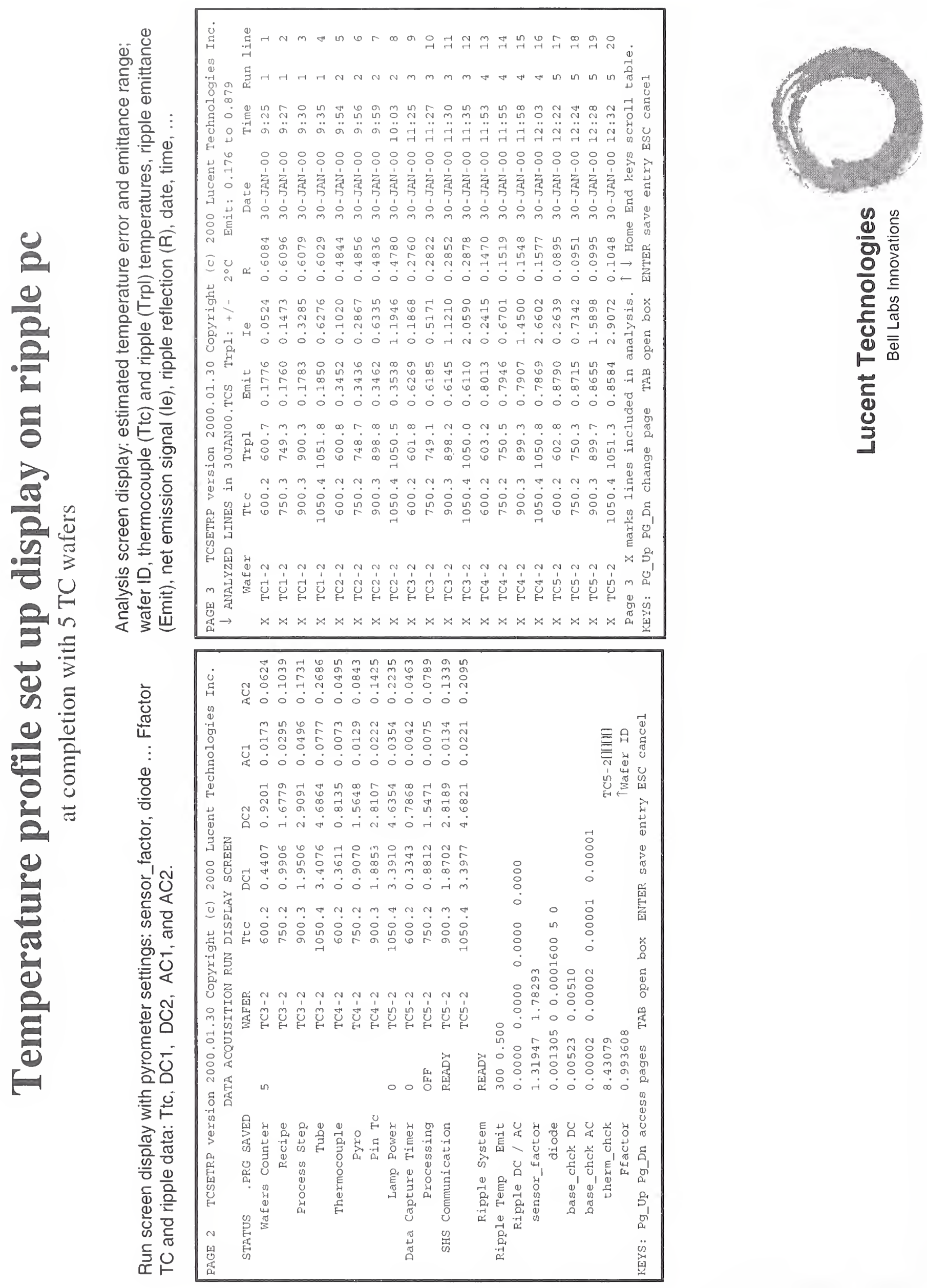

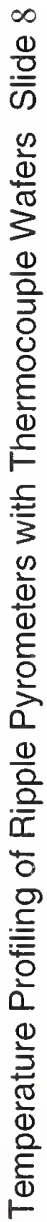




\title{
Issues with Using TC's to Calibrate RTP Tools
}

\author{
Jeff Gelpey \\ Vice President of Technology \\ STEAG RTP Systems \\ San Jose, CA
}

Workshop on

Temperature Measurement

of Semiconductor Wafers

Using Thermocouples

RTP 2000 Conference

September 19, 2000

\section{Issues with TC Measurements on Real Process Tools}

TC's have traditionally been used to calibrate and check RTP tools, but there are several problems:

- TC Problems

- Poor quality TC's

- Poor mounting

- Response time limitations

- Changes with temperature cycling

- Bulk vs. surface mount TC's

- Equipment Problems

- Difficult to use TC's with rotating wafers

- TC electronics may not be adequate

- Procedures do not provide good calibration of radiometer 


\section{Are TC's the Best Way to Calibrate?}

Is a TC "accurate enough"?

Is is better to use a process monitor?

* Can a process monitor be repeatable over time and from site to site?

- Is there some other calibration technique based on a fundamental physical property (e.g. melting point) that can be practical?

- Should TC's be used to measure uniformity as well as to calibrate radiometers?

- Thin Film TC wafer commercially available (and cheap!) using elemental TCs

Withstands hundreds of thermal cycles with no degradation

* Better than $1 \mathrm{~K}$ accuracy over entire temperature range

Has option of many junctions to measure uniformity

- Agreement by user community of accuracy, precision and repeatability requirements 

